\title{
Ruthenium Polypyridyl Complex-containing
}

\section{Bioconjugates}

\author{
Marta Martinez-Alonso, ${ }^{\mathrm{a},{ }^{*}}$ and Gilles Gasser ${ }^{\mathrm{a},{ }^{,}}$
}

a Chimie ParisTech, PSL University, CNRS, Institute of Chemistry for Life and Health Sciences, Laboratory for Inorganic Chemical Biology, F-75005 Paris, France.

* Corresponding authors: E-mail: $\quad$ m.martinez-alonso@chimieparistech.psl.eu; gilles.gasser@chimeparistech.psl.eu; WWW: www.gassergroup.com; Phone: +331 8578 4151

\section{ORCID Numbers}

Marta Martinez-Alonso: 0000-0002-0931-5274

Gilles Gasser: 0000-0002-4244-5097

\section{Highlights}

- Bioconjugation improves some of the features of the Ru(II) polypyridyl complexes.

- The properties of the complexes are not usually altered by the bioconjugation.

- Peptides are among the most common biomolecules used in bioconjugation.

- The bioconjugates were used for different purposes. 


\begin{abstract}
In the last decades, the number of articles describing the synthesis, characterization and applications of ruthenium polypyridyl complexes has significantly increased. One of the reasons is their tuneable, outstanding luminescent properties. However, ruthenium polypyridyl complexes usually have no intrinsic selectivity towards cancer cells, making them impractical, for example, in certain biological applications. To overcome this drawback, these complexes have been conjugated to biomolecules. In this review, we describe the different ruthenium polypyridyl complex-containing bioconjugates reported so far and their applications as, for example, anticancer drug candidates, sensors or biocatalysts. However, we are not reviewing ruthenium-containing nucleotides and DNA conjugates since these topics were recently reported. The multiple ways of attaching the biomolecules (i.e., peptides, antibodies, carbohydrates, lipids and vitamins) to the ruthenium core are also summarized.
\end{abstract}




\section{Graphical Abstract}

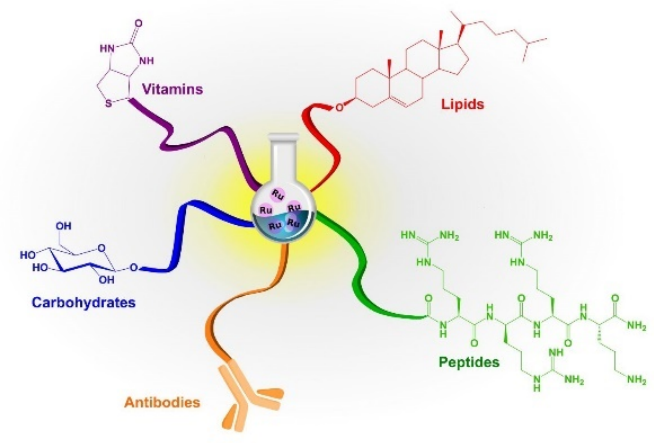

Keywords: Bioconjugates, Bioinorganic Chemistry, Inorganic Chemical Biology, Medicinal Inorganic Chemistry, Ruthenium Polypyridyl Complexes 


\section{Abbreviations}

3T3: mouse embryonic fibroblasts

5Bpy: 5'-amino-2,2'-bypyridine-5-carboxylic acid

A549: human lung carcinoma cells

A549R: cisplatin resistant human lung carcinoma cells

$\mathrm{Ab}$ : antibody

Abs: Absorption

$\mathrm{ABC}$ : avidin-biotin complex

ABDA: 9,10-anthracenediyl-bi(methylene)- dimalonic acid

ABTS: 2,2'-azino-bis[ethyl-benzothiazoline-(6)-sulfonic acid]

ADC: Antibody-drug conjugates

AE9a: leukaemia cancer cells

AML: acute myeloid leukaemia

amol: attomole

AQC: anthraquinone-2-carboxylic acid

AQS: anthraquinone-2-sulfonic acid

B16F10: murine melanoma cells

BBB: blood brain barrier

BBN: bombesin

BDC: bis(demethoxy)curcumin

biptpy: 4'-(4-biphenyl)- 2,2':6',2"-terpyridine

Biqbpy: 6,6'-bis[N-(isoquinolyl)-1-amino]-2,2'-bipyridine

BM: primary bone marrow cells

bpy: 2,2'-bipyridine

BQ: 1,4-benzoquinone

BR: biotin receptor

CA: chloroanil, tetrachlorobenzoquinone

CaSki: human caucasian cervical epidermoid carcinoma

CCOx: cytochrome $c$ oxidase

CD: circular dichroism

CD: cyclodextrine 
CHO: Chinese Hamster Ovary cells

CLSM: confocal laser scanning microscopy

ConA: concavalin A

CPP: cell-penetrating peptide

CsA: cyclosporine A

CT-DNA: calf thymus DNA

$\mathrm{CV}$ : cyclic voltammetry

DABA: 2,4-diaminobutyric acid

DAPA: 2,6-Diaminopimelic acid

DAPI: 4',6-Diamidino-2-phenylindole nuclear stain

dcbpy: 2,2'-bipyridine-4,4'- dicarboxylic acid

dcbpy: 6,6'-dichloro-2,2'-bipyridine

DCBQ: 2,6-dichlorobenzoquinone

dmbpy: 4,4'-dimethyl-2,2'-bipyridine

DMF: dimethyl formamide

DMPC: dimyristoylphosphatidylcholine

DMPG: dimyristoylphosphatidylglycerol

dpp: 4,7-diphenyl-1,10-phenanthroline

dppg: dipalmitoylphosphatidylglycerol

dppn: Benzo[i]dipyrido-[3,2-a:2',3'-c]phenazine

dppz: dipyrido-[3,2-a:2',3'-c]-phenazine

DTT: dithiothreitol

$\mathrm{EC}_{50}$ : Effective concentration; concentration at which a $50 \%$ survival rate on cell viability is observed.

Ect1/E6E7: ectocervical cells

EGFR: epidermal growth factor receptor

ER: endoplasmic reticulum

eT: electron transfer

ET: energy transfer

FA: folic acid

FLIM: fluorescence lifetime imaging

FP: fluorescence polarization 
GLUT: glucose transporters

H1299: human lung carcinoma cells

H1437: human lung carcinoma cells

$\mathrm{H}_{2} \mathrm{TPP}$ : tetraphenylporphyrin

HaCaT: normal keratinocyte

hdpa: 2,2'-dipyridylamine

HeLa: human cervical epitheloid carcinoma

HepG2: human hepatocarcinoma cells

HLF-a: primary human lung fibroblasts

HSA: human serum albumin

HT-29: human colon cancer cells

Htme: 2-(methylthio)ethanol

$\mathrm{IC}_{50}$ : Inhibitory potency; concentration at which a $50 \%$ of cells are death.

$\mathrm{IC}_{\min }$ : minimum inhibition concentration

Ig: immunoglobulin

IgG: immunoglobulin $\mathrm{G}$

ITC: isothermal titration calorimetry

L929: mouse fibroblast cells

LDC: lipid-drug conjugates

LF: lumiflavin

LLIM: Luminescent lifetime imaging microscopy

LS174T: colorectal cancer cells

mAb: monoclonal antibody

Mb: myoglobin

MBQ: 2-methylbenzoquinone

MCF-7: human breast adenocarcinoma

MCTSs: 3D multicellular tumour spheroids

MDA-MB-231: breast cancer cells

MDCK: Madin-Darby Canine Kidney cells

$\mathrm{MeCN}$ : acetonitrile

$\mathrm{MeOH}$ : methanol 
MPP: mitochondrial-penetrating peptide

MPT: mitochondrial permeability transition

MtMP: mitochondrial membrane potential

MTs: microtubules

MV: Methylviologen

NA: nicotinamide

NB: nanobody

NHS: $N$-hydoxysuccinimide

NLS: nuclear localizing sequence

NQ: naphtaquinone

PACT: Photoactivated Chemotherapy

PBS: phosphate saline buffer

PDT: Photodynamic Therapy

PEO: poly(ethylene oxide)

phen: phenanthroline

PI: phototoxicity index

PLPG: photolabile protecting group

PNA: peanut agglutinin

PS: photosensitizer

PS 140-b-PAA48: polystyrene140-b-poly(acrylic acid)48

PSII: photosystem II

ptrpy: 4'-phenyl-2,2';6',2'-terpyridine

RCA: Ricinus comunnis agglutinin 120

RF: riboflavin

RGD: Arginylglycylaspartic acid

RNS: reactive nitrogen species

ROS: reactive oxygen species

SATA: $N$-succinimidyl S-acetylthioacetate

SiHa: human squamous carcinoma of the cervix

Sp2/0-Ag 14: myeloma cells

SST: somatostatine 
SSTRs: somatostatine receptors

STD: saturation transfer difference

STED: stimulated emission depletion

TA: transient absorption

TCNQ: tetracyanoquinodimethane

TFA: trifluoroacetic acid

TP: two-photon

TPA: two-photon absorption

TPP: tripheynlphosphonium

tpy: 2,2':6',2''-terpyridine

TTC: Tetanus toxin c-fragment

VDAC: voltage-dependent anion channel

VEGF: vascular endothelial growth factor

VEGFR2: vascular endothelial growth factor receptor 2

WGA: Wheat germ agglutinin

YDS: yolk disialo oligosaccharide

$\beta$-CD: $\beta$-cyclodextrine 
Table of contents

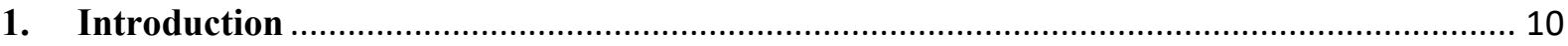

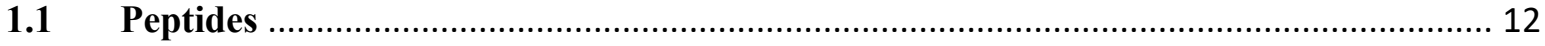

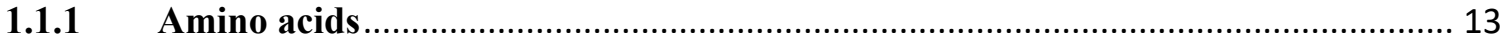

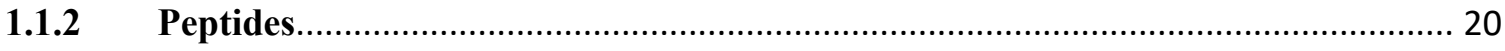

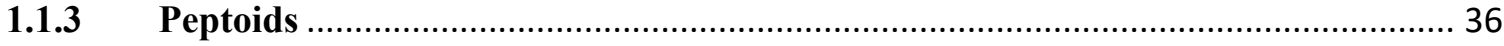

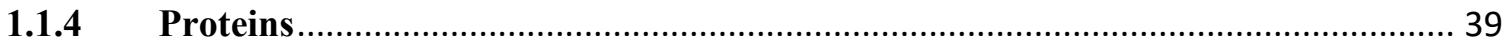

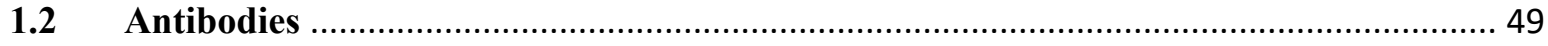

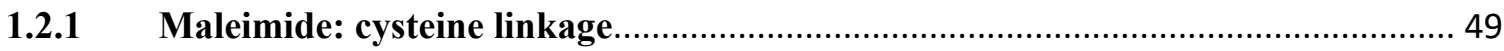

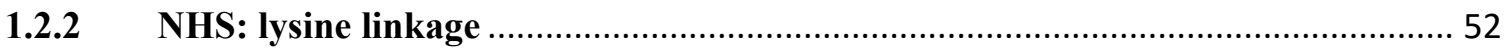

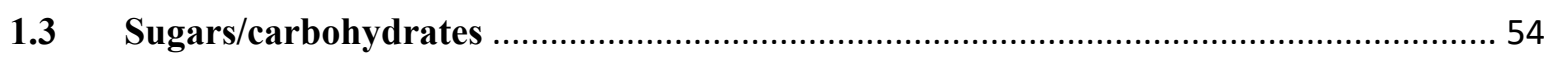

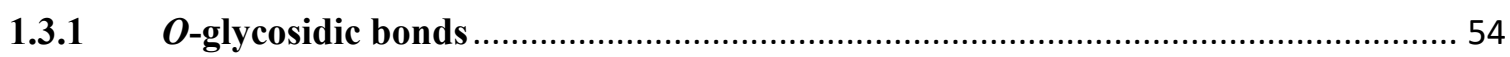

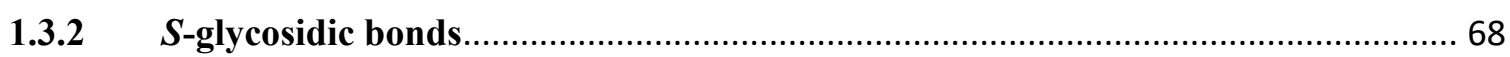

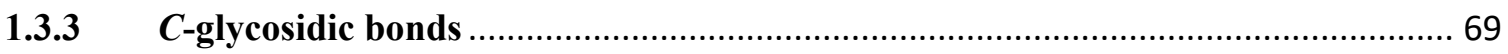

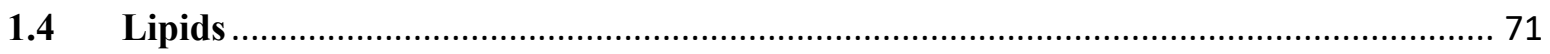

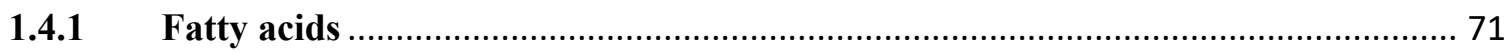

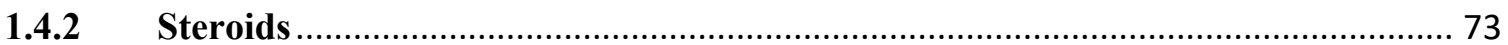

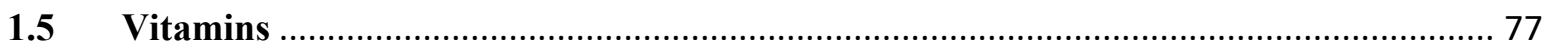

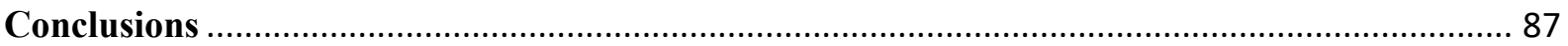

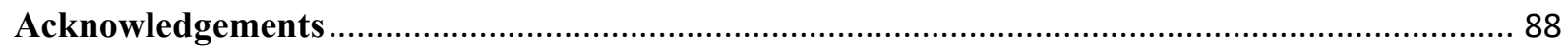

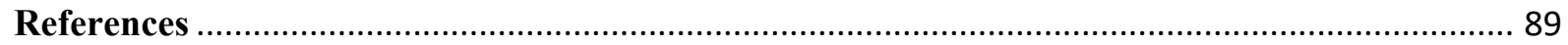




\section{Introduction}

In the last decades, $\mathrm{Ru}(\mathrm{II})$ polypyridyl complexes have gained great attention in different research areas due to their outstanding photophysical properties. The prototype of this family of complexes is $\left[\mathrm{Ru}(\mathrm{bpy})_{3}\right]^{2+}$, which shows strong absorption in the visible region of the spectra $\left(\lambda_{\max }=452 \mathrm{~nm}, 13^{\prime} 000 \mathrm{M}^{-1} \mathrm{~cm}^{-1}\right.$, MLCT $)$, strong phosphorescence emission $\left(\lambda_{\max }=620 \mathrm{~nm}\right.$, $\Phi_{\mathrm{PL}}=0.095$ in deoxygenated $\mathrm{CH}_{3} \mathrm{CN}$ at r.t., $\left.{ }^{3} \mathrm{MLCT}\right)$ and long emission lifetime $(\tau=930 \mathrm{~ns}$ in deoxygenated $\mathrm{CH}_{3} \mathrm{CN}$ at r.t.). The electrochemical properties of this complex are also relevant with an interesting redox behaviour: reversible oxidation of the $\mathrm{Ru}(\mathrm{II}) / \mathrm{Ru}(\mathrm{III})$ pair at $c a$. $1 \mathrm{~V}$ and three reduction peaks (the first two reversible and the last one quasi-reversible), corresponding to each of the bpy ligands. In addition, the versatility of $\mathrm{Ru}(\mathrm{II})$ polypyridyl complexes as energy donors, electron acceptors and electron donors along with their great stability in solution, tunability and ease of synthesis[1] make them excellent candidates as catalysts,[2-4] solar dyes,[5-7] in light-emitting electrochemical cells[8-10] and light-emitting diodes,[11] as well as in many biological applications such as anticancer agents[11-15] or photosensitizers for photodynamic therapy (PDT).[16-20] Fig. 1A displays the percentage of publications related to the different applications that $\mathrm{Ru}(\mathrm{II})$ polypyridyl complexes have been involved in. Almost half of them are in biological related areas.

\section{State-of-the-art}

In 1936, Burstall reported the synthesis of the first $\mathrm{Ru}(\mathrm{II})$ polypyridyl complex, namely $\left[\mathrm{Ru}(\mathrm{bpy})_{3}\right] \mathrm{Cl}_{2}$.[22]. In the early $80 \mathrm{~s}$, the discovery of the "ruthenium blue dimer" $\left(\left[(\text { bpy })_{2} \mathrm{Ru}\left(\mathrm{H}_{2} \mathrm{O}\right)(\mu-\mathrm{O})\left(\mathrm{H}_{2} \mathrm{O}\right) \mathrm{Ru}(\mathrm{bpy})_{2}\right]^{4+}\right)$ in water splitting [23] triggered the expansion of the preparation of this kind of complexes. Since then, an important variety of bipyridine-type ligands has been designed and developed to tune the physico-chemical properties of this type of complexes.[24] In the last 20 years, the number of publications about ruthenium polypyridyl complexes has grown exponentially (Fig. 1B), highlighting their relevance. 


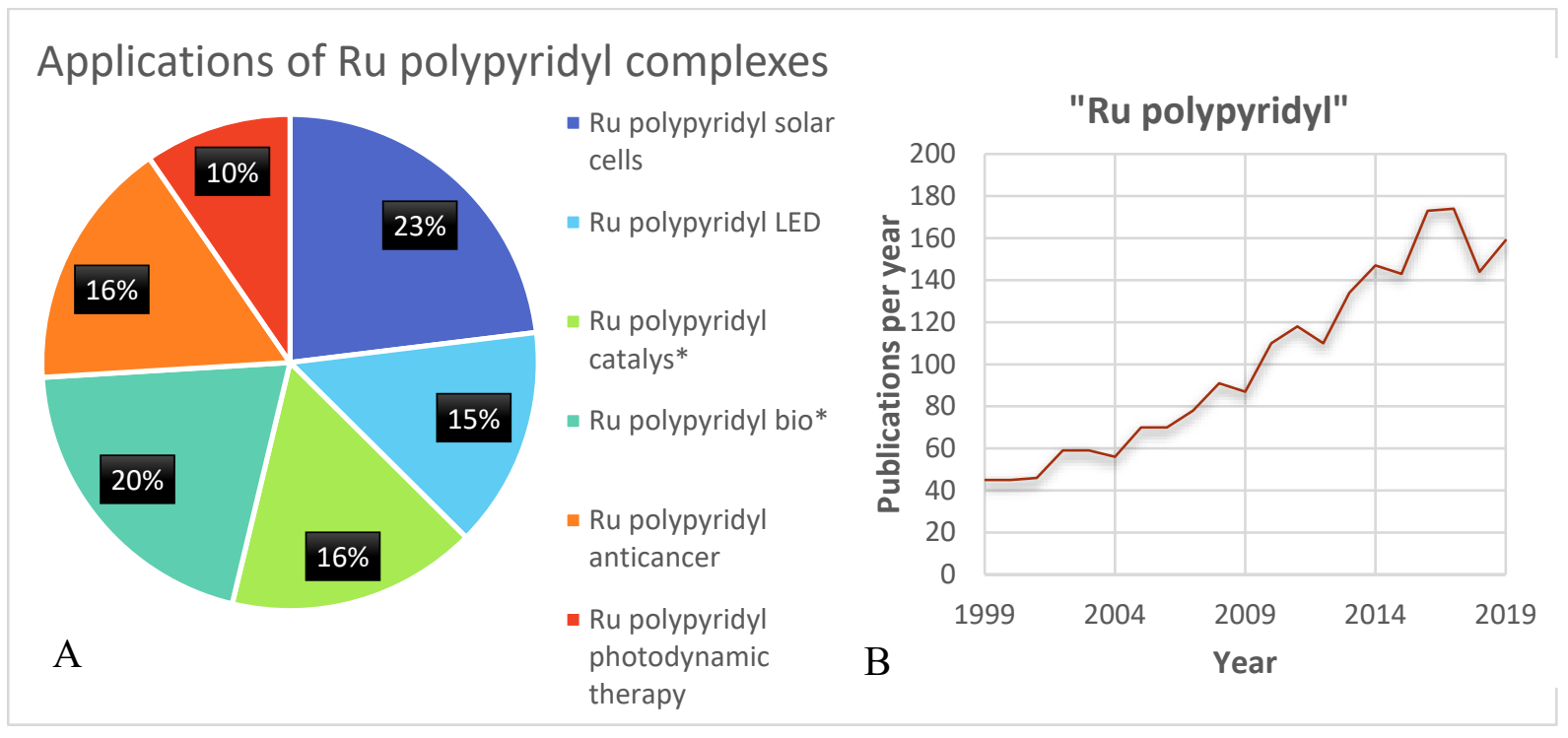

Fig. 1. A) Percentage of publications about different applications of Ru polypyridyl complexes. Searched on April $22^{\text {nd }} 2020$. B) Evolution of the number of publications per year related to "Ru polypyridyl" search in Web of Science in the last 20 years. Searched on May $9^{\text {th }} 2020$.

Regarding their use as anticancer drugs, a ruthenium polypyridyl complex (TLD-1433), developed by McFarland and co-workers[21,25] is currently in Phase II clinical trials as a photodynamic therapy photosensitizer against bladder cancer.[26] This achievement is definitively an encouragement for scientists to working with ruthenium complexes.

Bioconjugation is a strategy to covalently combine two or more molecules, where at least one of the fragments is a biomolecule or a bioactive compound.[27] The discovery of naturally occurring metal complexes like the haem group in haemoglobin $(\mathrm{Fe})$, vitamin $\mathrm{B}_{12}$, cobalamin (Co)[28] and hydrogenases $(\mathrm{Ni} / \mathrm{Fe}$ and $\mathrm{Fe} / \mathrm{Fe}),[29]$ has motivated an increasing interest in the development of new synthetic metal-containing biomolecules/bioconjugates. Some reviews concerning ruthenium-containing bioconjugates have been reported by Gunnlaugsson and coworkers, who reviewed only bioconjugates with in vitro and in vivo applications, by Lo and coworkers, who gathered some examples among luminescent Ruthenium polypyridyl complexes) and by Chen and co-workers, who reported different transition metal complexes as PSs for theranostic applications.[30-32] However, these reviews are not only exclusively dedicated to bioconjugation. In this review, we intend to discuss the recent advances on the preparation and 
use of ruthenium polypyridyl complex-containing bioconjugates. We have made sure to highlight the applications of these conjugates.

Among the biomolecules used in bioconjugation, DNA and nucleotides are on top of the list of biomolecules conjugates to ruthenium polypyridyl complexes ( $76 \%$ of publications), as shown in Fig. 2. The second place is for complexes bearing proteins, peptides and amino acids (21\%), and the remaining $3 \%$ (following decreasing order) is shared among lipids, sugars and carbohydrates, antibodies and vitamins. Thus, there is still place for the design, study and development of new bioconjugates, especially with uncommon biomolecules. We note that this review will not gather ruthenium-containing nucleotides and DNA conjugates[9,33-37] since this was recently reviewed by our group.[38] We also note that Chao and co-workers recently reported a review on how to design metal complexes to target specific organelles.[39] They previously published another review on the use of ruthenium complexes as anticancer drugs and their potential targets in cells.[14]

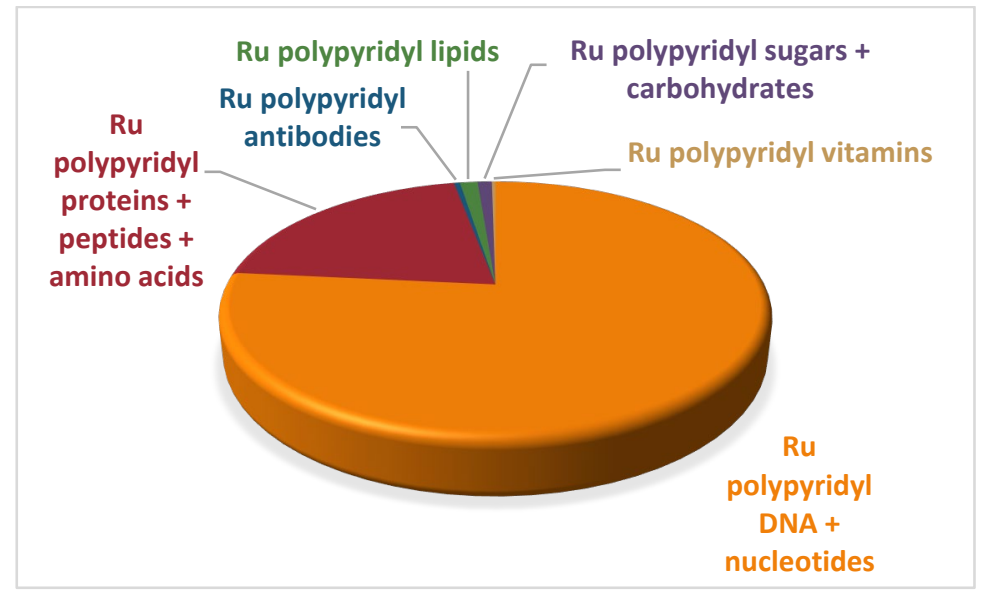

Fig. 2. Pie chart of number of publications for different Ru(II) polypyridyl bioconjugates. The label presents the search. Searched on June $9^{\text {th }} 2020$.

\subsection{Peptides}

There are many different synthetic pathways to covalently attach ruthenium complexes to peptides. This will depend on the target amino acid (AA). Lysine and cysteine are the most common AAs that have been used to attach novel functionalities to peptides. Lysine easily 
reacts with $N$-hydroxysuccinimide (NHS), thiocyanate or maleimide through the free amino group from its lateral chain. Maleimide can easily react with cysteines by Michael addition. In addition, cysteines, which are nucleophilic, can react with alkyl bromide, iodoacetamide and epoxides. Amino groups can react with the carboxylic acid of aspartic acid and glutamic acid in the presence of crosslinking carboxydiimide reagents. In the case of metal complex with a leaving group (i.e., a labile molecule like a water molecule), histidine is one of the best options for direct linkage.[40] Fig. 3 gathers some examples of structures bearing different reactive moieties that are coupled to amino acids. Meier-Menches and Casini recently reported strategies to prepare metal-peptide bioconjugates.[41]

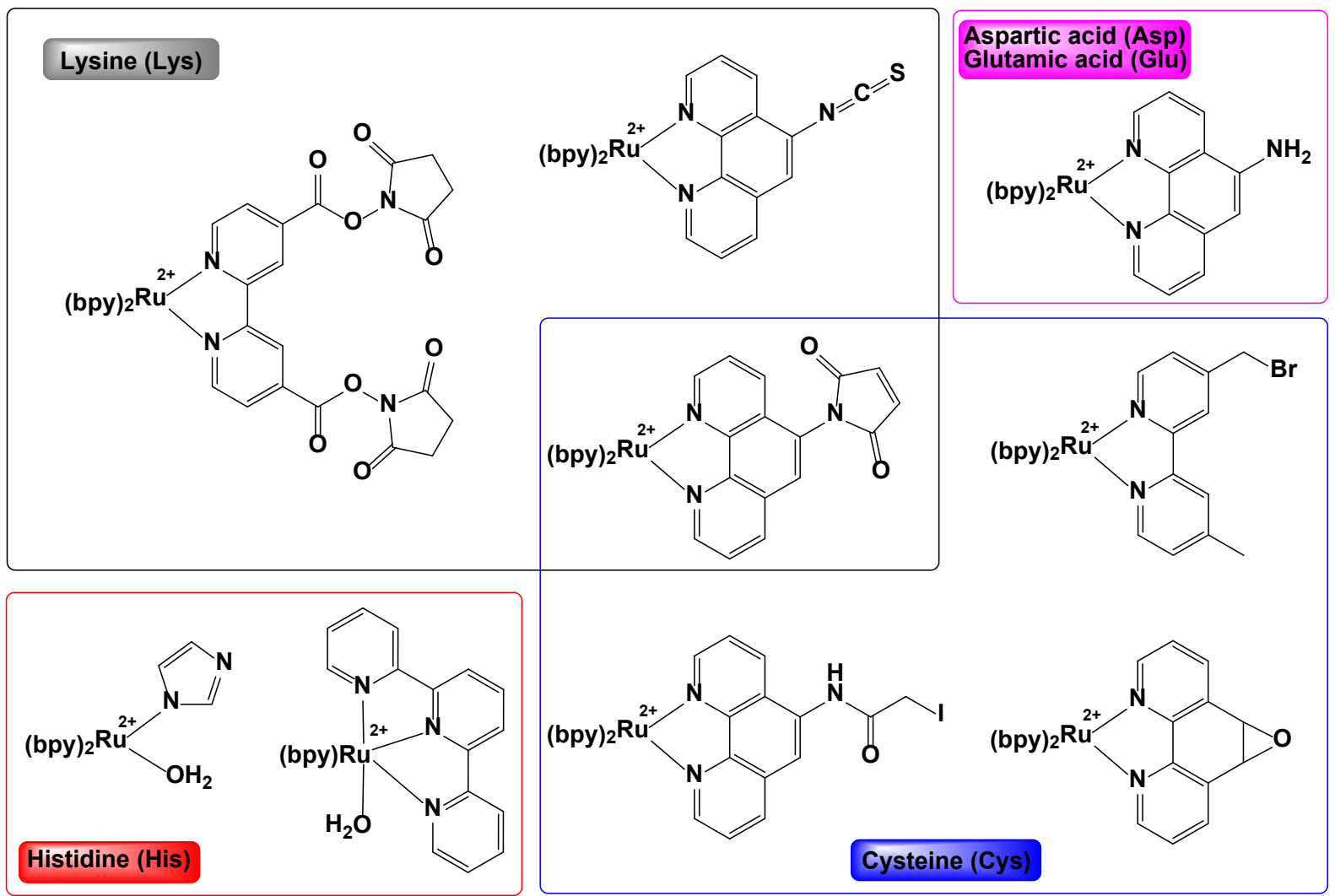

Fig. 3. Structures of Ru(II)-diimine functionalized complexes that can be covalently linked to proteins. Adapted from reference [40]. (C) 2015 Elsevier B.V.

\subsubsection{Amino acids}



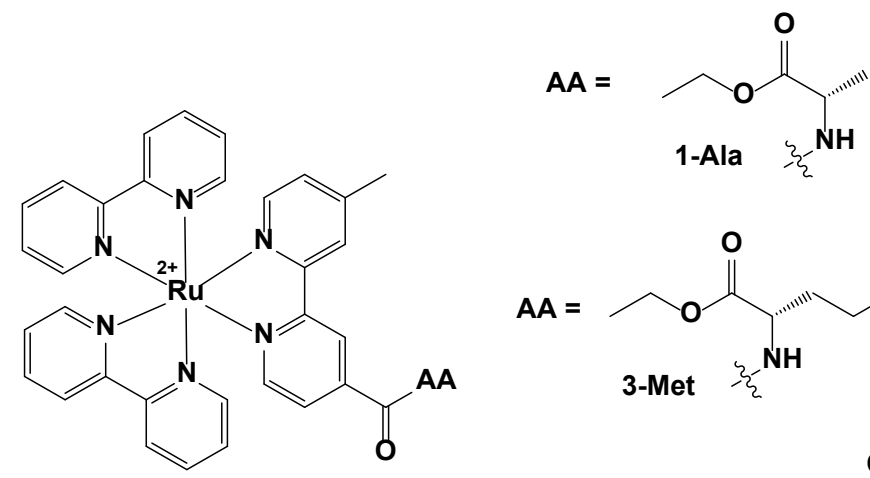<smiles>CC(C)N[C@@H](Cc1ccc(O)cc1)C(=O)OCC#[W]</smiles>

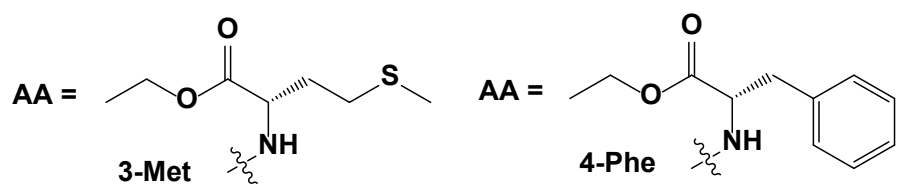

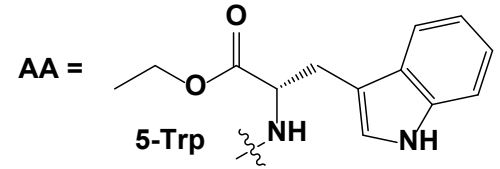

Fig. 4. Structures of the AA-labelled complexes 1-Ala, 2-Tyr, 3-Met, 4-Phe and 5-Trp.

One of the easiest and simplest ways to functionalize $\mathrm{Ru}(\mathrm{II})$ polypyridyl complexes is their coupling with an amino acid. Some amino acids were attached to bipyridyl ligands through amid bonds. One of the first examples of these AA-labelled complexes was reported by Magnuson et al. to mimic Photosystem II (PSII) reactions.[42] In the photosynthesis, once the water oxidation has occurred, the released electrons are delivered to a tyrosine (Tyrosine Z, TyrZ). To check this mechanism, photosensitizers (PS) 1-Ala and 2-Tyr (Fig. 4) bearing alanine and tyrosine, respectively, were synthesised. The two-step photoinduced electron transfer (eT) mechanism (only for 2-Tyr) occurs as follows. Firstly, in the presence of electron acceptors (Methylviologen, $\mathrm{MV}^{2+}$ and $\mathrm{Co}\left(\mathrm{NH}_{3}\right)_{5} \mathrm{Cl}^{2+}$ ) and light, the $\mathrm{Ru}(\mathrm{II})$ core is oxidized to $\mathrm{Ru}(\mathrm{III})$. In the second step, one electron is intramolecularly extracted from the covalently attached tyrosine and transferred back to the $\mathrm{Ru}(\mathrm{III})$, restoring the PS. This mechanism successfully met the actual water oxidation in PSII.

With the same purpose, Eswaran et al. described the photoinduced electron transfer reactions of $\mathrm{Ru}(\mathrm{II})$ derivatives with alanine (1-Ala), tyrosine (2-Tyr), methionine (3-Met) and phenylalanine (4-Phe) shown in Fig. 4.[43] In this case, however, different quinones were selected as quenchers. The emission intensities of the complexes were quenched by the quinones following a trend: higher quenching was observed for quinones with higher reduction potentials. 
Recently, Ramu et al. prepared and tested compounds 2-Tyr and 5-Trp (with tyrosine and tryptophan, respectively, see Fig. 4) in cells as photodynamic therapy (PDT) agents.[44] Both amino acid derivatives displayed improved water-solubility when compared with the nonconjugated ruthenium complex. Different DNA binding studies (i.e., UV-vis, fluorescence and isothermal titration calorimetry, ITC) revealed that complexes 2-Tyr and 5-Trp are able to bind DNA through groove binding and that the process was entropically driven. The binding affinity constants calculated by the different techniques were $\mathrm{K}_{\mathrm{a}}=1.18-3.2 \times 10^{5} \mathrm{M}^{-1}$ and $\mathrm{K}_{\mathrm{a}}=1.57$ $5.3 \times 10^{5} \mathrm{M}^{-1}$ for 2-Tyr and 5-Trp, respectively. Gel electrophoresis exhibited photoinduced DNA cleavage through singlet oxygen generation $\left({ }^{1} \mathrm{O}_{2}\right)$. Additionally, ${ }^{1} \mathrm{O}_{2}$ quantum yield values were 0.80 for $\mathbf{2 - T y r}$ and 0.72 for $\mathbf{5 - T r p}$, respectively in acetonitrile. Cytotoxicity was also tested in A549 cells (human lung carcinoma cells) and Hct116 cells (human colon cancer), by incubating cells with the complexes for $4 \mathrm{~h}$ in the dark before irradiation $(\lambda \sim 450-480 \mathrm{~nm}, 10$ $\mathrm{J} / \mathrm{cm}^{2}$ ). Both of the compounds were found to be non-toxic in the dark ( $\left.\mathrm{IC}_{50}>300 \mu \mathrm{M}\right)$. After light irradiation, the $\mathrm{IC}_{50}$ values decreased to 25 and $28 \mu \mathrm{M}$, for 2-Tyr and 5-Trp, respectively, showing a great potential as PDT PSs. The toxicity was assessed in 3D spheroids, reporting a 2-fold increase in $\mathrm{IC}_{50}$ values from $2 \mathrm{D}$ to $3 \mathrm{D}$ cell models. The phototoxicity index (PI) in 2D and $3 \mathrm{D}$ cell cultures were $>10$ and $>4$ for $\mathbf{2}$-Tyr and 5-Trp, respectively. ${ }^{1} \mathrm{O}_{2}$ was found again responsible for cell death since extra cell experiments using $\mathrm{NaN}_{3}$ as ${ }^{1} \mathrm{O}_{2}$ quencher demonstrated a lowering of cell toxicity. Comet assay performed in A549 cells showed that DNA cleavage was occurring in cells with complex 5-Trp causing more damage than complex 2-Tyr. Cellular imaging revealed that the complexes were preferably internalised in the mitochondria and, to some extent, in the cell membrane. These results are in good agreement with the lipophilic nature of the compounds $(\log \mathrm{P}=-1.31$ and -1.01 , for $2-\mathbf{T y r}$ and 5-Trp, respectively) since both lipophilicity and cellular uptake followed the same trend (2-Tyr $>\mathbf{5 -}$ Trp). Further assays to check the antimetastatic effectiveness (mimic the ability of cells to spread to other tissues) of the complexes in MDA-MB231 cells (breast cancer cells) were 
performed. Both derivatives showed ability to inhibit cell migration ( $4 \mathrm{~h}$ incubation + irradiation $+10 \mathrm{~h}$ incubation in the dark) in the wound healing assay. Moreover, complex 2-Tyr prevented cell invasion more efficiently than 5-Trp (17.5\% and 37.5\% reduction for 2-Tyr and 5-Trp, respectively, compared to $100 \%$ for the control experiment). Finally, apoptosis was determined as the cell death pathway. All these results highlight the promising ability of these amino acid derivatives as PDT PSs.

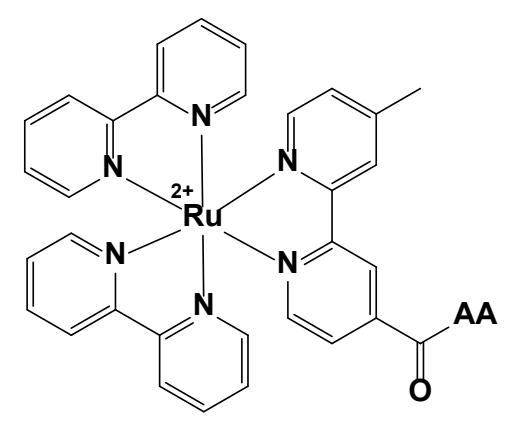<smiles>CC(C)NC[C@H](N)C(=O)[O-]</smiles><smiles></smiles>

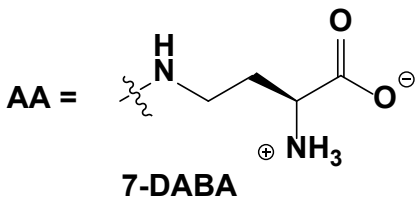

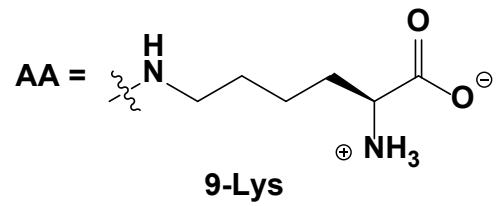

Fig. 5. Structures of the AA-labelled complexes 6-DAPA, 7-DABA, 8-Orn and 9-Lys.

Geisser et al. studied the effect of the alkyl chain length of different amino acid derivatives (6DAPA, 7-DABA, 8-Orn and 9-Lys) on the luminescent properties of the complexes in function of the $\mathrm{pH}$ (Fig. 5).[45] They used DAPA (2,6-Diaminopimelic acid), DABA (2,4diaminobutyric acid), ornithine and lysine as the amino acids, attached through an amid bond to a bipyridine ligand. Thus, the number of carbons increase from 1 in 6-DAPA, to 4 in 9-Lys. Each complex has three $\mathrm{pK}_{\mathrm{a}}$, corresponding to the amide, carboxylic acid and amine groups. At very low and high $\mathrm{pH}$, no difference was found in the UV-vis absorption. This fact suggests the absence of direct electronic interactions between the amino acid and the ruthenium core. However, regarding the emission at $\mathrm{pH} 1$, it got completely quenched, due to the protonation of the amide bond. At intermediate $\mathrm{pH}$ values, between 2 and 8, the emission intensity and the lifetimes increased with the number of methylene groups. These findings revealed that there is no interaction between the amino acids and the ruthenium chromophore in the ground state, but there is in the excited state. This difference of states (i.e., ground and excited state) is smaller 
for 6-DAPA and 7-DABA. Therefore, the amid linkage could be a key factor to control the photophysical properties of this kind of complexes.
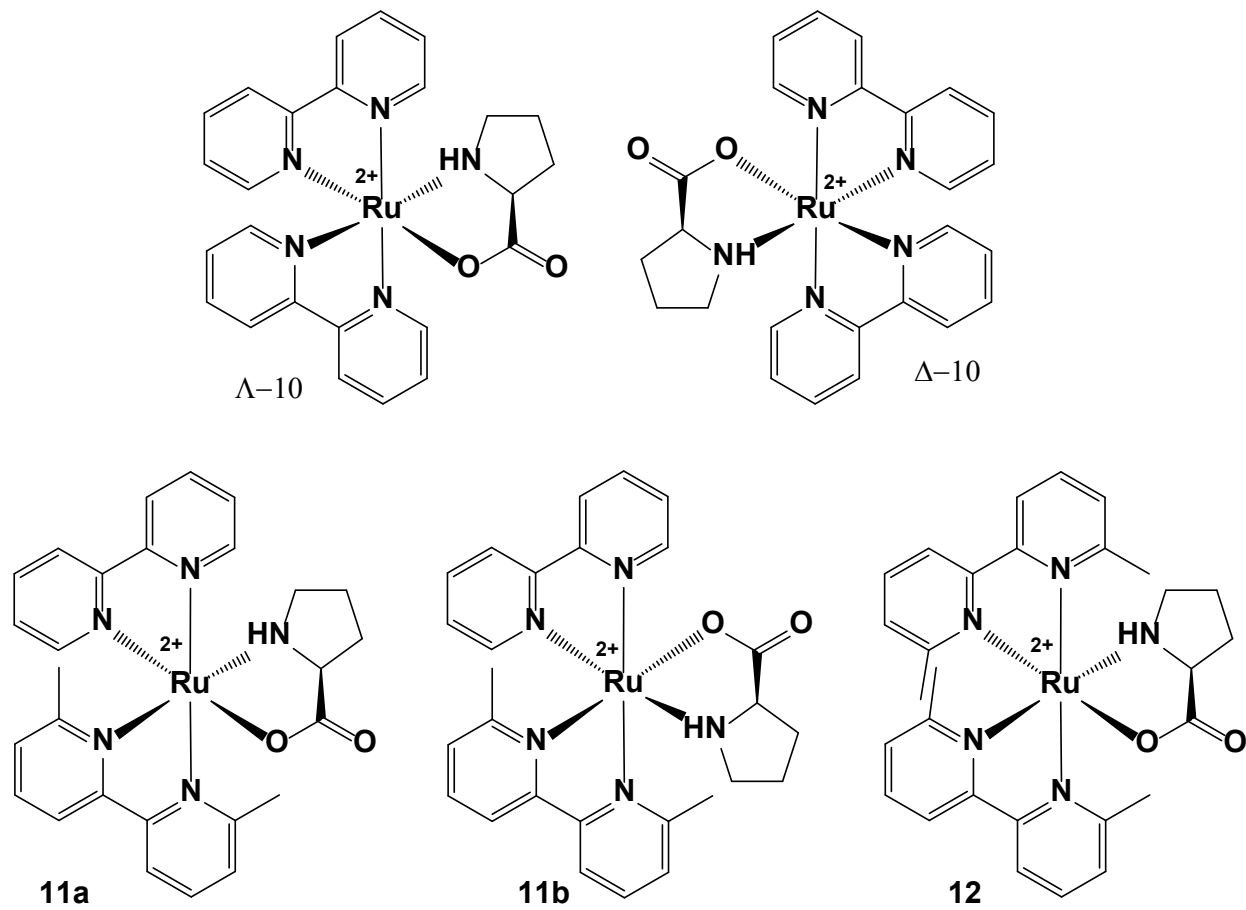

Fig. 6. Structures of L-proline conjugates $\Lambda-10, \Delta-10,11 a, 11 b$ and 12 .

Unlike other amino acids, L-proline has been coupled to $\mathrm{Ru}(\mathrm{II})$ complexes as a chiral auxiliary for the synthesis and isolation of enantiomerically pure complexes. Although some other chiral molecules were used (2-diphenylphosphino-2'-hydroxy-1,1'-binaphthyl (HO- MOP), 2sulfinylphenols (SO), salicyloxazolines (Salox) or N-acetyl-tert-butanesulfinamide (ASA)), Meggers and co-workers were pioneers in using L-proline as a cheap, simple and efficient strategy to prepare enantiomerically pure complexes.[46] The reaction of racemic $\left[\mathrm{Ru}(\mathrm{bpy})_{2} \mathrm{Cl}_{2}\right]$ with L-proline in ethylene glycol in the presence of $\mathrm{K}_{2} \mathrm{CO}_{3}$ at $190{ }^{\circ} \mathrm{C}$, yielded both $\boldsymbol{\Lambda} \mathbf{- 1 0}$ and $\boldsymbol{\Delta - 1 0}$ (Fig. 6) diastereomers in $\geq 20: 1$ ratio. Although both diastereomers are probably formed in the reaction, at high temperatures, only the $\Lambda$ derivative is stable, whereas the $\Delta$ isomer might release the proline ligand. This turns the $\Lambda$ isomer into the thermodynamically stable diastereomer. To check the scope of this reaction, the minor isomer $(\Delta-10)$ was heated in ethylene glycol at $190^{\circ} \mathrm{C}$ under argon. After $10 \mathrm{~min}$, conversion to the 
major isomer $\Lambda$ was observed ( $\geq 20: 1)$. In addition, the replacement of L-proline by a bipyridine (bpy) or phenanthroline (phen) in acetonitrile in acid conditions (trifluoroacetic acid, TFA) at $110^{\circ} \mathrm{C}$ resulted in the formation of the $\Lambda$ isomer (99:1 and 98:2 for bpy and phen, respectively). Nevertheless, it did not work that well with other Ru complexes. The exposition of the $\Lambda$ isomer in different solvents (i.e., $\mathrm{MeCN}, \mathrm{DMF}, \mathrm{MeOH}$ ) to visible light at room temperature resulted in the racemization of the complex in about 2 days. This rate increased by diminishing time to 10 $\mathrm{h}$, when the evolution was performed at $50{ }^{\circ} \mathrm{C}$. In dark conditions, however, no racemization was observed. We note that this interesting methodology of asymmetric synthesis is not exclusive for ruthenium complexes and was found to be also successful, for example, with Ir(III) biscyclometalated complexes.[47] In addition, the conversion from $\Delta$ to $\Lambda$ enantiomers in aqueous solution of $\mathrm{Ru}(\mathrm{II})$ polypyridyl complexes coupled to amino acids were firstly observed by Vagg and Williams in 1981. In this case, the tested complexes used L-serine and L-tryptophan N,O-coordinated to the ruthenium core, instead of L-proline, to yield $\left[\mathrm{Ru}(\mathrm{bpy})_{2}(\mathrm{~L}-\right.$ serine $)] \mathrm{ClO}_{4}, \quad\left[\mathrm{Ru}(\text { phen })_{2}(\mathrm{~L}-\right.$ serine $\left.)\right] \mathrm{ClO}_{4}, \quad\left[\mathrm{Ru}(\text { bpy })_{2}(\mathrm{~L}\right.$-tryptophan $\left.)\right] \mathrm{ClO}_{4}$ and $\left[\mathrm{Ru}(\text { phen })_{2}(\mathrm{~L}-\right.$ tryptophan)]ClO4, respectively.[48,49]

A distinct application as a protecting ligand was found for L-proline. Bonnet and co-workers. reported sterically hindered complexes 10, 11a, 11b and 12 (Fig. 6), by systematically adding methyl groups on the bpy ligand(s) [from zero (10) to two (11a and 11b) and to four (12)].[50] All complexes were obtained as racemic mixtures, with the $\Lambda$ as the major isomer, except for the most hindered 12, which was obtained as the single $\Lambda$-isomer. The photoreactivity of the complexes was studied under different conditions and solvents. Thus, 10 showed loss of hydrogen atoms in the proline ligand after irradiation with $493 \mathrm{~nm}$ light under air in PBS as seen by UV-vis and MS. The same experiment performed under argon did not display any change, except for the racemization of the complex. With these features, the authors proposed a mechanism of photooxidation and photoisomerization. The same experiments showed no photooxidation for 12. Photoconversion from 11a (kinetic product) to 11b (thermal product) 
was detected. Photooxidation, but in a slower rate, was also observed. The explanation dwells in the acidity of the $\mathrm{NH}$ of the proline and in the number of methyl substituents on the bpy ligands. An increment of the number of methyls causes an increase of the electron density on the ruthenium, as the methyl groups are electron donors, which decreases the acidity of the proline amine. When these experiments were performed in $\mathrm{MeCN}$, non-selective photosubstitution of either the proline or the dmbpy (4,4'-dimethyl-2,2'-bipyridine) by solvent molecules was observed. Thus, this study highlights the value of the solvent in the photoreactivity of ruthenium polypyridyl complexes, especially when studying biological systems and some microenvironments that are more hydrophobic than $\mathrm{H}_{2} \mathrm{O}$.

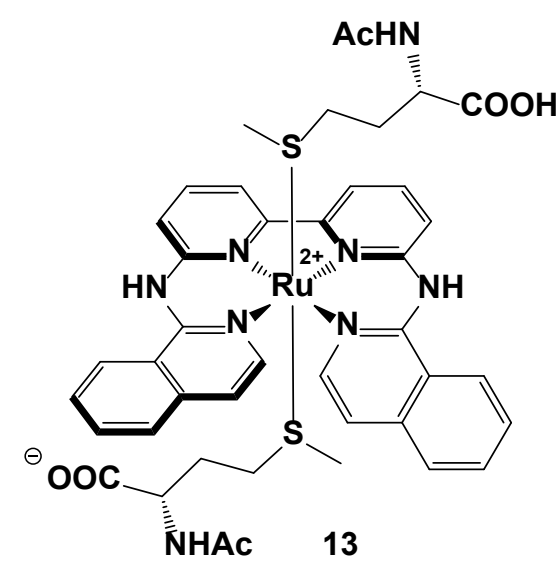

Fig. 7. Structure of the tetradentate water-soluble complex 13.

The same authors also prepared the first light-activated trans ruthenium-based anticancer prodrug candidates.[51] The water-soluble complex 13 is based on a tetrapyridyl ligand $\left(6,6^{\prime}\right.$ bis[N-(isoquinolyl)-1-amino]-2,2'-bipyridine, biqbpy), leaving two trans positions for the coordination of monodentate ligands, like N-acetyl-L-methionine (Fig. 7). A parent compound was also prepared with the same tetradentate ligand and a chloride and a DMSO molecule in the trans positions. The stability studies of $\mathbf{1 3}$ in aqueous solution in the dark displayed the loss of the proton of the carboxylic acid. However, upon green light irradiation $(\lambda=520 \mathrm{~nm})$, the replacement of one of the methionines by a water molecule occurred. The cytotoxicity was investigated in three cell lines A549 (human lung carcinoma cells), A431 (human epidermoid 
carcinoma cells) and MRC-5 (noncancerous human foetal lung fibroblasts). The EC50 values showed low toxicity in the dark, but an increase of the phototoxicity upon 60 min irradiation with green light $\left(520 \mathrm{~nm}, 21 \mathrm{~mW} \mathrm{~cm}{ }^{-2}, 75 \mathrm{~J} \mathrm{~cm}^{-2}\right)$. For A549 cells, for instance, the $\mathrm{EC}_{50}$ decreased from $20 \mu \mathrm{M}$ to $3.6 \mu \mathrm{M}$ after $6 \mathrm{~h}$ of irradiation, and from $11 \mu \mathrm{M}$ to $5 \mu \mathrm{M}$ after $24 \mathrm{~h}$. Furthermore, $\mathbf{1 3}$ was less toxic in the dark than its chloride-DMSO derivative. Apoptosis was found as the unique mechanism of cell death after irradiation by flow cytometry analysis. The cellular uptake (ICP-MS) after $6 \mathrm{~h}$ showed a lower uptake of $\mathbf{1 3}$ with regard to the parent compound. 13 was mainly accumulated in the membrane fraction (i.e., mitochondria, endosomes, lysosomes, etc). Since the singlet oxygen quantum yield was low (2.3\%), and the DNA binding studies revealed just small interactions between the ruthenium complex and DNA $-{ }^{1} \mathrm{O}_{2}$-based DNA cleavage was not observed - the cell death mechanism is not triggered by a, but through PACT (photoactivated chemotherapy), and DNA represents only one of the possible targets.

\subsubsection{Peptides}

Peptides are simple models of proteins, and are commonly used as organelle-targeting agents (i.e., cell-penetrating peptides (CPPs), nuclear localization sequences (NLSs) or mitochondrial penetrating peptide (MPP)).[52] Furthermore, some cancer cells overexpress some peptide receptors contrary to healthy cells. Therefore, the conjugation of such peptides can help to target tumour cells.[53] Among the peptide conjugations used, the classic functionalizations involves the amides linkages on bipyridines, phenanthrolines, imidazo-phenanthrolines and benzimidazoles. 


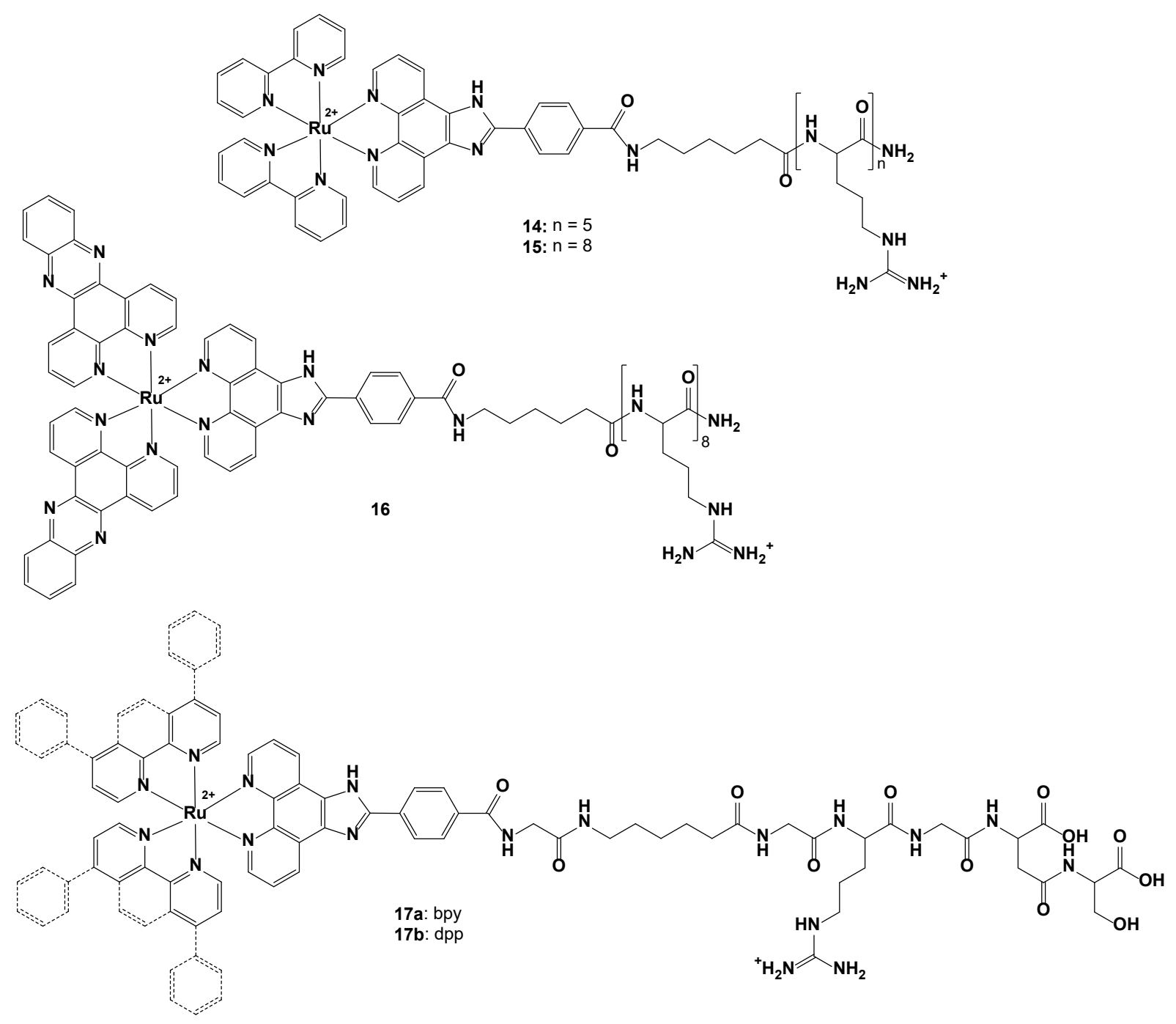

Fig. 8. Structures of the peptide conjugates $14,15,16,17 \mathbf{a}$ and $\mathbf{1 7 b}$.

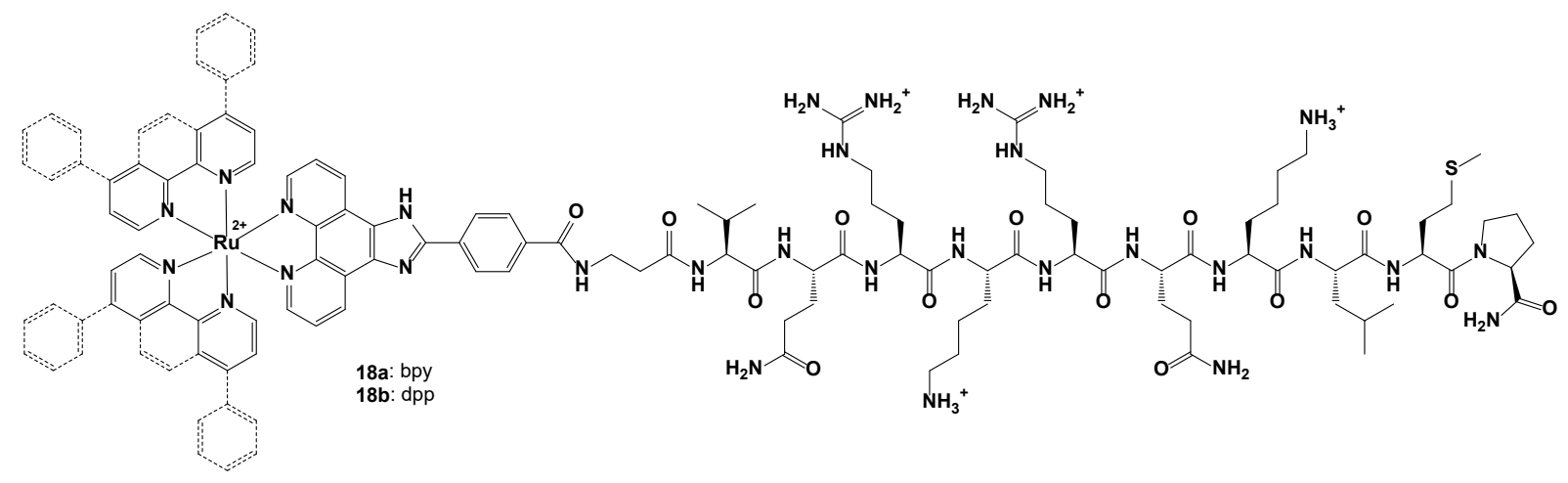

Fig. 9. Structures of $\mathbf{1 8 a}$ and $\mathbf{1 8 b}$.

Among the different imidazo-phenanthroline derivatives reported so far, Keyes and co-workers prepared a series of $\mathrm{Ru}(\mathrm{II})$ peptide conjugates, mainly in view of cell imaging agents directed to different cellular targets. Complexes 14 and 15, shown in Fig. 8, were prepared as first examples of water-soluble arginine labelled cell-penetrating probes.[54,55] These complexes 
were conjugated to 5 or 8 arginine (Arg, R) residues, respectively. The photophysical properties in PBS of both complexes exhibited no differences, since the arginine chain is far away from the ruthenium core. Two methods were tested for imaging the complexes in the same conditions: fluorescence lifetime imaging and resonance Raman mapping. The luminescence lifetime was oxygen sensitive and $\mathrm{pH}$ independent, whereas Raman spectroscopy was $\mathrm{pH}$ dependent but not oxygen-dependent. Thus, the authors probed the effectiveness of both methods to independently map two parameters. The cellular uptake was investigated in Sp2/0Ag 14 myeloma cells and human blood platelets by confocal laser scanning microscopy (CLSM). Complex $15\left(\mathrm{Ru}_{-} \mathrm{R}_{8}\right)$ was found to be passively transported through myeloma cells in about $12 \mathrm{~min}$. In the first 2-3 min, the dye accumulates in the membrane and passively diffuses inside the cell. After 10 or $15 \mathrm{~min}$, the process is finished and no more changes are observed. In platelets, compound 15 showed intense luminescence in the cytoplasm, but complex 14 was not emissive, highlighting the relevance of the chain length. Myeloma cells treated with $\mathbf{1 5}$ and incubated for $48 \mathrm{~h}$ showed slight toxicity, with $30 \%$ of cell death. In addition, unlike other organic chromophores, complex 15 showed photostability, a key future in cell imaging. As a result, two imaging methods (i.e., resonance Raman and FLIM) can be successfully used to image cells with the ruthenium probes, mainly with the $\mathrm{R}_{8}$ derivative.

A similar complex, 16 (Fig. 8), in which the bipyridyl ligands were replaced by dppz (dipyrido[3,2-a:2',3'-c]-phenazine), was prepared as a cell membrane probe.[56] The dppz ligands make the complex behave as a "molecular light-switch". Moreover, the arginine coupling confers enhanced luminescence properties to 16 (in MeCN/DMSO 9:1), better than those of the corresponding complex without the arginine moiety. However, when increasing amounts of water were added to an acetonitrile solution, the emission got completely quenched at $18 \% \mathrm{v} / \mathrm{v}$ water/acetonitrile. When the complex was suspended in lipid vesicles of dipalmitoylphosphatidylglycerol (dppg) in PBS at pH 7.4, a strongly switch on of the emission was observed. CLSM under the same conditions (in myeloma cells) as previously reported 
showed strong emission from the outer and internal membranes of organelles, specifically from endosomal vesicles, which are usually related to endocytosis as the mechanism of internalization. Resonance Raman mapping was recorded following some characteristic Raman bands associated to the complex inside the cell. This technique revealed that $\mathbf{1 6}$ crossed the membrane and distributed throughout the cell. This complex acts as a light-switch to stain membranes.

The peptide conjugates $\mathbf{1 7} \mathbf{a}$ and $\mathbf{1 7 b}$ (Fig. 8) were prepared as $\alpha_{\mathrm{IIb}} \beta_{3}$ integrin binders. Integrins, which are over-expressed in some kind of tumour cells, have specificity for an RGD (Arg-GlyAsp) motif binding site.[57] Thus, these complexes have been labelled with this tripeptide. The binding affinity of the complexes towards BSA (bovine serum albumin, a nonspecific protein without RGD recognition site) showed only small increase of the emission intensity - meaning weak interaction -, whereas for $\alpha_{\mathrm{IIb}} \beta_{3}$ integrin the increment was around an order of magnitude - suggesting strong interaction. The dissociation constants were in the micromolar range, with a single binding site for $\mathbf{1 7} \mathbf{a}\left(\mathrm{K}_{\mathrm{d}}=0.09 \pm 0.01 \mu \mathrm{M}\right)$ and a two-step binding for $\mathbf{1 7} \mathbf{b}$ (first $\mathrm{K}_{\mathrm{d}}=$ $0.25 \pm 0.29 \mu \mathrm{M}$ and second $\left.\mathrm{K}_{\mathrm{d}}=4.37 \pm 0.82 \mu \mathrm{M}\right)$, being stronger for the former. The interaction of the Ru conjugates with the integrin was found to be through the RGD binding site, since a displacement experiment with Eptifibatide (an integrin inhibitor that specifically binds the RGD motif site with a $\mathrm{K}_{d}$ in the nanomolar range) was performed. The presence of the inhibitor inhibited the binding of the complexes to the integrin. The binding affinity was also checked in the presence of $\mathrm{Mn}^{2+}$ and DTT (dithiohtreitol), which are able to alter the active-like conformations. The affinity of $\mathbf{1 7 a}$ towards the integrin treated with $\mathrm{Mn}^{2+}$ or DTT was the same as the non-treated one, whereas for $\mathbf{1 7} \mathbf{b}$, the binding affinity was much higher. Cellular uptake and localization (confocal imaging) of the conjugates in Chinese Hamster Ovary cells wild type (CHO-WT, not expressing $\left.\alpha_{\mathrm{IIb}} \beta_{3}\right)$ and transfected $\mathrm{CHO}-\alpha_{\mathrm{IIb}} \beta_{3}\left(\right.$ expressing $\left.\alpha_{\mathrm{IIb}} \beta_{3}\right)$ revealed weak emission for the CHO-WT cells but strong staining for $\mathrm{CHO}-\alpha_{\mathrm{IIb}} \beta_{3}$ after $4 \mathrm{~h}$ incubation. This emission was localized at the cell surface, suggesting binding with the integrins located in the 
cell membrane. The same experiment with the addition of SZ22, an $\alpha_{I I b}$ specific antibody, displayed stronger emission from the cell surface, confirming the co-localization in these cell membrane integrins. All these findings suggest the better ability of $\mathbf{1 7} \mathbf{a}$ to deeper penetrate in the integrin pocket, rather than $\mathbf{1 7 b}$, due to the smaller size and higher hydrophilicity of the former.

Complexes 18a and 18b (Fig. 9), however, were prepared as targeted delivery dyes to direct them to the nucleus through the attachment of NLS (nuclear localization sequence) peptides.[58] The NLS peptide is derived from the transcription factor NF- $\kappa \mathrm{B}$, a transmembrane molecular carrier. In this case, the cellular uptake by CLSM after $16 \mathrm{~h}$ incubation in CHO cells showed fast penetration of both conjugates in the cell and also in the nucleus in less than 5 min (co-stained with DAPI, a nuclear dye). Furthermore, $\mathbf{1 8 b}$ was also distributed in the cytoplasm and the nucleolus. Both complexes exhibited nearly complete cytotoxicity at $144 \mu \mathrm{M}$ in the same cell line after $16 \mathrm{~h}$. Nonetheless, the parent complexes (without the peptide) did not show any toxicity and therefore, the toxicity of the $\mathrm{Ru}$ conjugates is not due to interaction with the nuclear material. Thus, the attachment of this peptide allowed to successfully target the nucleus. 


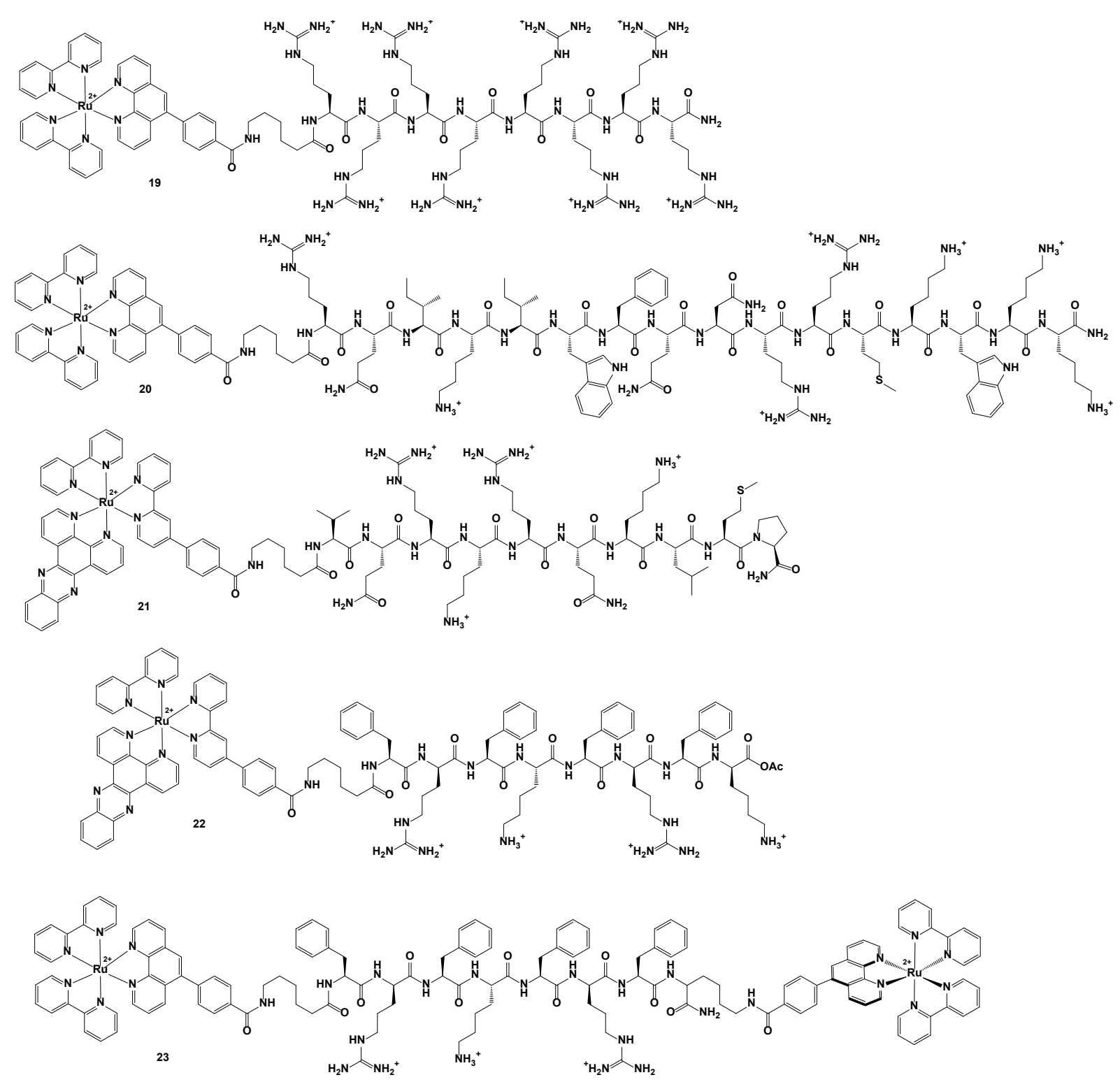

Fig. 10. Structures of the peptide conjugates 19, 20, 21, 22 and 23.

Keyes and co-workers also prepared the phenanthroline-peptide conjugates. Complexes 19, 20 and 21 (Fig. 10) were prepared as the octaarginine conjugate, endoplasmic reticulum (ER) targeting peptide and NLS derivatives, respectively, to direct the dyes to the ER and nucleus.[59] Compound 21 behaves as a molecular light-switch due to the dppz ligand. The cellular uptake (CLSM) and co-localization studies were assessed in HeLa cells (human cervical epitheloid carcinoma). For 20, the ER-directed complex, the uptake was fast. After 2 $\mathrm{h}$, the complex was distributed exclusively in the cytoplasm, and after $4 \mathrm{~h}$, localized in the ER. The polyarginine derivative 19 was also taken up quickly, but located in the cytoplasm, without 
specificity over time. The NLS conjugate $\mathbf{2 1}$ exhibited emission from the membrane after less than $6 \mathrm{~h}$ and, after $24 \mathrm{~h}$ the complex had crossed the nuclear membrane and bound to DNA. The images are shown in Fig. 11. STED (stimulated emission depletion) imaging was also performed. This technique allowed to distinguish the tubules in the ER using $\mathbf{2 0}$ and the different cell phases through the chromosomes in the cell with $\mathbf{2 1}$. The photostability of the ERtargeting complex was found to be comparable to AlexaFluor 532, a well-known ER dye. This complex was not toxic at $100 \mu \mathrm{M}$ after $24 \mathrm{~h}$ incubation, whereas for $\mathbf{1 9}$, no cell viability was detected at the same conditions. The NLS derivative showed partial toxicity, with $55 \%$ of cell viability at $200 \mu \mathrm{M}$. However, at the working concentration $(50-70 \mu \mathrm{M})$, viability increased to $73 \%$, enough so as not to induce excessive cell death. Thus, these complexes are promising candidates as cell imaging dyes for ER and nucleus.
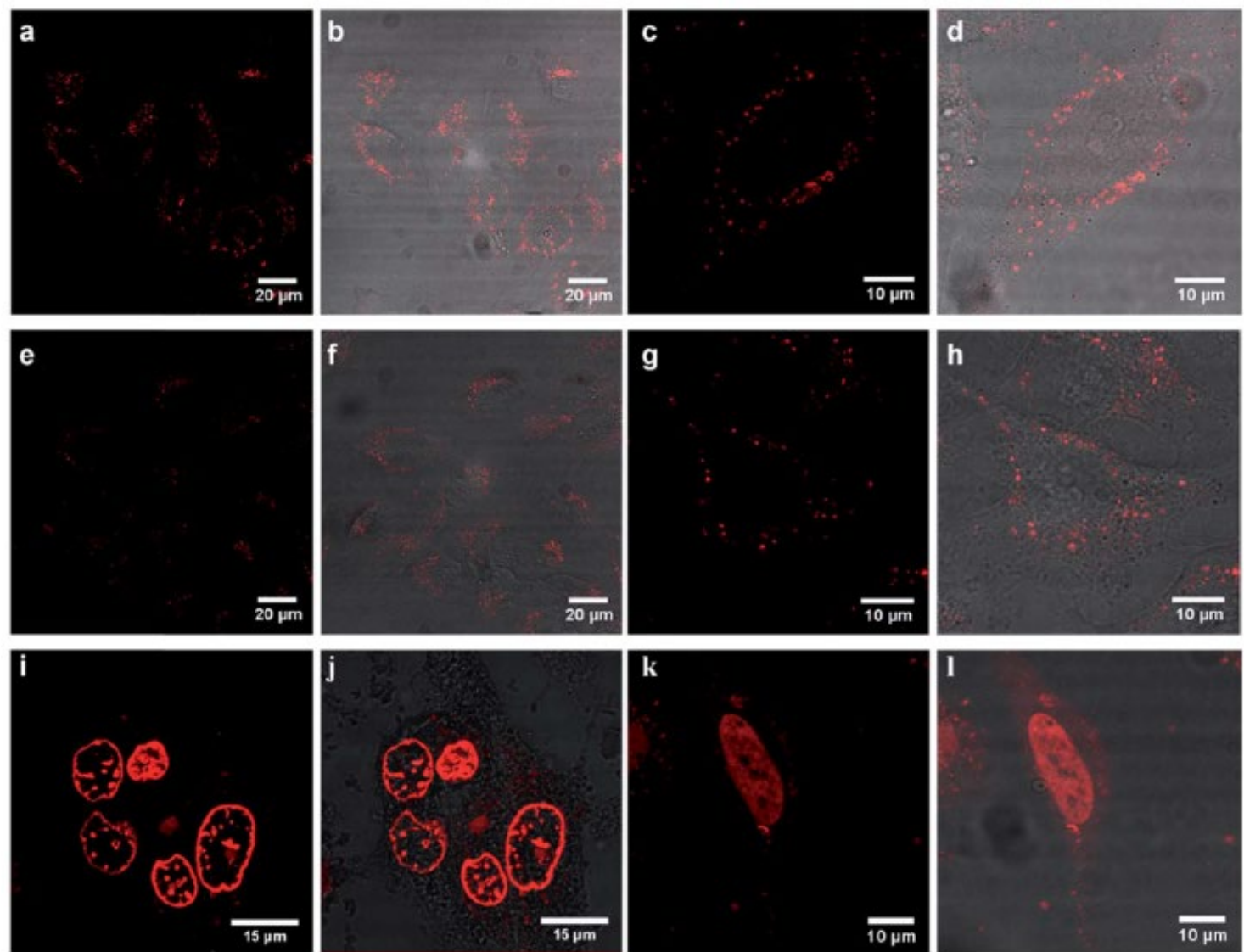

Fig. 11 Confocal luminescence images of $(\mathrm{a}-\mathrm{d}) \mathbf{2 0},(\mathrm{e}-\mathrm{h}) \mathbf{1 9}$ and $(\mathrm{i}-1) 21$ in live HeLa cells where the ruthenium channel and overlay channel are shown for each complex. Cells were incubated in the absence of light with 70 mM 20 and 19 for $4 \mathrm{~h}$, and $40 \mathrm{mM}$ with 21 for $24 \mathrm{~h}$. The distribution of each complex is shown in a group of cells (column 1 and 2) and then focused on a single HeLa cell (column 3 and 4). 20 and 19 were excited using a 488 
$\mathrm{nm}$ white light laser and the emission was collected between 590 and $700 \mathrm{~nm}$. 21 was excited using a $470 \mathrm{~nm}$ white light laser and the emission was collected between 565 and $700 \mathrm{~nm}$. Figure extracted from reference [59], published by The Royal Society of Chemistry, 2016.

A recent work from the same authors compared and analysed complexes 21 and 22 (Fig. 10) as NLS and MPP.[60] They were found to intercalate in ctDNA (calf thymus DNA) through the dppz ligand, due to increments in emission intensity and changes in the circular dichroism (CD) spectrum after addition of DNA. Higher binding constants $\left(\mathrm{K}_{\mathrm{a}}=3.6 \times 10^{7} \mathrm{M}^{-1}\right.$ and $\mathrm{K}_{\mathrm{a}}=2.8 \times$ $10^{7} \mathrm{M}^{-1}$ for $\mathbf{2 1}$ and $\mathbf{2 2}$, respectively) than those for the parent complexes $\left[\mathrm{Ru}(\mathrm{bpy})_{2}(\mathrm{dppz})\right]^{2+}$ were determined, suggesting an additional electrostatic interaction from the peptide chain. The uptake of the complexes in HeLa cells by CLSM showed fast internalization of $22(10 \mu \mathrm{M}$ in the dark). After $1 \mathrm{~h}$, the conjugate reached the cytoplasm and, after $2 \mathrm{~h}$, the mitochondria. As shown before, compound $\mathbf{2 1}$ was distributed in the cytoplasm after $2 \mathrm{~h}$, and reached the nucleus after $24 \mathrm{~h}(40 \mu \mathrm{M})$. Both of them showed a temperature-dependent uptake (no permeation was detected at $4{ }^{\circ} \mathrm{C}$ ), showing an endocytosis mechanism of internalization. Co-localization studies confirmed nuclear and mitochondria localization for $\mathbf{2 1}$ and 22, respectively, with the latter likely to be in mitochondrial substructures (mitochondrial DNA, mtDNA). Luminescent lifetime imaging microscopy (LLIM) was used to confirm the binding of 22 to mtDNA and 21 to nuclear DNA. Cell viability assays unveiled some toxicity of 21 at $50 \mu \mathrm{M}$ (after $24 \mathrm{~h}, 50 \%$ cell viability), but acceptable viability at $10 \mu \mathrm{M}$ (after $24 \mathrm{~h}, 80 \%$ cell viability). After 15 min irradiation $(470 \mathrm{~nm}, 0.8 \mu \mathrm{W})$, cell death was observed. These findings demonstrate the ability of $\mathbf{2 2}$ to act as a theranostic probe.

The dinuclear complex 23 (Fig. 10), bearing the same MPP sequence as 22, exhibited quick cellular uptake in $\mathrm{HeLa}$ and $\mathrm{CHO}$ cells when incubated at $37^{\circ} \mathrm{C}$.[61] Initially, the complex was detected in the cytoplasm, which was diffusing towards mitochondria, so that the internalization was complete after $2 \mathrm{~h}$. Nonetheless, when incubated at $4{ }^{\circ} \mathrm{C}$, the complex was unable to cross the cell membrane. As shown in Fig. 12, incubation of complex 23 with MitoTracker Deep Red 
showed strong co-localization. Through colour distribution chart, the intracellular $\mathrm{O}_{2}$ concentration was determined to be $\approx 183 \mu \mathrm{M}$, which is a common value for normally metabolizing cells. Incubation of the complex with Antimycin A, a classical mitochondrial uncoupler, showed quenching of emission luminescence probably caused by ROS (reactive oxygen species). This dinuclear complex displayed low cell viability (15\%) at $200 \mu \mathrm{M}$ after 24 $\mathrm{h}$ in HeLa cells $\left(\mathrm{IC}_{50}=47 \pm 1.1 \mu \mathrm{M}\right)$. A time-dependent experiment at $75 \mu \mathrm{M}$ showed $40 \%$ viability after $5 \mathrm{~h}$. However, after $2 \mathrm{~h}$, cells were viable. Phototoxicity was induced when the cells (after $2 \mathrm{~h}$ incubation with $75 \mu \mathrm{M}$ of the complex) were irradiated (488 nm, $20 \mathrm{~min}, 0.64$ $\left.\mu \mathrm{W} / \mathrm{cm}^{-3}\right)$. Again, the complex was found to be a good mitochondria imaging agent, thanks to the right selection of the directed peptides.
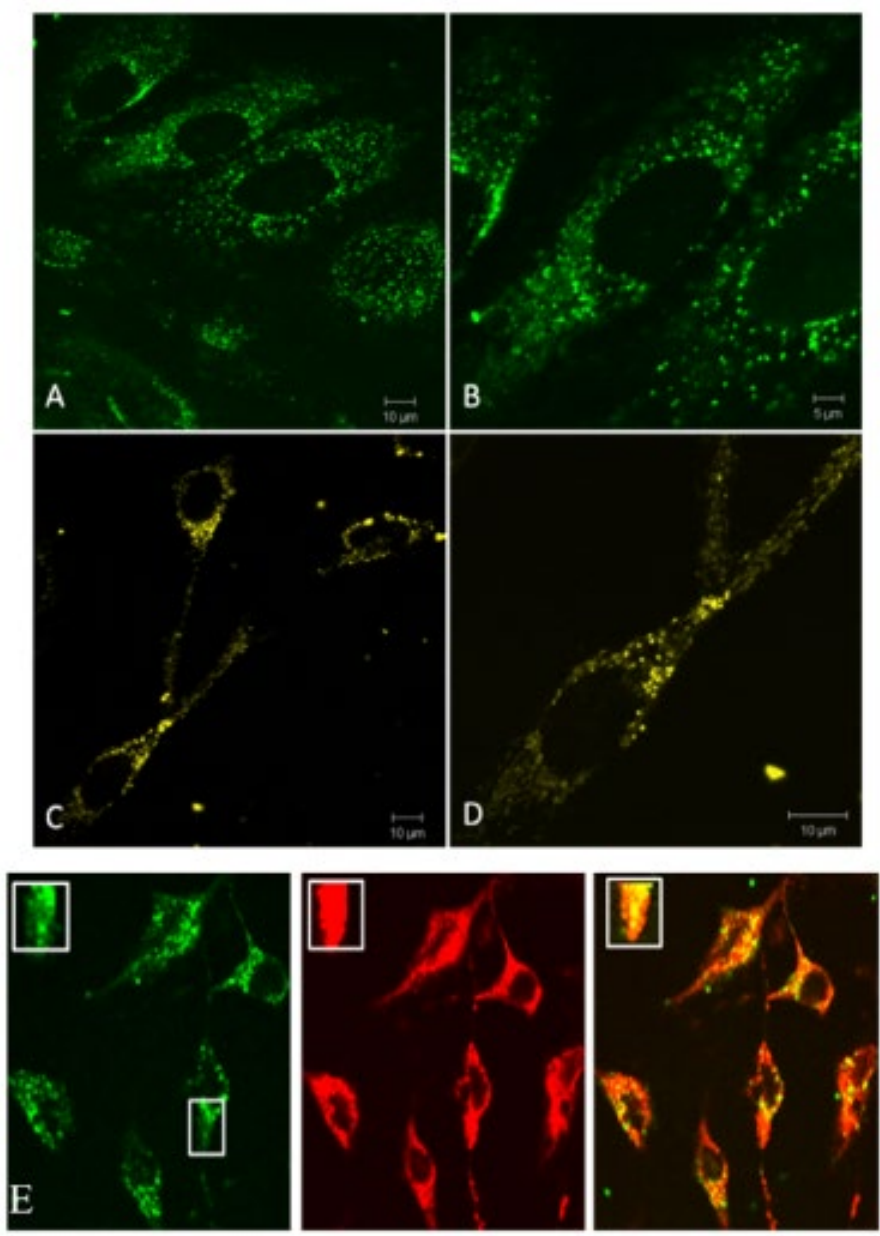

Fig. 12 (A,B) Confocal luminescence Imaging of 23 in HeLa cells. (C,D) Confocal luminescence Images of 19 in HeLa cells. (E) Co-localization studies were carried out using $500 \mathrm{nM}$ of the mitochondrial marker MitoTracker Deep Red. Cells were treated with 23 for $2 \mathrm{~h}$ and MitoTracker Deep Red for $30 \mathrm{~min}$. 23 is shown in green, 
Mitotracker in red, and co-stained regions are shown in yellow on the left. Adapted with permission from [61]. Copyright 2014 American Chemical Society.

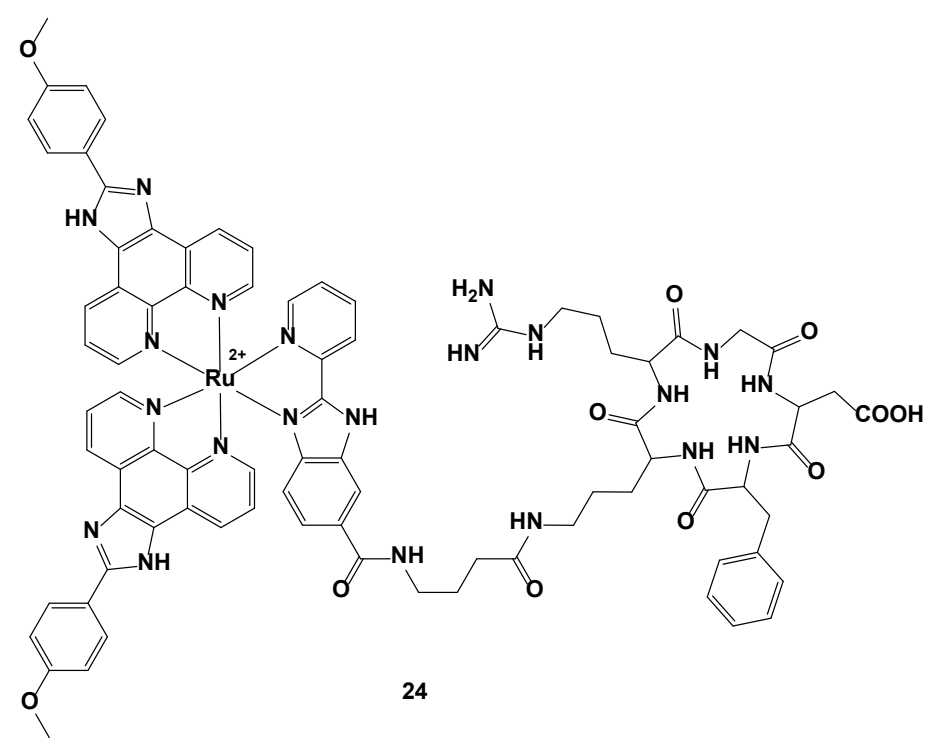

Fig. 13. Structure of the Ru-cRGD conjugate 24.

Recently, Chen and co-workers reported a Ru-cRGD (cyclic RGD) conjugate 24 (Fig. 13) with theranostic activity against cervical carcinoma. [62] The ruthenium conjugate was found to preferentially accumulate in malignant cells (CaSki: human caucasian cervical epidermoid carcinoma, SiHa: human squamous carcinoma of the cervix and HeLa: human cervical epitheloid carcinoma) over non-cancerous cells (Ect1/E6E7: normal ectocervical cells), even when CaSki were co-cultured with Ect1/E6E7. CaSki Multicellular tumour spheroids (MCTSs) were used as $3 \mathrm{D}$ model. After $3 \mathrm{~h}$ incubation, the conjugate $\mathbf{2 4}$ displayed strong two-photon luminescence and was able to suppress the spheroid growth by $60 \%$. The metabolic in vivo experiments in mice (intravenous injection for $36 \mathrm{~h}$ ) showed preferential internalization of $\mathbf{2 4}$ in tumour tissues rather than in other organs. The in vivo antitumour activity in mice inoculated with CaSki cells displayed inhibition rates of $58 \%$ and $74 \%$ at intravenous injection doses of $2 \mu \mathrm{mol} / \mathrm{kg}$ and $4 \mu \mathrm{mol} / \mathrm{kg}$, respectively. In addition, no death or change in the body weight of the mice were observed and no side effects were detected. Staining tissues with $\mathbf{2 4}$ also showed preferential accumulation in tumour tissues, with a Pearson's correlation coefficient of 0.85 . Thus, this Ru-bioconjugate is a good candidate as a theranostic probe. 

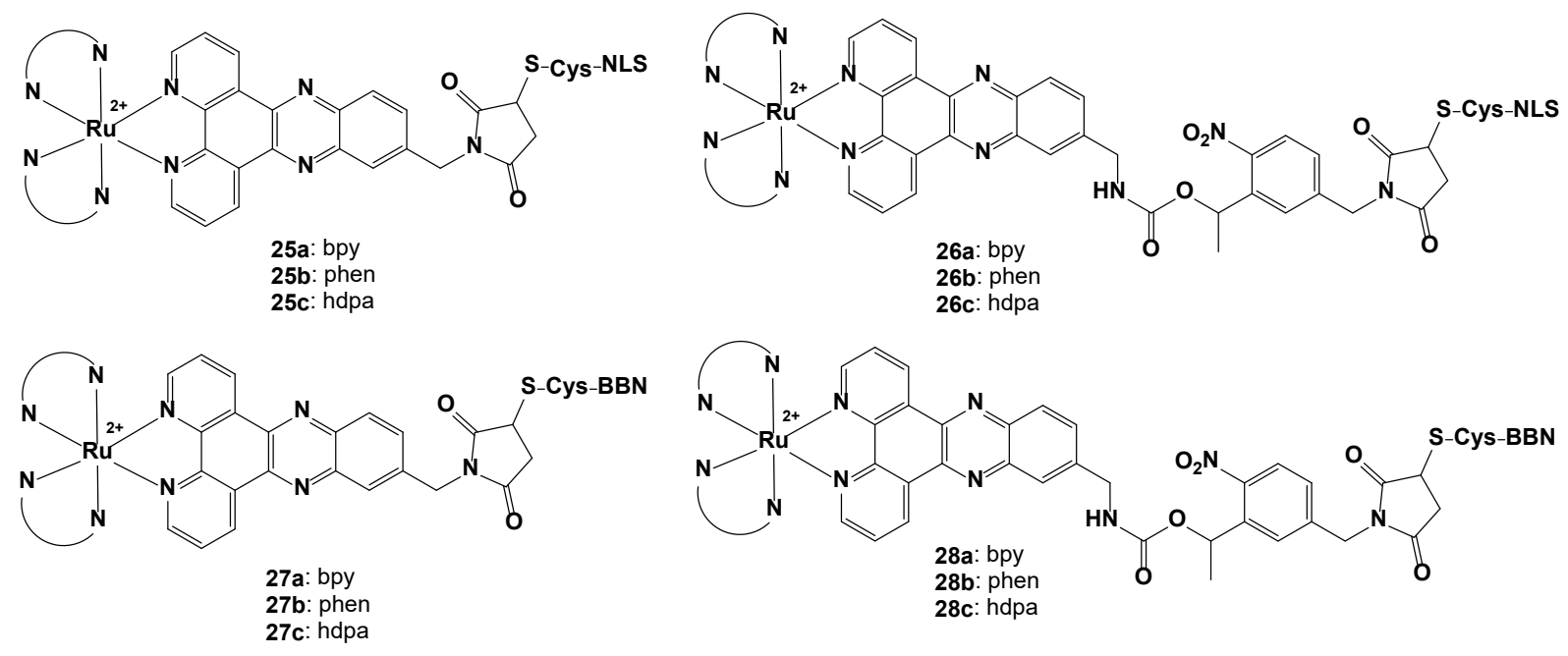

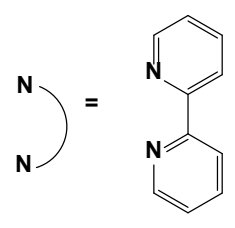

bpy

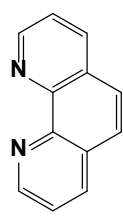

phen

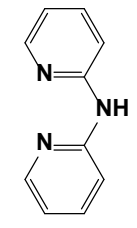

hdpa
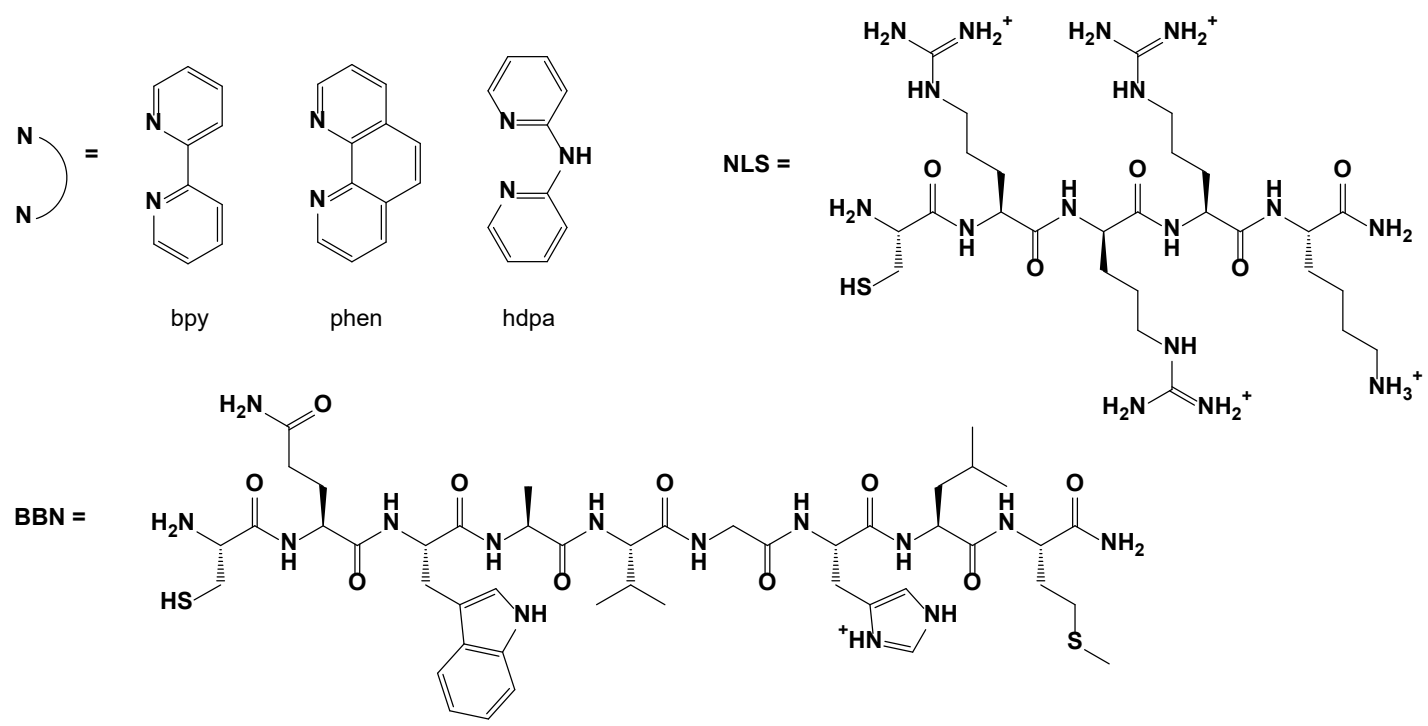

Fig. 14. Structures of complexes 25a-28c (bpy $=2,2^{\prime}$-bipyridine, phen $=$ phenanthroline and hdpa $=$ dipiyridylamine).

Gasser and co-workers reported a series of Ru(II) polypyridyl complex-peptide conjugates 2528 (Fig. 14), bearing two bipyridine (bpy), phenanthroline (phen) or dipyridylamine (hdpa) ligands, to modulate the lipophilicity of the complexes.[63] The peptides were selected to improve the cellular uptake of the Ru(II) complexes. There were a NLS to target the nucleus and bombesin (BBN) to target a membrane receptor overexpressed in certain cancer cells. Moreover, a photolabile protecting group (PLPG or photo-cage), an $o$-nitrobenzyl moiety, was chosen as a spacer and to control drug activation by light to give the Ru-PLPG-peptide bioconjugate. Complexes without the photo-cage (25 and 27) were prepared as controls. Upon 
light irradiation $(350 \mathrm{~nm}$ ) of the bioconjugates 25-28 in PBS solution, a full photo-release of the metal complexes was achieved in 6 to $10 \mathrm{~min}$ (light dose: $1.55-2.58 \mathrm{~J} \mathrm{~cm}^{-2}$ ). The efficiency in photo-uncaging is similar for both the NLS and BBN series: serie-c $>$ serie-a $>$ serie-b. This means that there is no relevant effect of the peptide on the photo-release. The correlation of uncaging efficiency with the extinction coefficient showed that different energy is needed for full release, being higher for serie-b than for serie-c. The cytotoxicity of the complexes was investigated in HeLa and MRC-5 cells after $4 \mathrm{~h}$ incubation, in the dark or after $10 \mathrm{~min}$ irradiation at $350 \mathrm{~nm}$. The cellular uptake was assessed after $2 \mathrm{~h}$ incubation in HeLa cells. The NLS conjugates $26 \mathbf{a}$ and $\mathbf{2 6} \mathbf{b}$ showed cellular internalization and localization in the nucleus, whereas localization for the control derivatives $\mathbf{2 5 a}$ and $\mathbf{2 5 b}$ were detected in the cytoplasm. Both 25c and 26c were not emissive and therefore were not detected. 26a was not toxic in the dark up to $100 \mu \mathrm{M}$, whereas $\mathbf{2 6 \mathbf { b }}$ and $\mathbf{2 6 c}$ displayed some toxicity more pronounced in HeLa than in MRC-5 cells. The irradiation of the complexes did not show any improvement of the activity. All the NLS controls $(\mathbf{2 5 a}, \mathbf{2 5 b}$ and $\mathbf{2 5 c})$ were non-toxic on both cell lines in the dark and after irradiation. Regarding the BBN conjugates, 28a showed nuclear localization, while $\mathbf{2 8 b}$ was spread in the cytoplasm. 28c was detected in cells and located weakly in the cytoplasm and strongly in the membrane. 28a exhibited moderate toxicity both with and without light irradiation $\left(\mathrm{IC}_{50} \approx 50 \mu \mathrm{M}\right) . \mathbf{2 8 b}$ and $\mathbf{2 8 c}$ showed phototoxicity; $\mathrm{IC}_{50}$ of $\mathbf{2 8 \mathbf { b }}$ in the dark was 93.8 $\mu \mathrm{M}$, and diminished by half upon irradiation, obtaining a $\mathrm{PI}=2.2 . \mathbf{2 8 c}$ was non-toxic in the dark $\left(\mathrm{IC}_{50}>100 \mu \mathrm{M}\right)$, but slightly toxic after irradiation $\left(\mathrm{IC}_{50}=60 \mu \mathrm{M}\right)$. Thus, the PI $>1.7$. None of these complexes showed toxicity on the MRC-5 cells. Controls 27a, 27b and 27c showed weak emission and only $\mathbf{2 7} \mathbf{b}$ was found to localize in the cytoplasm and none of them were found to be toxic. These studies highlight the relevance of the PLPG for the photorelease of the peptides and to achieve the desire toxicity of the conjugates. In a previous study, the same group reported some bombesin, NLS and MLS (mitochondrial localization signal) conjugates 
with mild or no cytotoxicity in HeLa cells and main cellular localization in the nucleus for all of them.[64]

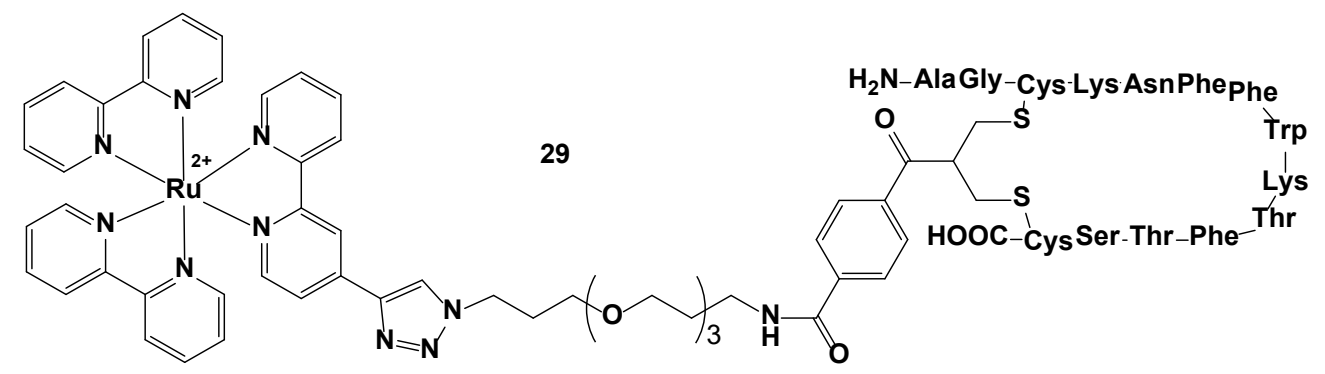

Fig. 15. Structure of the Ru-somatostatin bioconjugate 29.

Weil and co-workers prepared the first ruthenium somatostatine (SST) conjugate 29 (Fig. 15).[65] SST was selected since some somatostatine receptors (SSTRs) are overexpressed in some tumour cells. This photostable conjugate under visible light $(\lambda=470 \mathrm{~nm}, \mathrm{P}=50 \pm 3 \mathrm{~mW}$, $50 \pm 3 \mathrm{~mW} \mathrm{~cm}^{-2}$ ) was also an efficient ${ }^{1} \mathrm{O}_{2}$ generator (> $70 \%$ ). Complex 29 was tested in $\mathrm{A} 549$ cancer cells, which overexpress SSTRs. After 4h incubation, 29 successfully accumulated inside cells, with a higher uptake compared to the control experiment (the $\mathrm{Ru}(\mathrm{II})$ derivative without the SST moiety). The phototoxic activity of 29 in A549 cells revealed non-toxicity up to $300 \mu \mathrm{M}$ in the dark and $\mathrm{IC}_{50}=13.2 \mu \mathrm{M}$ after light irradiation $(\lambda=470 \mathrm{~nm}, 5 \mathrm{~min}, 6.9 \pm 0.9$ $\mathrm{J} \mathrm{cm}^{-2}$ ), resulting in a PI $>23$. Very recently, the same compound was tested in acute myeloid leukaemia (AML) with promising results.[66] The uptake of bioconjugate 29 was finished in 4 $\mathrm{h}$ in OA3 cells. Clonogenic assays after incubation with $\mathbf{2 9}$ in different leukaemic cell lines revealed reduction of colony growth of $99 \%, 98 \%$ and $92 \%$ for OCI-AML3, HL60 and THP1, respectively, after 6 min light exposure and only $25 \%$ in healthy cord blood cells (CB). This fact emphasizes the selectivity of $\mathbf{2 9}$ for AML cells over normal cells. Co-localization experiments in OCI-AML3 spotted 29 mainly in the lysosomes (Pearson's coefficient 0.94), with some detection also in membranes $(0.70)$ and mitochondria $(0.60)$. However, it was poorly taken up by the nucleous (0.35). In addition, ROS production experiments showed 7.4-fold 
increase in ROS levels in leukaemic cells rather than CB cells. These new findings demonstrate the effective conjugation of SST to a ruthenium-based PDT PS.
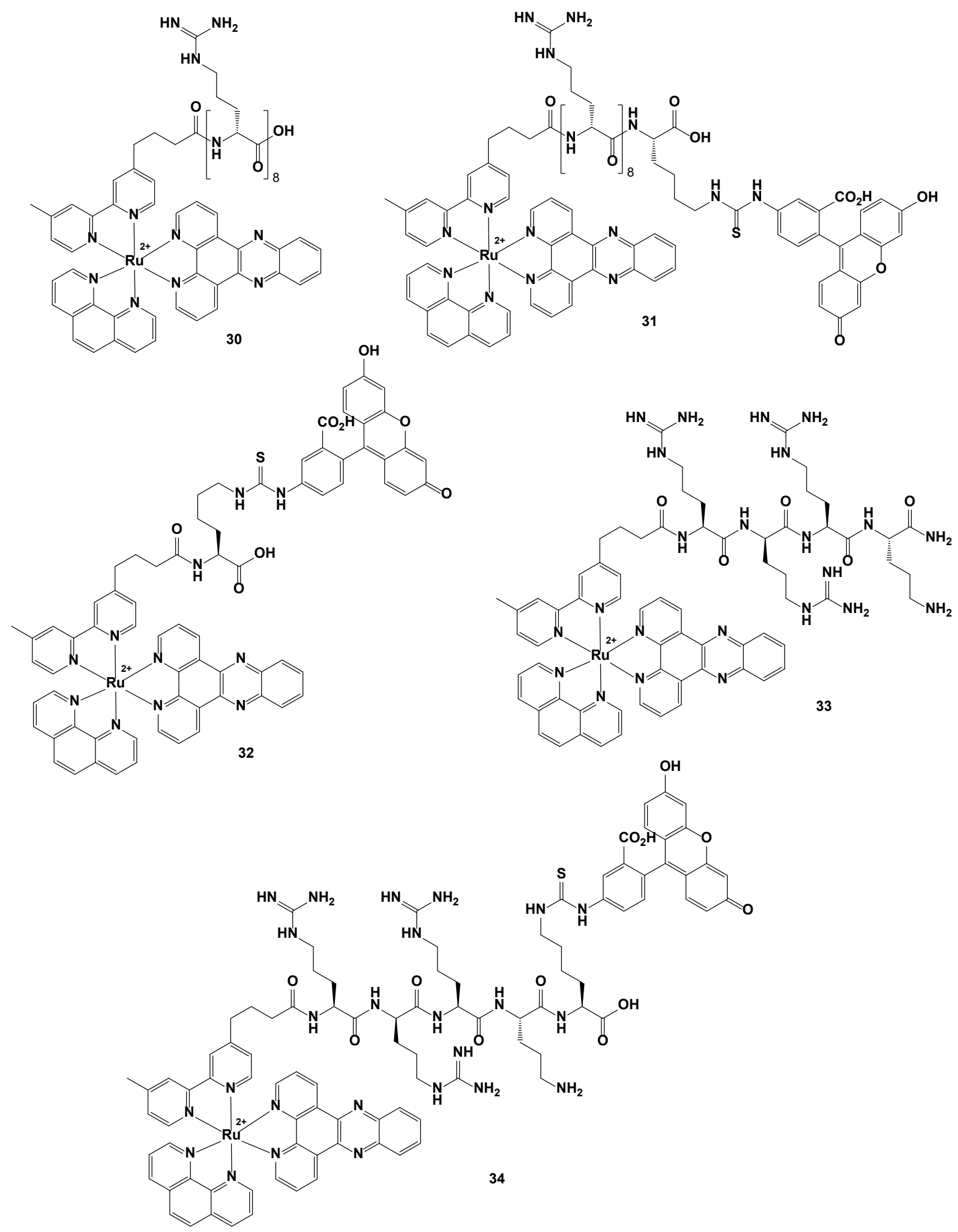

Fig. 16. Structures of the peptide conjugates 30-34. 


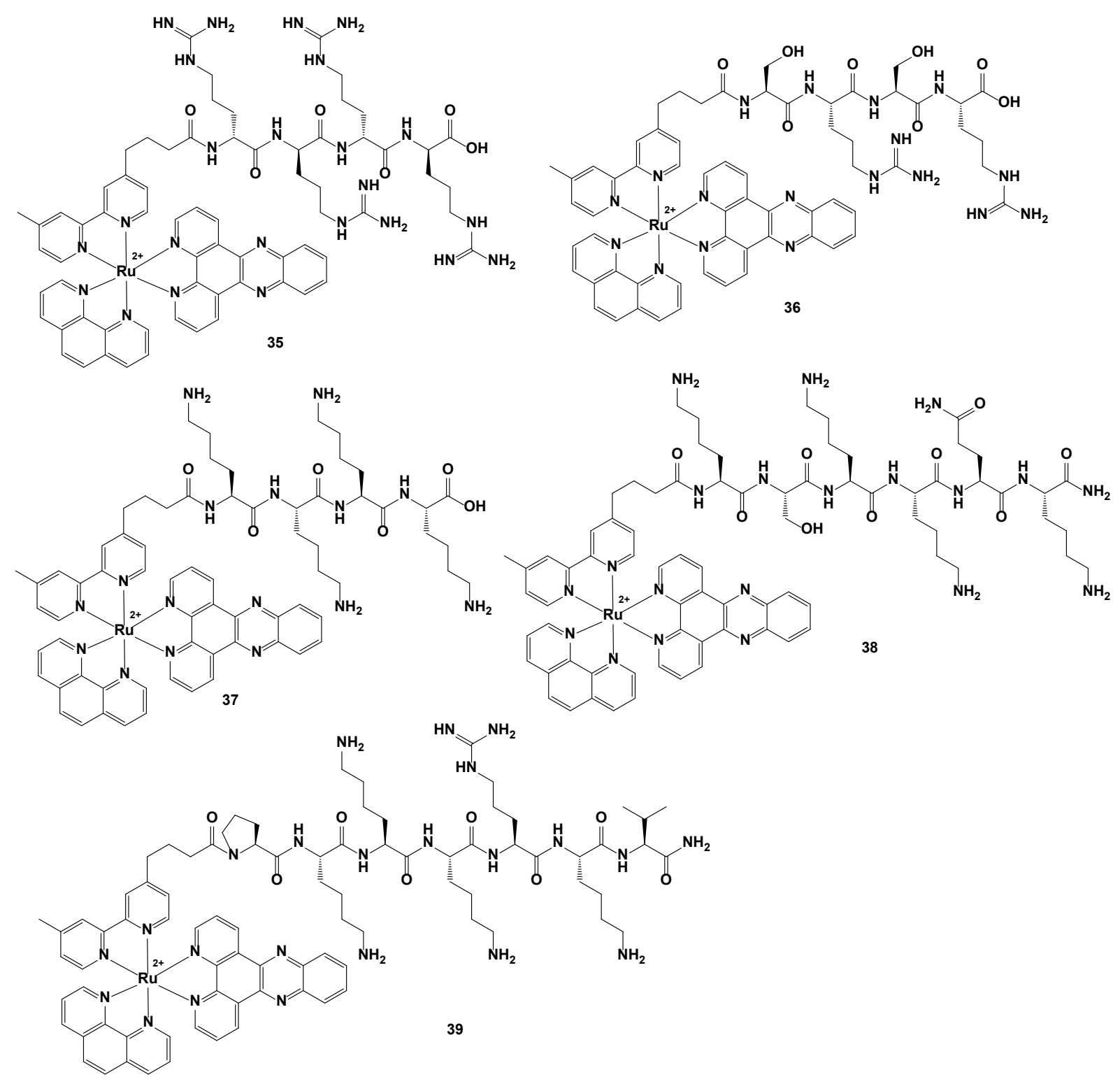

Fig. 17. Structures of the peptide conjugates 35-39.

So far, octaarginine conjugates enters the cell but their distribution is in the cytoplasm, without targeting specific organelles. Puckett and Barton found a way to direct these complexes to the nucleus by attaching a fluorescein moiety to the octaarginine.[67] Complexes 30 (Ru-Doctaarginine), 31 (Ru-D-octaarginine-fluorescein) and 32 (Ru-fluorescein) were synthesised (Fig. 16) and imaged in HeLa cells after 30 min incubation. Complex $30(5 \mu \mathrm{M})$ was found to be distributed, as expected, as intense blebs in the cytoplasm, with exclusion from the nucleus. An endocytosis mechanism of internalization was unveiled. Conjugate $\mathbf{3 1}$ entered the nucleus under the same incubation conditions. It displayed diffuse emission in both the cytoplasm and 
the nucleus and strong luminescence in the nucleoli and blebs in the cytoplasm. Compound 32, however, did not enter the cells after $30 \mathrm{~min}$, and was poorly internalized even after longer incubation times and a higher concentration $(20 \mu \mathrm{M}$ for $41 \mathrm{~h})$. At $10 \mu \mathrm{M}, 30$ showed exclusively blebs in the cytoplasm and, at $15-20 \mu \mathrm{M}$, there were mixed stains. For 31, nucleolar and blebs in the cytoplasm were of same intensity and weaker emission was found in the cytoplasm and nucleus. These findings suggest that above $5 \mu \mathrm{M}$, the mechanism is non-endocytotic, whereas at lower concentrations, it is endocytotic. The role of the fluorescein moiety is to increase the lipophilicity of the conjugates, enhancing their ability to cross the cell membrane.

When the peptide was shortened in derivatives 33 and $\mathbf{3 4}$ (Fig. 16), the uptake of the conjugates in HeLa cells after 2 or $24 \mathrm{~h}$ incubation was changed. $33(5-20 \mu \mathrm{M})$ showed non-nuclear staining and only emission in the cytoplasm.[68] At higher concentrations (30-40 $\mu \mathrm{M})$, the distribution was heterogeneous and, at $100 \mu \mathrm{M}, 74 \%$ of cells displayed nuclear localization. Unlike 30, conjugate $\mathbf{3 3}$ presented less effective cellular internalization due to the short oligoarginine chain (4 units instead of 8) and needed higher concentrations to accumulate in the nucleus. As for $\mathbf{3 4}$, no stain was found in the cells and, at $30 \mu \mathrm{M}$, only some emissive blebs were detected in the cytoplasm. The reason could be the length of the peptide and the carboxylic acid terminal group in the fluorescein conjugate, increasing the charge of the compound, whereas, in the non-fluorescein derivative, there is an amide terminal group. A tetraarginine derivative 35 (Fig. 17) was also prepared, with similar uptake as for 33. Since oligoarginines show better cellular uptake than oligolysines, and this might be consequence of the global charge, some complexes were prepared with other peptide sequences, varying the number of arginines. Conjugates 36, with two arginines (less total charge) and 37, bearing lysines (Fig. 17), showed luminescence from the cytoplasm at $40 \mu \mathrm{M}$ after $2 \mathrm{~h}$. At $100 \mu \mathrm{M}$ and $4 \mathrm{~h}$, the internalization improved, although still weakly, with higher number of cells with nuclear localization. Emission intensity in cells was higher for $\mathbf{3 7}$ than for $\mathbf{3 6}$, as a consequence again of the charge. Longer peptide chains (NLS) were attached, forming complexes $\mathbf{3 8}$ and $\mathbf{3 9}$, 
respectively (Fig. 17). The overall charge of these complexes was reduced, if compared with the octaarginine derivative. In both cases, the uptake at $10 \mu \mathrm{M}$ after $2 \mathrm{~h}$ was weak, showing exclusively faint blebs without nuclear localization. As a result, none of these strategies achieved an improvement of the uptake over the octaarginine derivatives.
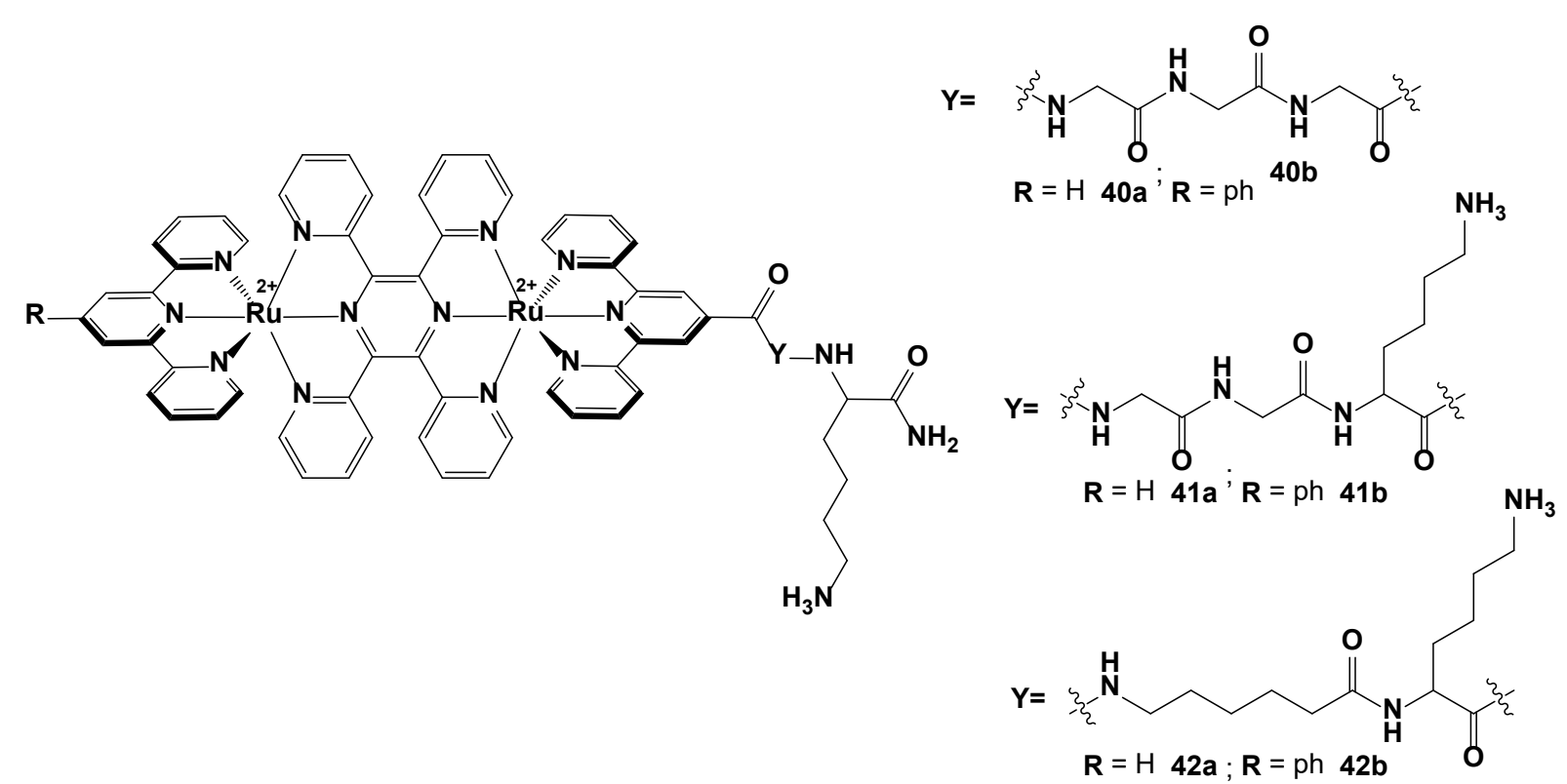

Fig. 18. Structures of the bimetallic conjugates $\mathbf{4 0 a - 4 2 b}$, where $R=H$ or ph (phenyl).

Examples of bimetallic complexes with terpyridine bearing different peptide chains (40a-42b) were reported by Ypsilantis et al. (Fig. 18).[69] They assayed the interactions of complexes 40a and 40b with an oligonucleotide d(5'-CGCGAATTCGCG-3') ${ }^{\prime}$. ${ }^{1}$ H-NMR studies (298 K, [complex]:nucleotide 1:1) revealed fast kinetics binding of 40b in the middle part of the sequence, suggesting an orientation of the ptrpy (4'-phenyl-2,2';6',2”-terpyridine) ligand towards the minor groove. However, 40a did not show any specific binding, as the peaks slightly shifted. Cytotoxicity of $\mathbf{4 0 a}$ and $\mathbf{4 0 b}$ was investigated in human lung carcinoma cell lines H1299 and H1437. None of the complexes were found to be cytotoxic in any of the cell lines after $24 \mathrm{~h}\left(\mathrm{IC}_{50}>750 \mu \mathrm{M}\right)$, despite the interaction with the oligonucleotide, suggesting a different target than DNA.

\subsubsection{Peptoids}


Peptoids were firstly explored in the early 90s. They consist on $\mathrm{N}$-alkylated glycine oligomers that can form and mimic secondary structures such as $\alpha$-helix or $\beta$-turns. Furthermore, they are better cellular transporters than the classic peptides due to their increased hydrophobicity and cell permeability. Therefore, they are promising drug candidates.[70] 


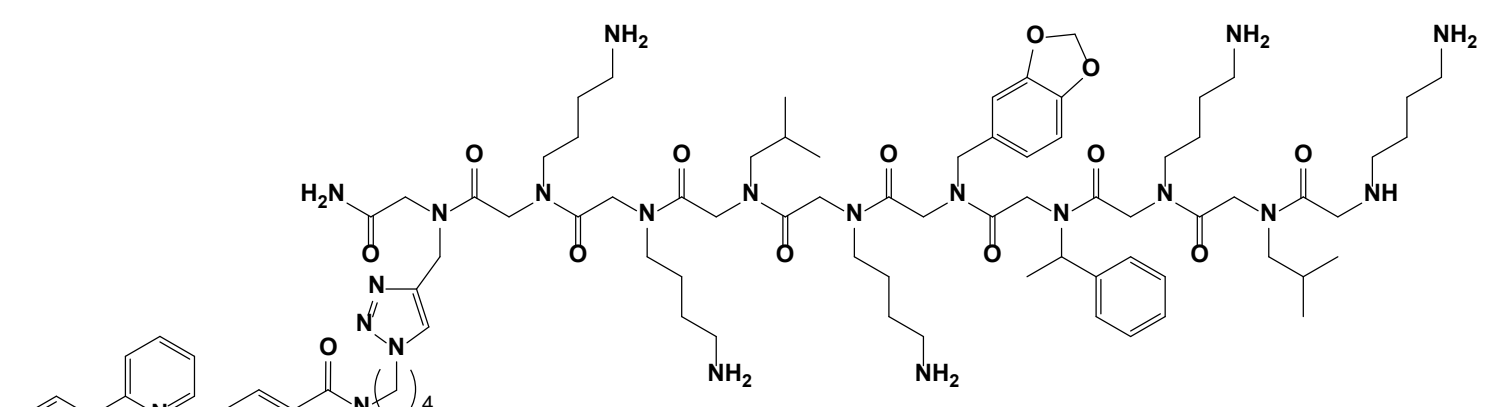

$$
43
$$

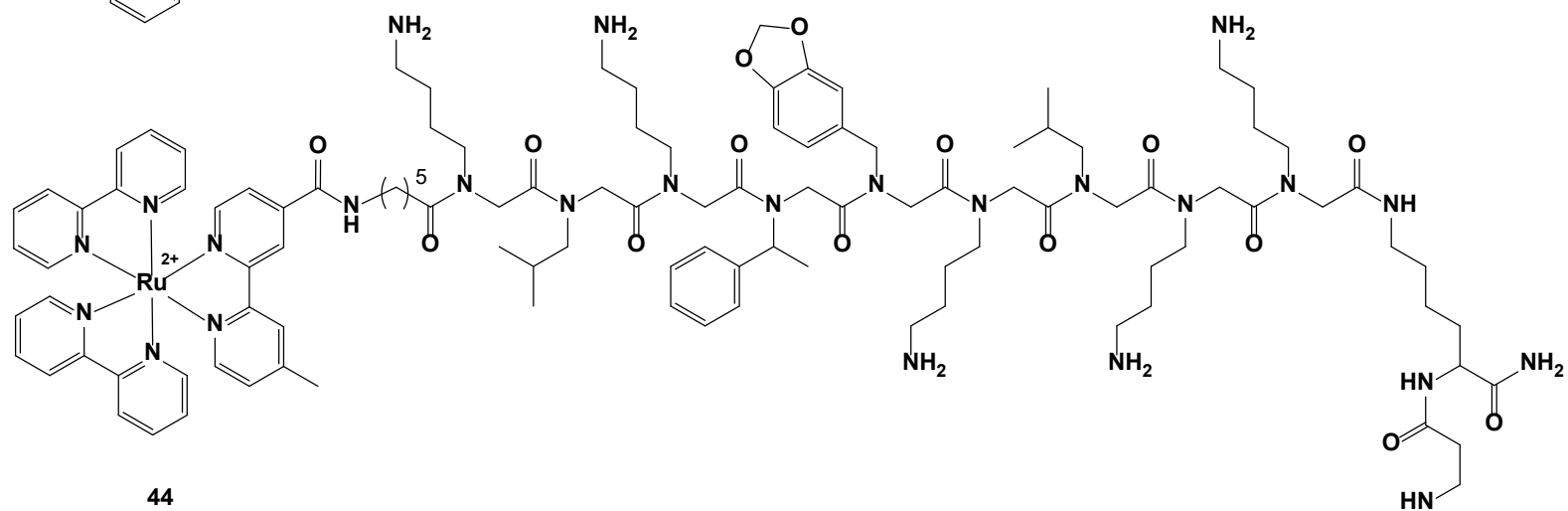

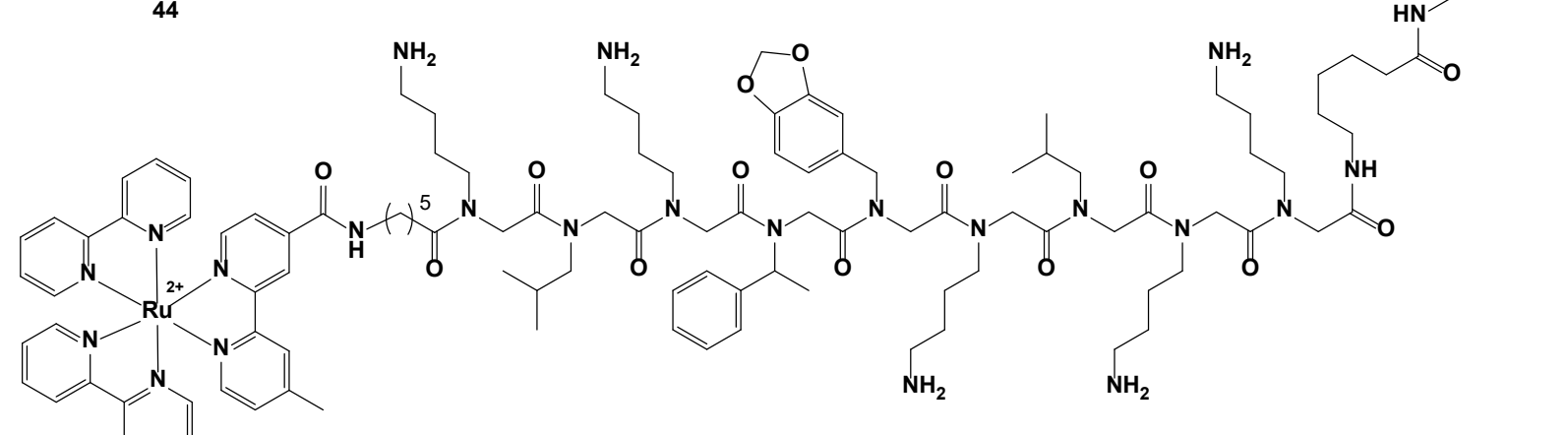

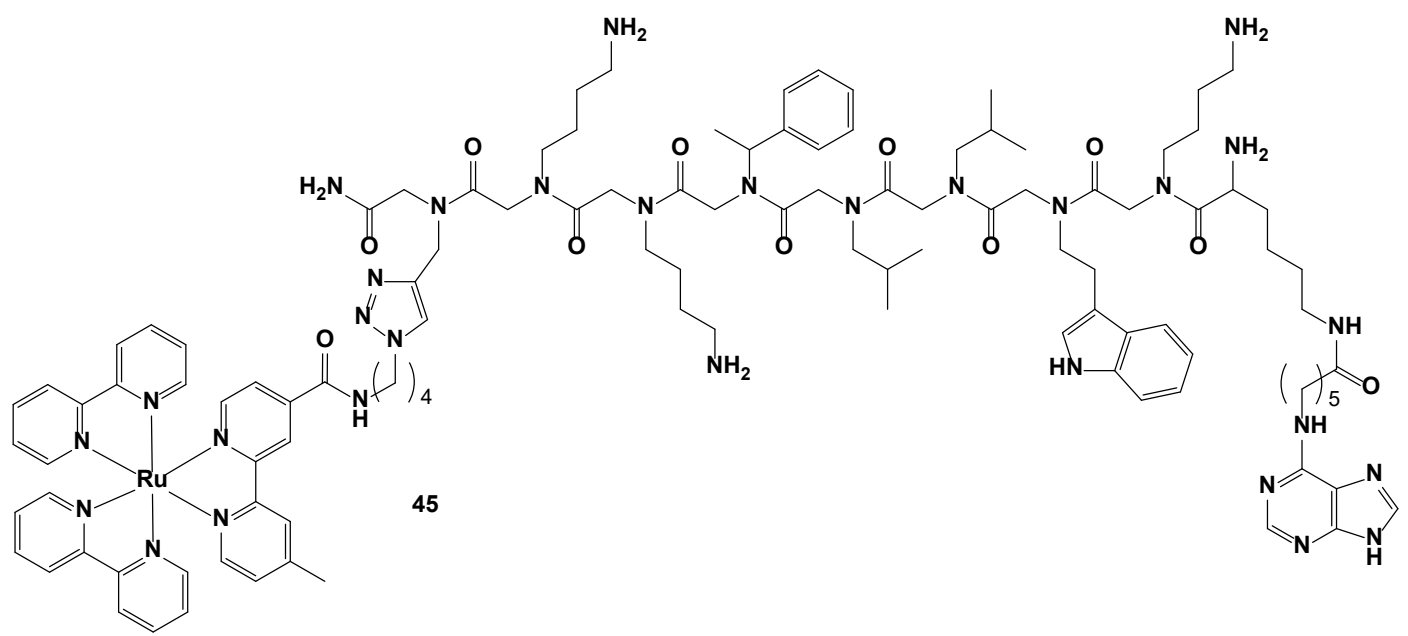

Fig. 19. Structures of the ruthenium-containing peptoid conjugates 43-45. 
Among the bipyridine-peptoid conjugates, Lee et al. prepared the mono- and bi-metallic complexes 43, 44 and 45 (Fig. 19) as CALI (chromophore-assisted light inactivation) reagents.[71] Peptoid GU40C, a highly selective antagonist of vascular endothelial growth factor (VEGF)-induced activation of the VEGF receptor 2 (VEGFR2) was used in these conjugates. Thus, the activity of $\mathbf{4 3}$ was investigated in endothelial cells exposed to VEGF and the activation of VEGFR2 was monitored. Without irradiation, the conjugate was not able to inhibit VEGFR2. Nevertheless, after irradiation ( $>380 \mathrm{~nm}, 10 \mathrm{~min})$, the inhibition was successful. The $\mathrm{IC}_{50}$ of $\mathbf{4 3}$ was $49 \mu \mathrm{M}$ in the dark and $59 \mathrm{nM}$ upon irradiation (> 800-fold increase). Complex $\mathbf{4 3}$ was also found to inhibit the formation of vessel-like tube structures in endothelial cells, also when irradiated $\left(\mathrm{IC}_{50}=50 \mathrm{nM}\right) .43$ was also incubated in $\mathrm{H} 441$ cells, which express epidermal growth factor receptor (EGFR) and VEGFR2. Cell viability remained unaffected and VEGFR2 was reduced whereas EGFR was not. This highlights the specificity towards VEGFR2. Regarding 44, the complex contains the peptoid GU40C4, where two GU40C units are joined by a linker. 44 was found to bind the VEGFR2 extracellular domain. Inhibition assays showed $50 \%$ inhibition in the dark at $500 \mathrm{nM}$, similar to that of GU40C4. Upon irradiation, however, this $\mathrm{IC}_{50}$ decreased to $590 \mathrm{pM}$, a 1,700-fold increase in potency due to the $\mathrm{Ru}(\mathrm{II})$-peptoid singlet oxygen generation. Compound $\mathbf{4 5}$ was prepared as the peptoid RIP1 (which targets an ATPase) conjugate. This derivative was irradiated in HeLa cells and inhibition of peptidolysis was observed. The potency increased after $10 \mathrm{~min}$ and $20 \mathrm{~min}$ irradiation, from $\mathrm{IC}_{50}=300 \mathrm{nM}$ to $85 \mathrm{nM}$, respectively, suggesting a dependence of singlet oxygen generation. A dose-dependent assay showed peptidolysis after 30 min irradiation, but no effect was detected in the dark. Comparing both $\mathbf{4 3}$ and $\mathbf{4 5}$, the binding of the latter was weaker, probably owing to the indole side chain and the adenine molecule.

\subsubsection{Proteins}

Many articles have reported the binding ability of $\mathrm{Ru}(\mathrm{II})$ polypyridyl complexes with proteins (e.g., determination of their binding or dissociation constants). Some of these compounds have 
been used as probes to determine the hydrodynamics of proteins.[72,73] However, not many articles have reported on the synthesis and isolation of the conjugates. In the 90s, Winkler and Gray studied and gathered the ET mechanisms in aminoruthenium complexes covalently attached to the histidine moieties of some proteins.[74]

\subsubsection{Protein conjugates}

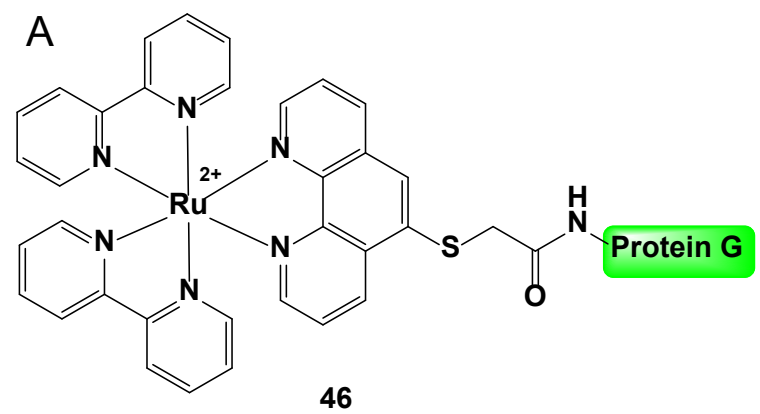

C Immobilization of recombinant protein

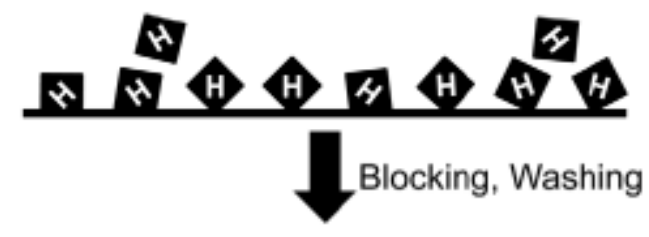

Incubation with Anti-6X His tag IgG
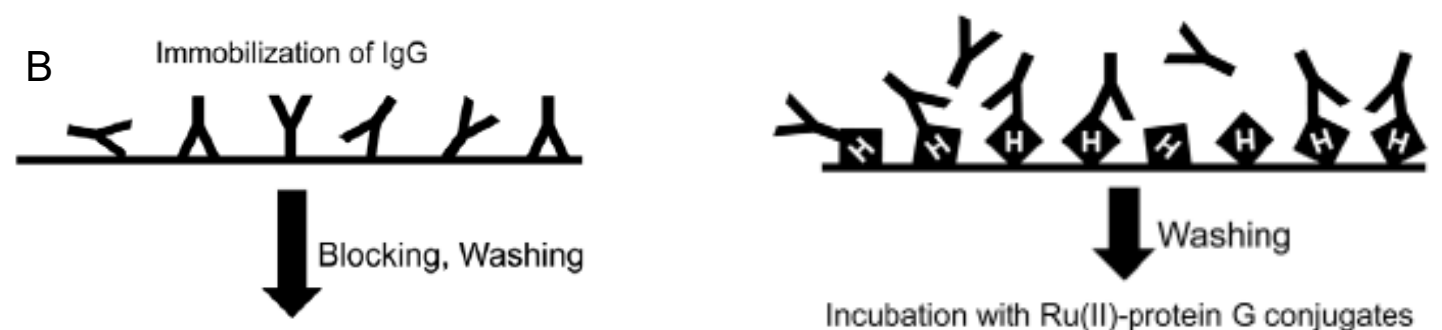

Incubation with Ru(II)-protein $\mathrm{G}$ conjugates

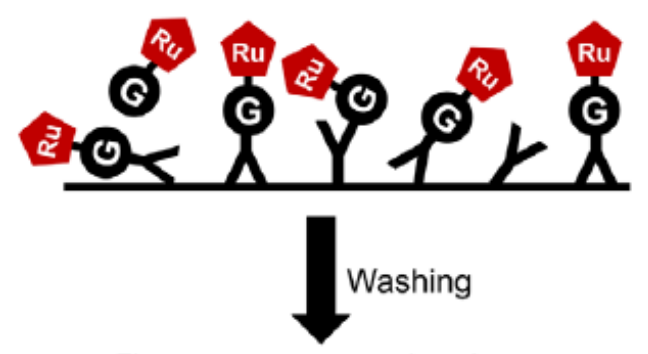

Fluorescence scan and analyze
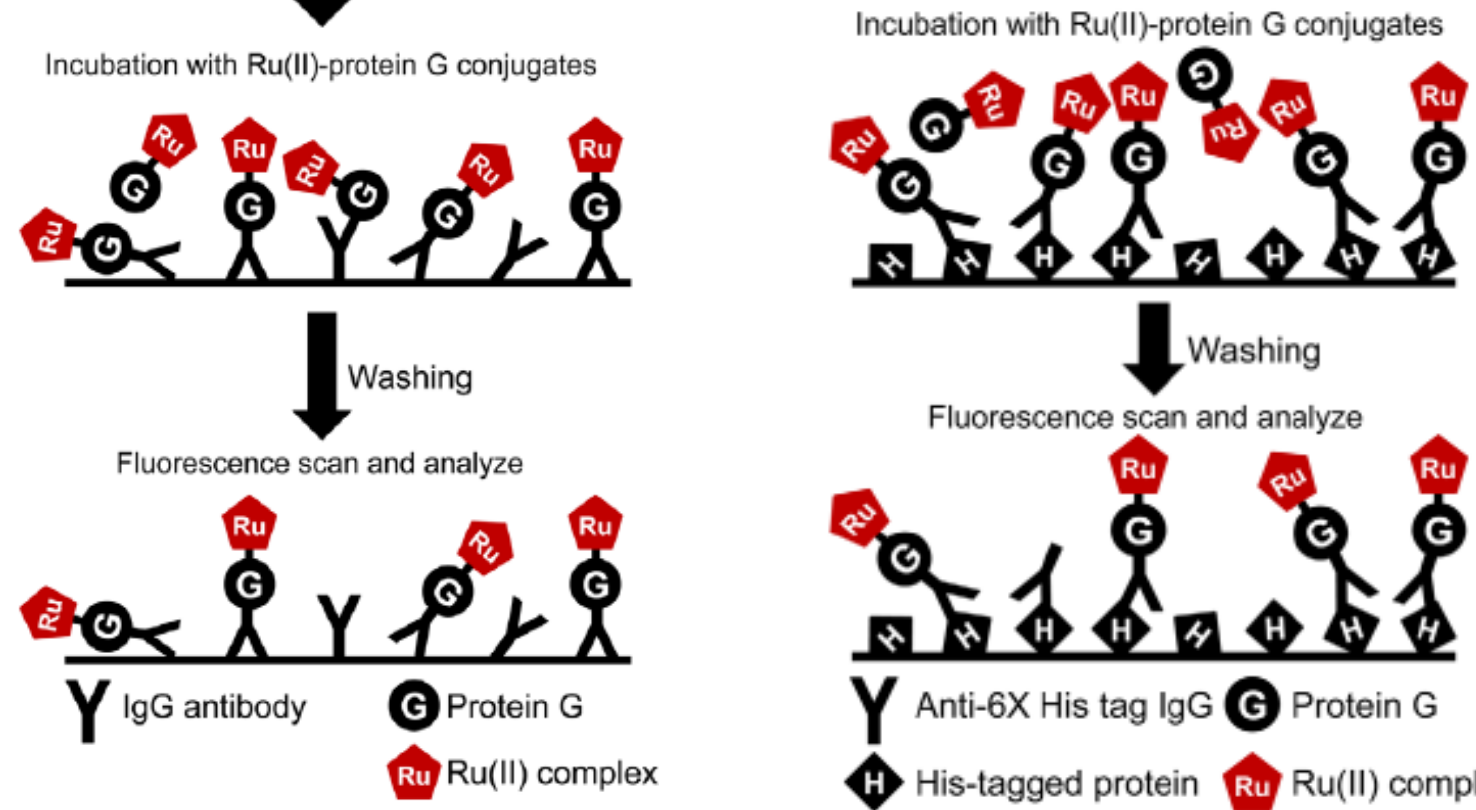

Fluorescence scan and analyze

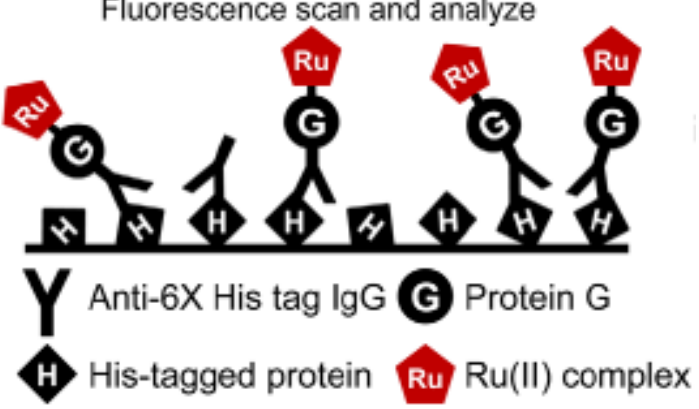

Fig. 20. A) Structure of complex 46. B) Schematic of IgG-binding assays of $R u(I I)-$ protein $G$ conjugates. Normal sheep IgG was immobilized on the 96 well plate, and then Ru(II)-protein G conjugates bound to the Fc region of IgG. C. Schematic of Ru(II)-protein G conjugates for detecting histidine-tagged protein. The purified histidinetagged protein BasR was first immobilized on the 96 well plate and then recognized by anti- His antibody. Finally, the $\mathrm{Ru}(\mathrm{II})$-protein $\mathrm{G}$ conjugates bound to the Fc region of anti-His antibody. Reproduced from reference [75], $\mathrm{C}$ 2012 Lin et al. 
Chen et al. described the synthesis and conjugation of a $\mathrm{Ru}(\mathrm{II})$ complex to protein $\mathrm{G}$ as a probe for fluorescence immunoassays.[75] Protein $\mathrm{G}$ is an immunoglobulin-binding protein expressed in Streptococcus bacterial cell walls, which has affinity with lots of $\operatorname{IgG}$ (immunoglobulin G) antibodies in mammalian cells. Complex 46 (Fig. 20A) was prepared from $\left[\mathrm{Ru}(\mathrm{bpy})_{2}\right.$ (phen$\mathrm{Br})]^{2+}$, using SATA ( $N$-succinimidyl S-acetylthioacetate) as a cross-linker. The absorption and emission properties of the resulting complex did not change with regard to the parent compound without the protein. The IgG binding assay was performed to evaluate the binding ability of 46 to IgG. Firstly, IgG was immobilized on a plate. The Ru-protein G conjugate was then added for the detection of the IgG Fc fragment (Fig. 20B). The emission intensity increased with regard to the negative control ([Ru(bpy $)_{2}($ phen-Br $\left.\left.)\right]^{2+}\right)$, demonstrating the binding ability of $\mathbf{4 6}$. As for the fluorescence immunoassay, the histidine-tagged recombinant protein (the most common recombinant protein) was immobilized. Afterwards, the antibody (anti-6X His tag) was added to bind the histidine-tagged protein. Finally, the Ru-containing conjugate was added to bind to the antibody as a universal signal reporter (Fig. 20C). Again, the luminescence intensity showed an 8-fold increment when compared with the negative control, showing its successful ability to be used as a probe for immunoassays.

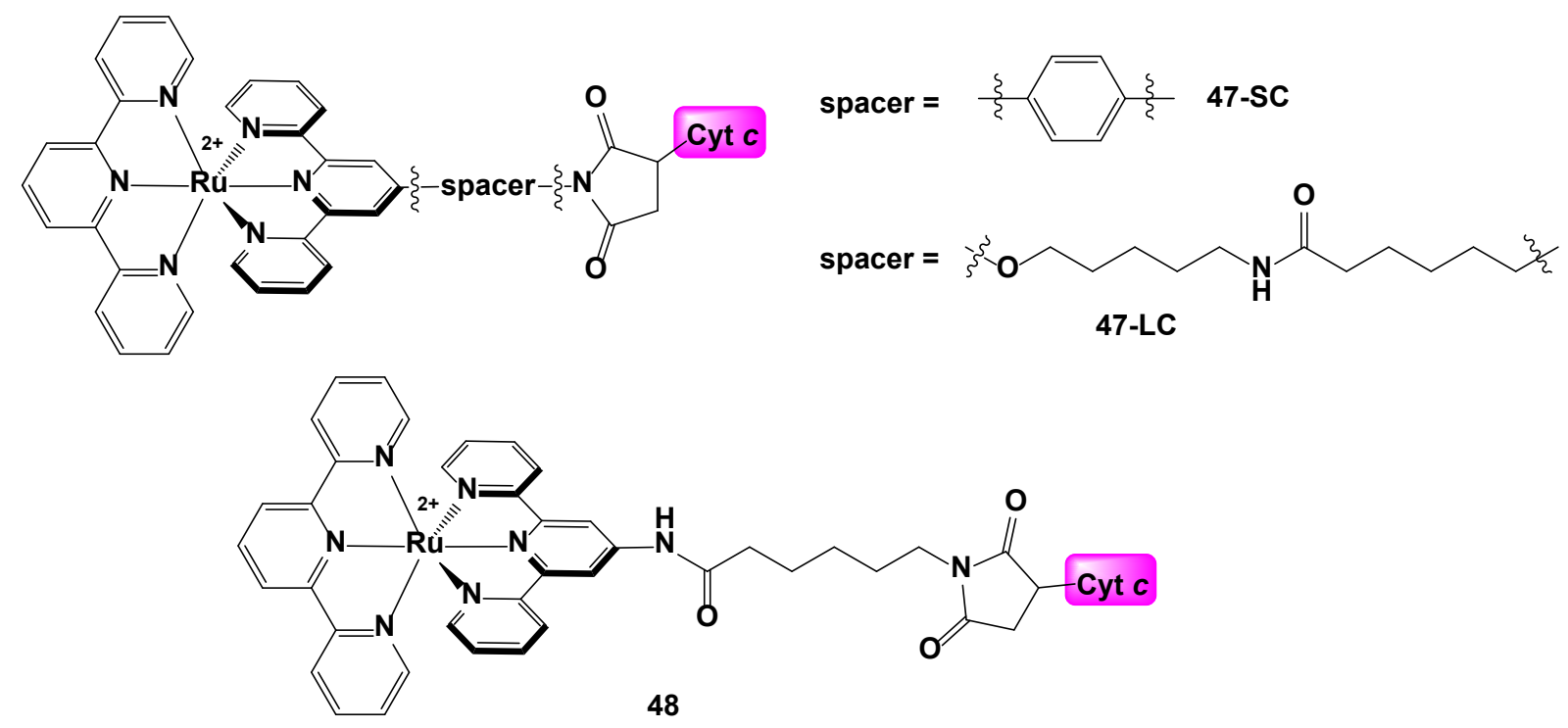

Fig. 21. Structures of the protein conjugates $47-\mathrm{SC}, 47-\mathrm{LC}$ and 48 . ( $\mathrm{SC}=$ short chain, $\mathrm{LC}=$ long chain). 
Thordarson and co-workers studied the photoreduction of a series of $\mathrm{Ru}(\mathrm{II})$ terpyridine cytochrome $c$ (cyt $c$ ) bioconjugates. The complexes were conjugated to cyt $c$ through a Michael addition involving a maleimide with two different spacers: one with a long, flexible alkyl chain to yield 47-LC and another one with a short, rigid aromatic chain to give 47-SC (Fig. 21).[76] The maleimide function was selected to selectively attach the single free cysteine (Cys102) of the protein. These spacers did not lead to significant modifications of the photophysical characterization of the complexes. In order to evaluate the catalytic and biological activity of the conjugates, the oxidation of 2,2'-azino-bis[ethyl-benzothiazoline-(6)-sulfonic acid (ABTS) and cytochrome $c$ oxidase (CCOx) was assessed for 47-LC and 47-SC, respectively. This assay demonstrated that none of the bioconjugates modified the structure or activity of the protein. The energy/electron transfer rates, measured by time-resolved emission experiments, were 2.78 $\times 10^{5} \mathrm{~s}^{-1}$ and $5.95 \times 10^{5} \mathrm{~s}^{-1}$ for 47-LC and 47-SC, respectively. UV-vis and TA (transient absorption) measurements allowed to determine the mechanism as an electron transfer pathway. When comparing the UV-vis spectra of both derivatives, before and after irradiation $(480 \mathrm{~nm})$, the changes in the spectra showed the reduction of the haem group from $\mathrm{Fe}^{3+}$ to $\mathrm{Fe}^{2+}$ (initially, cyt $c$ is oxidized). These changes also suggested photoinduced electron transfer from the ruthenium moiety as the donor, to $c y t c$ as the acceptor. In addition, TA emission intensity of 47-SC in the reduced form $\left(\mathrm{Fe}^{2+}\right)$ was higher than that of the initially oxidized form $\left(\mathrm{Fe}^{3+}\right)$. Although the photoreduction mechanism is unknown, the authors pointed out glycerol as the ultimate electron source.

The same authors prepared a similar conjugate 48 (Fig. 21) to understand the photoinduced electron transfer (eT) mechanism.[77] In this case, yeast iso-1 cytochrome $c$, an electron carrier protein that is light-activatable at room temperature, was used. These studies were performed in mixtures of the parent complex (i.e., the Ru(II) complex with the maleimide moiety, but no protein) and iso-1 cyt $c$ in PBS solutions or encapsulated in a $\mathrm{PS}_{140}-b$-PAA48 (polystyrene140b-poly(acrylic acid)48) membrane. Low concentrations were used to prevent intramolecular 
electron transfer. In the encapsulated complex, the haem reduction was completed in $50 \mathrm{~min}$. The quantum efficiency (electrons/absorbed photons) in the encapsulated solution was found to be twice that of $\mathbf{4 8}\left(1.1 \times 10^{-3} \%\right)$. Thus, the encapsulation increased the eT rate. The effect of the covalent binding ability was determined in the same conditions. When comparing the reduction curve of the bioconjugate with that of the parent compound and cyt $c$, a dramatic decreased was observed for the latter. This highlights that the link to the protein is crucial to ensure the activation. As in the previous complexes 47, the ruthenium moiety behaves as the donor and $c y t c$ as the acceptor. Nevertheless, it was noticed that encapsulation increased the photoreduction process. Moreover, the addition of EDTA as a sacrificial electron donor was essential to provide the complex with extra electrons for the eT mechanism, since the photoreduction of $\mathbf{4 8}$ in PBS was negligible.<smiles></smiles>

49

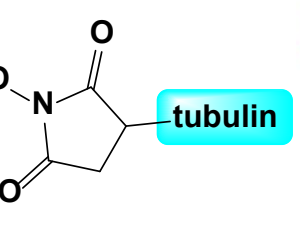

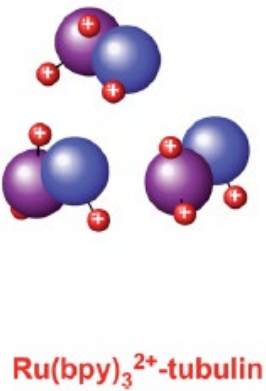

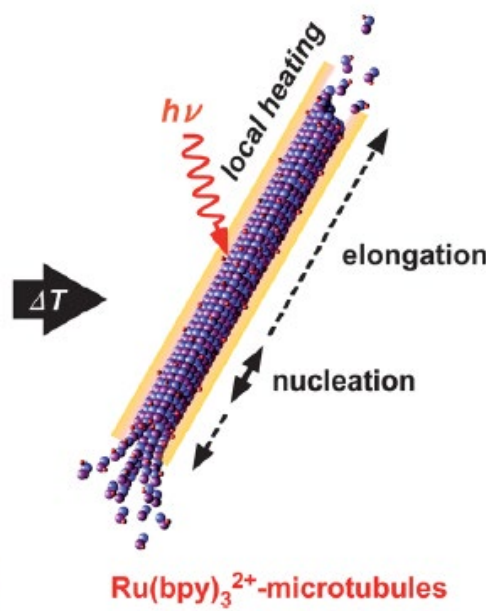

Fig. 22. Structure of Ru-tubulin conjugate 49 and schematic illustration of the formation of photo-enhanced MTs assembled from Ru-conjugated tubulin. Reproduced from Ref. [78] with permission from The Royal Society of Chemistry.

Larger proteins have been also used. $\alpha / \beta$-tubulin is the responsible of microtubules (MTs) formation, a kind of cytoskeletal filaments in cells. Osada et al. prepared a Ru-tubulin conjugate 49 to self-assemble into MTs (Fig. 22). [78] To check the capability of self-assembly of the conjugate, a solution of 49 along with free tubulin was heated from 3 to $25{ }^{\circ} \mathrm{C}$ and the changes were tracked by UV-vis spectroscopy. Free tubulin did not show any change, implying that any 
MT was formed. However, the absorption increased when 49 was added. The self-assembly finished in just $10 \mathrm{~min}$, when the Ru-tubulin/tubulin ratio was over 0.5 . When the temperature was decreased from 25 to $3{ }^{\circ} \mathrm{C}$, a depolymerization reaction was observed, indicating a reversible process. The self-assembly only occurred when a minimum ratio of 0.2 was achieved. The kinetics was analysed at 0.22 ratio and temperatures from 15 to $37^{\circ} \mathrm{C}$. The rate of assembly increased with the rise of the temperature, whereas the increment was low for the free tubulin. The rate increased by 30 times at $37{ }^{\circ} \mathrm{C}$ and the activation energy of MTs formation was 15 times higher than for the non-conjugated tubulin. Photoirradiation of 49 also increased the formation of MTs at 25 and $30{ }^{\circ} \mathrm{C}$. Thus, this conjugate can behave as a photothermal energy sensitizer. This effect was also observed by cross-polarized light at $29^{\circ} \mathrm{C}$. The assembly of 49 was enhanced by photo-irradiation, and the process was observed to start from the wall to the central axis of the tubule. Furthermore, this conjugate was capable of inducing parallel orientation of the MTs. The length of MT was found to be $20-50 \mu \mathrm{m}$, as measured by fluorescence microscopy. Thus, the conjugate 49 was able to enhance the self-assembly by using both thermal energy and photoenergy, despite the positive charges and the steric hindrance of the metal complex. This curious thermal behaviour is the consequence of the release of non-radiative energy (i.e. heat) from the excited state of the $\mathrm{Ru}(\mathrm{II})$.

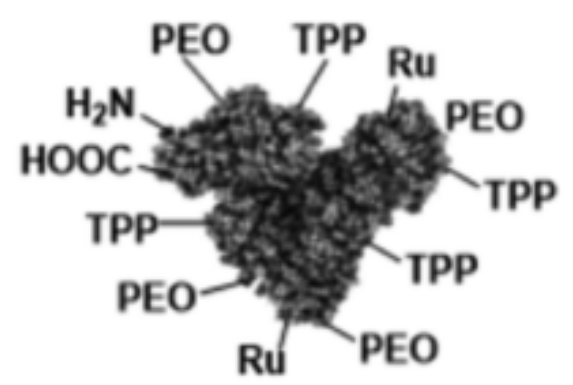




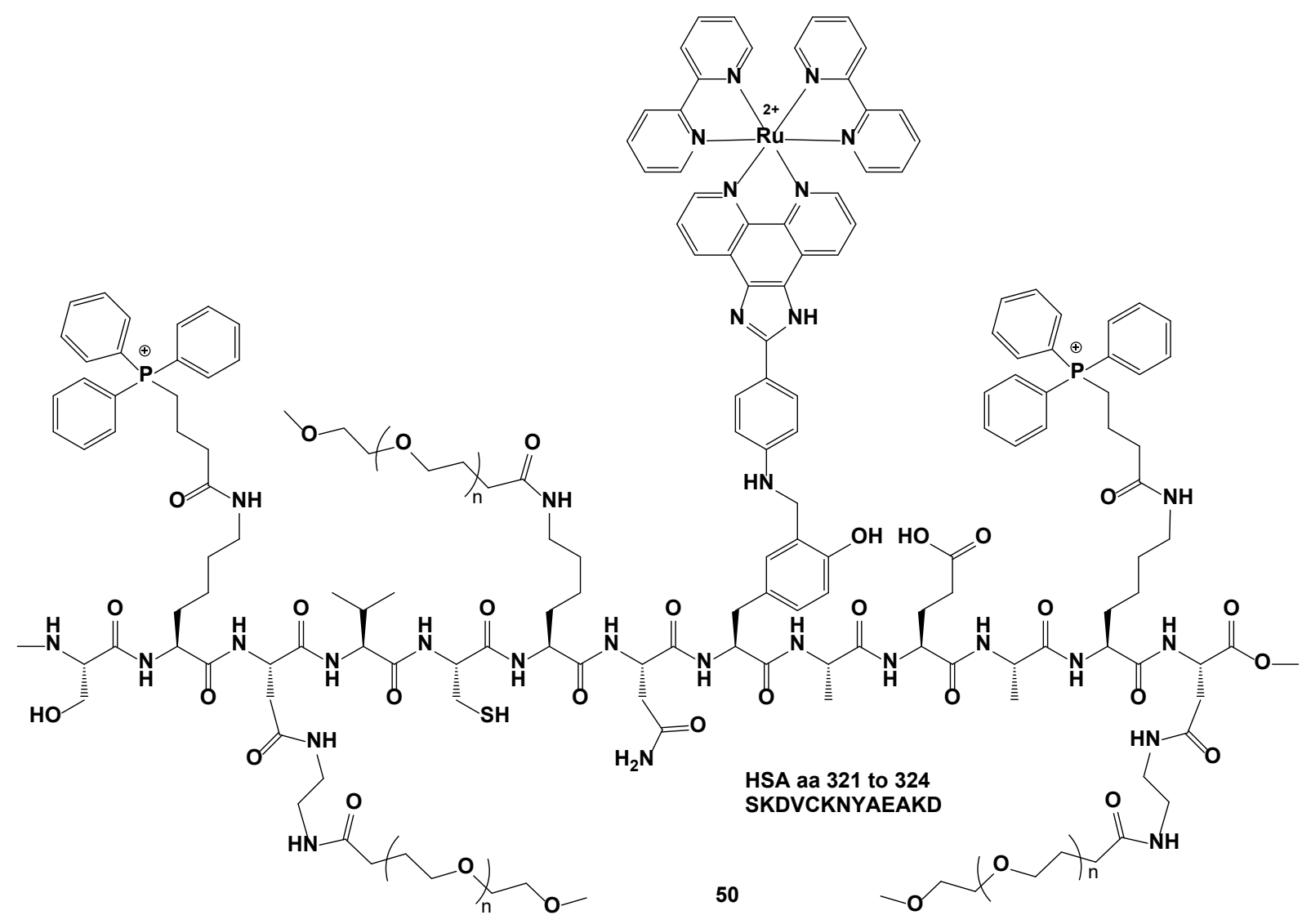

Fig. 23. Scheme of the transporter 50 based on HSA and schematic illustration of a part of the HSA polypeptide sequence exemplary with the PEO, TPP groups attached to, e.g., lysine and Ru conjugated to tyrosine residues. Adapted from reference [79]. Copyright (C) 2017 American Chemical Society.

Weil et al. used HSA as a backbone to attach different Ru polypyridyl complexes with the aim to specifically target organelles in view of PDT applications.[79] HSA was modified with 20 PEO (poly(ethylene oxide)) units to make it water soluble, 34 TPP (triphenylphosphonium) units to target mitochondria and $10 \mathrm{Ru}$ (II) polypyridyl complexes to act as PDT PSs (Fig. 23). The resulting conjugate $\mathbf{5 0}$ was found to be stable and water-soluble. In addition, the photostability of the conjugate was higher than the one of the free $\mathrm{Ru}(\mathrm{II})$ complex, even after long irradiation times $(65 \mathrm{~h})$. The indirect method $(9,10$-anthracenediyl-bi(methylene)dimalonic acid (ABDA)) for singlet oxygen production $\left(470 \mathrm{~nm}, 20 \mathrm{~mW} / \mathrm{cm}^{2}, 5 \mathrm{~min}\right)$ revealed efficient generation of ${ }^{1} \mathrm{O}_{2}$ for 50, whereas the modified HSA without a $\mathrm{Ru}(\mathrm{II})$ complex remained inactive. The emission quantum yield and the lifetime slightly improved when the solution was changed from water $(\Phi=6.1 \%, \tau=625 \mathrm{~ns})$ to a simulated body fluid $(\Phi=6.7 \%$, 
$\tau=735 \mathrm{~ns})$. The cellular uptake of $\mathbf{5 0}$ was imaged in HeLa cells $(500 \mathrm{nM}, 4 \mathrm{~h})$ and colocalization with different stains (i.e., membrane, nucleus, mitochondria and lysosomes) revealed internalization mostly in the mitochondria. The cytotoxicity in HeLa cells after 240 min incubation in the dark $\left(\mathrm{IC}_{50}=9 \mu \mathrm{M}\right)$ and upon light irradiation $\left(470 \mathrm{~nm}, 20 \mathrm{~mW} / \mathrm{cm}^{2}\right)(34.9$ nM) was measured. An impressive PI of 250 was determined. The phototoxicity was also assessed in other cell lines: CHO (Chinese Hamster Ovary cells), MCF-7 (human breast adenocarcinoma) and A549 (human lung carcinoma cells). All of them showed low IC50 values after light irradiation; $\mathrm{IC}_{50}=135.2 \mathrm{nM}$ for $\mathrm{CHO}, \mathrm{IC}_{50}=114.3 \mathrm{nM}$ for MCF-7 and $\mathrm{IC}_{50}=119.1$ nM for A549. Clonogenics in acute myeloid leukaemia (AML) OCI-AML3 cells treated with 50 after 2 and 5 min irradiation showed reduction of colony growth (44\% and $84.4 \%$, respectively) with regard to the non-irradiated cells. Also, remaining colonies were smaller in size. This assay was also performed in healthy BM cells (primary bone marrow) and murine AML cells (AE9a, leukaemia cells). After 2 and 5 min irradiation, the decrease was $37 \%$ and $88 \%$, respectively, in AE9a cells, whereas the reduction was $10 \%$ and $28 \%$ in healthy BM cells, revealing specificity towards leukaemia cells. Two-photon absorption (TPA) experiments showed the great ability of the conjugate to act as a TP probe, with a TP cross-section 5-times higher than the one of the free $\mathrm{Ru}(\mathrm{II})$ complex.

\subsubsection{Artificial Metalloproteins}

Some proteins include a cofactor, which can be a metal ion, a cluster or a small organic molecule. When the proteins are bound to a metal ion, they are called metalloproteins. A great example of naturally occurring metalloproteins is myoglobin (Mb).[80] The similarities between iron and ruthenium instigated the researchers to replace them in the haem group. In 1979, Paulson et al. successfully achieved the preparation of RuMb. The studies revealed the coordination of carbon monoxide, as in $\mathrm{Mb}$. Nonetheless, unlike the original $\mathrm{Mb}$, dioxygen irreversibly oxidized $\mathrm{RuMb}$ to $\mathrm{RuMb}^{+} .[81]$ 


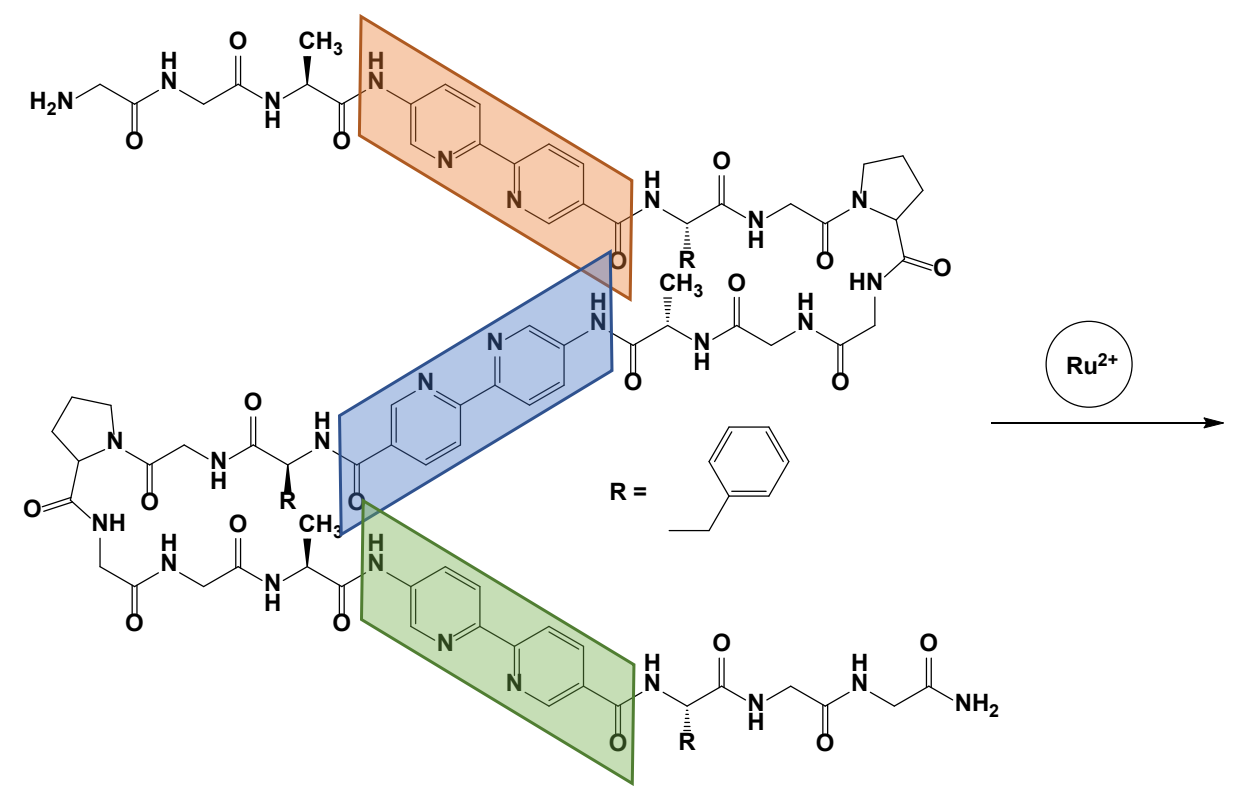

H-GGA-5Bpy-FGPGGA-5Bpy-FGPGGA-5Bpy-FGG-NH 2

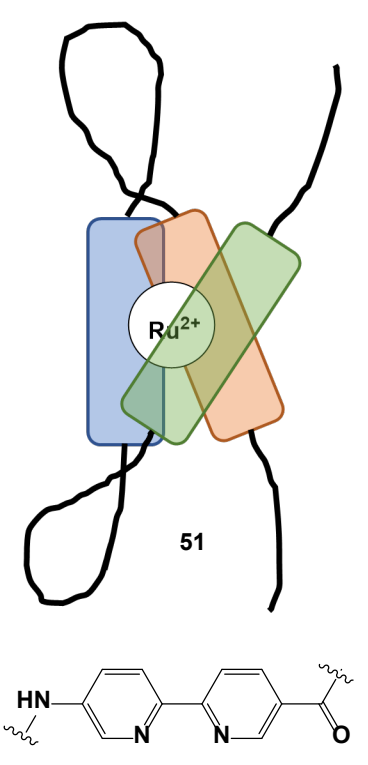

5Bpy

Fig. 24. Molecular design of the artificial metalloprotein with a ruthenium(II) tris(bipyridyl) complex as the core. Adapted from reference [82]. Copyright (C) 2006 WILEY-VCH Verlag GmbH \& Co. KGaA, Weinheim.

In 2006, Ishida et al. reported the synthesis and complete characterization of the first artificial metalloprotein bearing a $\mathrm{Ru}(\mathrm{II})$ ion as the metallic core.[82] This artificial metalloprotein, $\mathbf{5 1}$ (Fig. 22), was designed with the insertion of unnatural amino acid 5'-amino-2,2'-bypyridine-5carboxylic acid (5Bpy) fragments in the peptide chain, so that the 5Bpy units can fold to accommodate $\mathrm{a} \mathrm{Ru}^{2+}$ atom and lead to the formation of a $\mathrm{Ru}(\mathrm{bpy}) 3^{2+}$-type complex, as shown in Fig. 22. Thus, two -L-Pro-Gly- were introduced between two 5Bpys. L-Ala and L-Phe were placed at the $\mathrm{N}$ and $\mathrm{C}$ terminal of 5Bpy and the sequence was completed with glycines. The authors precisely characterized the metalloprotein and found similar spectroscopic properties as for $\mathrm{Ru}(\mathrm{bpy}) 3^{2+}$-type complexes. Furthermore, circular dichroism (CD) allowed them to determine the optical isomers for the different fractions obtained in the synthesis. 


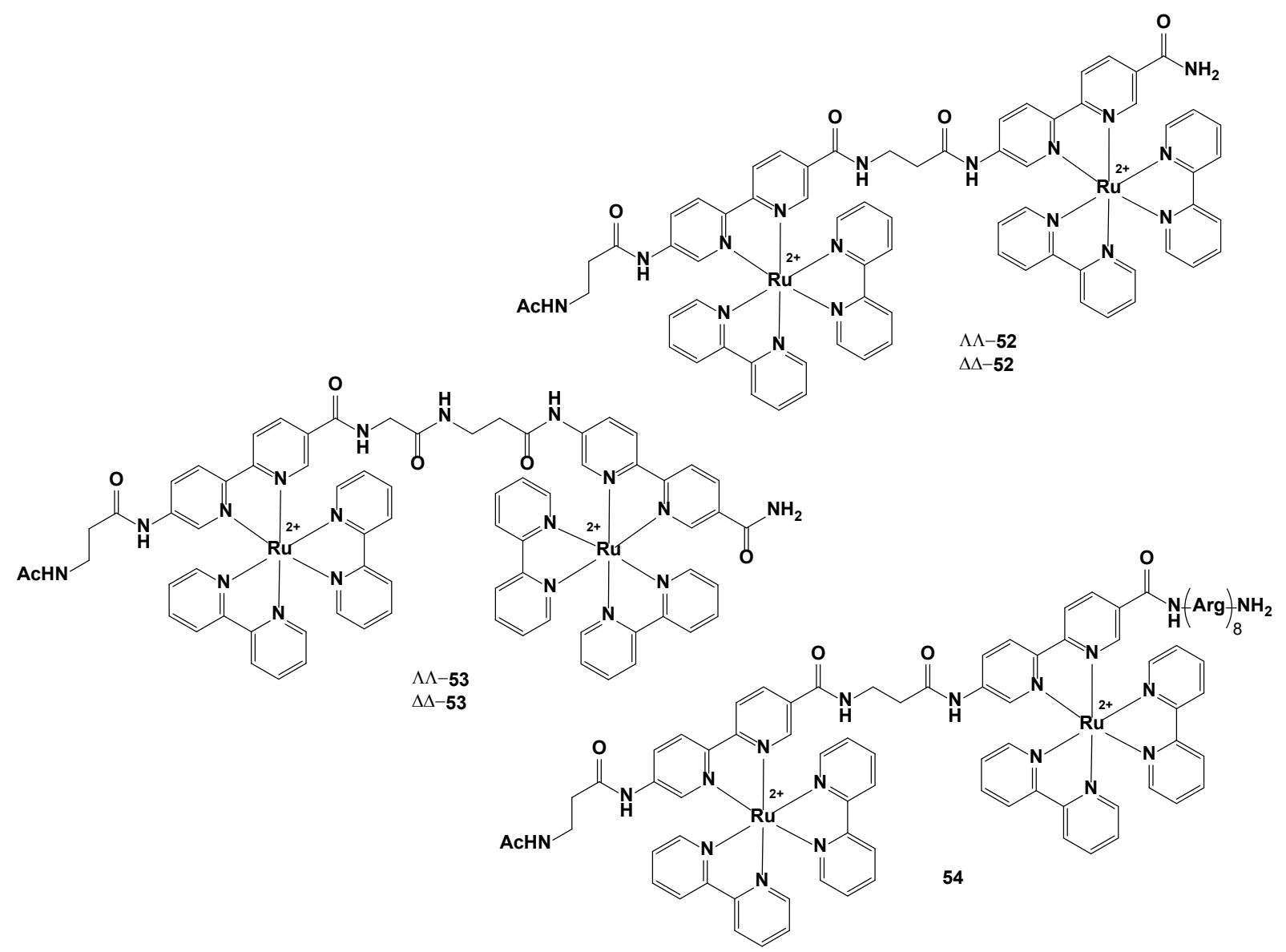

Fig. 25. Structures of the dimeric metallopeptides $\mathbf{\Lambda} \mathbf{\Lambda - 5 2}$ and $\mathbf{\Delta} \Delta-\mathbf{5 2}, \mathbf{\Lambda} \mathbf{\Lambda}-\mathbf{5 3}$ and $\Delta \mathbf{\Delta - 5 3}$ and 54 .

Two metallopeptides, also incorporating bpy in their peptide sequence, were later reported by Gamba et al.[83] These dinuclear complexes were prepared as optically-pure isomers and bear similar peptide sequences: Ac- $\beta$ Ala-bpy- $\beta$ Ala-bpy- $\mathrm{NH}_{2}$ for $\mathbf{\Lambda} \mathbf{\Lambda - 5 2}$ and $\mathbf{\Delta} \mathbf{\Delta - 5 2}$, and Ac- $\beta$ Alabpy-Gly- $\beta$ Ala-bpy- $\mathrm{NH}_{2}$ for $\mathbf{\Lambda} \mathbf{\Lambda - 5 3}$ and $\boldsymbol{\Delta} \boldsymbol{\Delta}-\mathbf{5 3}$ (Fig. 25). DNA binding was evaluated using ethidium bromide displacement studies. Emission-quenching experiments revealed interaction of the four complexes with DNA. However, higher affinity (i.e., low dissociation constants) was observed for $\mathbf{\Lambda} \mathbf{\Lambda} \mathbf{- 5 2}$ and $\mathbf{\Lambda} \mathbf{\Lambda} \mathbf{- 5 3}$ than for the $\boldsymbol{\Delta \Delta}$-enantiomers. Moreover, the affinity was higher for A/T-rich oligonucleotides than for $\mathrm{G} / \mathrm{C}$-rich sequences. Curiously, the trends of dissociation constants were different for the $\mathbf{5 2}$ and $\mathbf{5 3}$ series. A negative effect was detected for $\mathbf{\Lambda} \mathbf{\Lambda - 5 3}$ compared with $\mathbf{\Lambda} \mathbf{\Lambda} \mathbf{- 5 2}\left(\mathrm{K}_{\mathrm{d}}[\mathrm{AAATTT}] \approx 8.2\right.$ and $5.8 \mu \mathrm{M}$, respectively), whereas the opposite effect was observed for $\boldsymbol{\Delta \Delta} \mathbf{- 5 3}$ and $\boldsymbol{\Delta} \boldsymbol{\Delta - 5 2}\left(\mathrm{K}_{\mathrm{d}}[\mathrm{AAATTT}] \approx 31\right.$ and $14 \mu \mathrm{M}$, respectively). CD and STD (saturation transfer difference) NMR experiments confirmed the 
previous results. Since these conjugates were not internalized in cells, a derivative with octaarginine $\mathbf{5 4}$ was synthesised as the diasteromeric mixture since the synthesis of the optically pure complexes was unsuccessful. Compound $\mathbf{5 4}$ displayed the same features than the other complexes and the preference for A/T-rich oligonucleotides was slightly increased. AFM studies of $\mathbf{\Delta} \mathbf{\Delta - 5 2}$ and $\mathbf{5 4}$ with DNA showed alteration of the DNA plasmid, with higher affinity for 54. Cellular uptake studies with $\mathbf{5 4}(25 \mu \mathrm{M}$ for $30 \mathrm{~min})$ in Vero cells (kidney epithelial cells) confirmed internalization and showed blebs in the cytoplasm and diffuse emission from the nuclei. The cytotoxic activity was evaluated in different cells lines for $\boldsymbol{\Delta} \boldsymbol{\Delta} \mathbf{- 5 2}$ and $\mathbf{5 4}$. In A2780cis (ovarian carcinoma cells), $\mathbf{5 4}$ was more toxic than $\mathbf{\Delta} \mathbf{\Delta - 5 2}\left(\mathrm{IC}_{50} \approx 7 \mu \mathrm{M} v s 286 \mu \mathrm{M}\right)$. Similar results were obtained in MCF-7 (breast cancer cells) and NCI-H460 (lung carcinoma), in which only the octaarginine derivative showed cytotoxicity.

\subsection{Antibodies}

The main strategies to conjugate organic compounds with antibodies or other heavy proteins imply maleimide and NHS ( $N$-hydoxysuccinimide) moieties. Maleimides can easily react with thiol groups from cysteines. This is of interest since the number of sulfhydryl groups in a protein is reduced, in comparison with the number of amino groups. For instance, immunoglobulin G1 (IgG1) has 8 thiol groups from cysteines versus 30 available amino groups from lysines.[84] Interestingly, cysteine residues are usually found in the specific binding sites of the protein, making this conjugation more selective.[85] NHS moieties, however, react with lysines. Zhou et al. described a detailed protocol to prepare $\mathrm{Ru}-\mathrm{Ab}$ bioconjugates through NHS linkage.[86] The conjugation of $\mathrm{Ab}$ with metal complexes could improve their applications as chemotherapeutic agents,[87] theranostics,[88] or probes.[89] Thus, the search for novel metalbased antibody-drug conjugates (ADC) has increased in the last years.

\subsubsection{Maleimide: cysteine linkage}




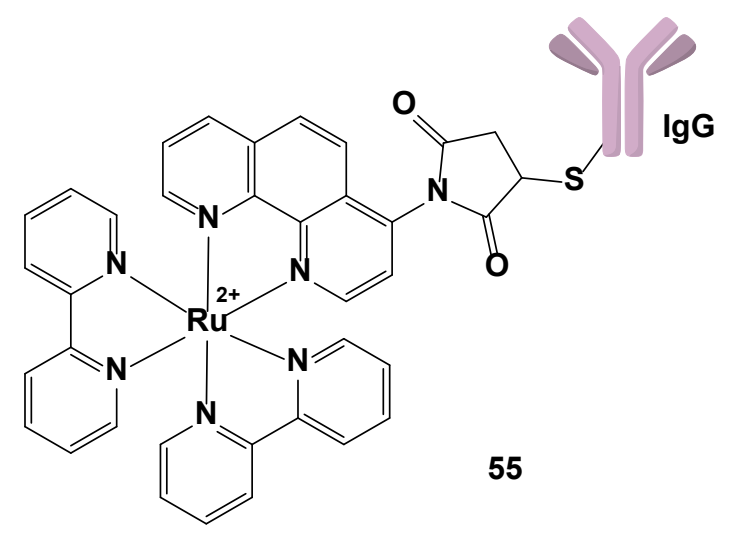

Fig. 26. Structure of the ruthenium(II) antibody conjugate 55.

Terpetschnig et al. prepared a $\mathrm{Ru}(\mathrm{II})$ polypyridyl maleimide probe to detect proteins (HSA, human serum albumin), enzymes ( $\beta$-galactosidase) and antibodies (IgG, immunoglobulin G).[85] The reaction of this complex $\left[\mathrm{Ru}(\mathrm{bpy})_{2}\right.$ (phen-5-maleimide) $]\left(\mathrm{PF}_{6}\right)_{2}$ with the corresponding proteins was performed at $\mathrm{pH} 6.5$ to avoid side reactions with the amino groups of other amino acids. The interest of these probes lies in the long-lived emission decays (over $1 \mu$ s). Complex 55 (Fig. 26) showed an effect of oxygen quenching (45\%) in the analyses by intensity decays in phosphate buffer. These quenching detections allowed the authors to measure the oxygen quenching constant $\left(k_{\mathrm{q}}\right)$. For an efficient quencher, this constant should approximately be $1 \times 10^{10} \mathrm{M}^{-1} \mathrm{~s}^{-1}$. The value found for 55 was $2.93 \times 10^{9} \mathrm{M}^{-1} \mathrm{~s}^{-1}$, which corresponds to a $96 \%$ quenching, when compared with the parent maleimide compound. Anisotropy decays (fluorescence polarization) were also measured. The Ru-antibody conjugate displayed short rotational correlation time $(15-30 \mathrm{~ns})$. Both results might indicate that the cys residues are mainly exposed to the buffer. 

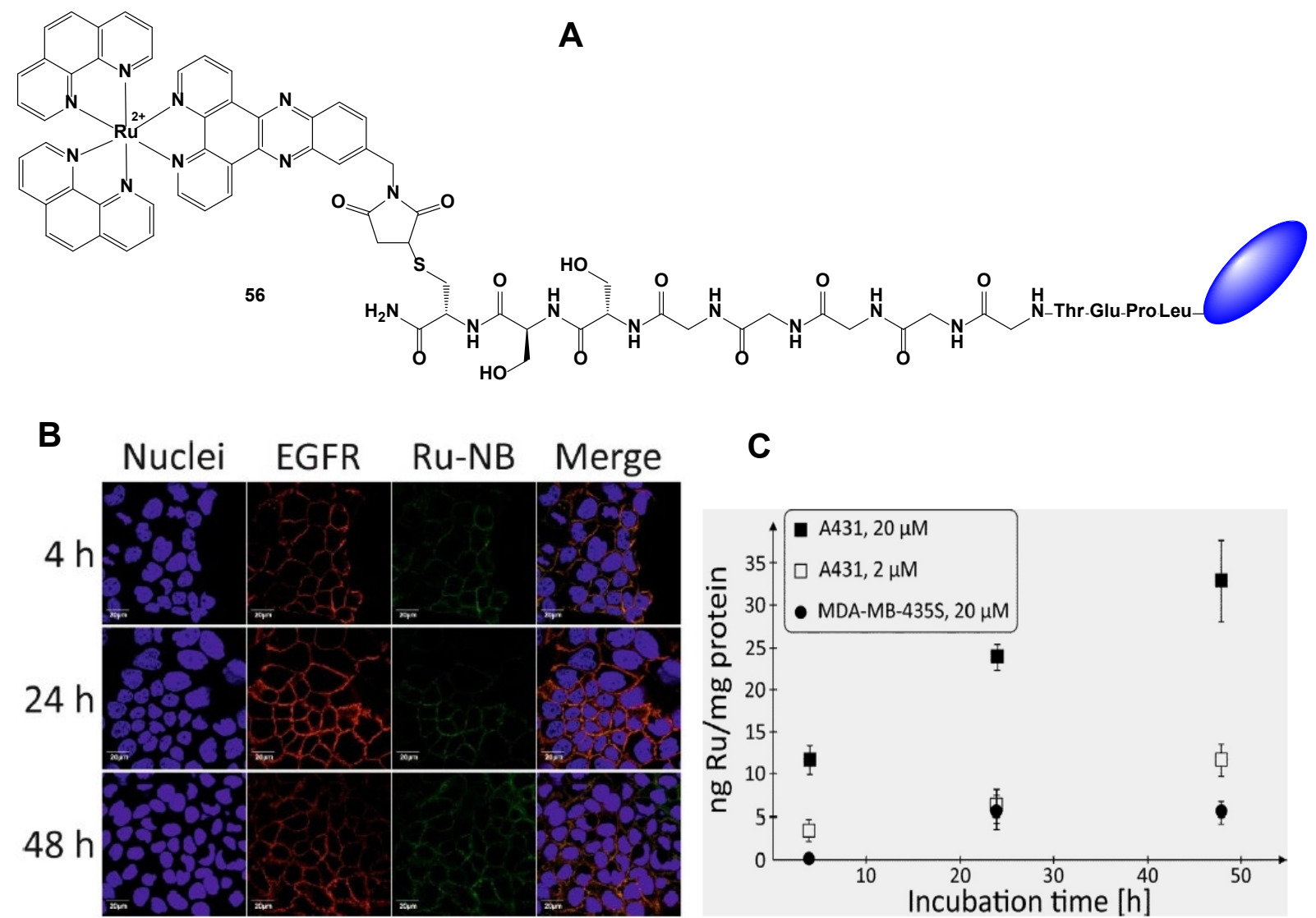

Fig. 27. A) Structure of Ru-NB 56. B) Confocal immunofluorescence microscopy images of A431 cells exposed to 56 for 4,24 , and $48 \mathrm{~h}$ at $37^{\circ} \mathrm{C}$ showing specific binding and co-localization of the single-conjugated NB with EGFR. Scale bars:20 mM. C) Amount of cell-associated ruthenium after incubation of EGFR-positive A431 and EGFR-negative MDA-MB-435S cells with 2 or $20 \mathrm{mM}$ of Ru-NB for up to $48 \mathrm{~h}$ at $37^{\circ} \mathrm{C}$. The level of ruthenium in cell lysates of MDA-MB- 435S exposed to $2 \mathrm{mM}$ of Ru-NB were below the analytical limit and are thus not shown. Figures extracted from reference [90]. C 2019 The Authors. Published by Wiley-VCH Verlag GmbH \& Co. KGaA.

Very recently, Gasser, Zarschler and co-workers reported on the synthesis of a Ru-nanobody conjugate as a PS for PDT.[90] Nanobodies (NBs) are small fragments of an antibody (Ab), which represent the antigen-binding domain of heavy-chain-only Abs. The authors selected the 7C12NB, which specifically binds the epidermal growth factor receptor (EGFR), overexpressed in some types of solid tumours. Thus, complex 56 (Fig. 27) is composed of three building blocks: the $\left.\left[\mathrm{Ru}(\mathrm{phen})_{2}(\mathrm{dppz})\right)\right]^{2+}$ complex, the $7 \mathrm{C} 12 \mathrm{NB}$ and a peptide chain containing polyglycines. The photophysical properties of the bioconjugate $\mathbf{5 6}$ were similar to those of similar $\mathrm{Ru}(\mathrm{II})$ polypyridyl complexes. Singlet oxygen production was determined since the 
emission lifetime was found to be affected by oxygen $\left(\tau_{\text {degassed }}=589 \mathrm{~ns}\right.$ and $\left.\tau_{\text {aerated }}=134 \mathrm{~ns}\right)$. Singlet oxygen quantum yield $\left(\Phi_{\Delta}\right)$ evaluated by an indirect method in DMSO or PBS showed low values and quenching in PBS due to hydrogen bonding interactions $\left(\Phi_{\Delta}=9 \%\right.$ in DMSO and $\Phi_{\Delta}=4 \%$ in PBS). The co-localization (by CLSM) of the NB-conjugate with EGFR in A431 cells (human epithelial cells) displayed mainly membrane staining after $48 \mathrm{~h}$ incubation at $37^{\circ} \mathrm{C}$. The cellular uptake was assessed by ICP-MS in EFGR-positive A431 cells and EFGRnegative MDA-MB-435S cells after different incubation times (4, 24 and $48 \mathrm{~h}$ ) and concentrations in the dark at $37^{\circ} \mathrm{C}$. A higher metal amount was found in the EGFRoverexpressing cells than in the negative one. Fig. 27 gathers the co-localization images and cellular uptake graph of 56. These findings suggested that the cellular internalization occurs through an EGFR-mediated process. Conjugate 56 exhibited similar cytotoxicity in A431 cells before and after irradiation $\left(480 \mathrm{~nm}, 6 \times 3.5 \mathrm{~min}\right.$ with $15 \mathrm{~min}$ gap in between, $\left.6.74 \mathrm{~J} / \mathrm{cm}^{2}\right)$ with $\mathrm{IC}_{50}>25 \mu \mathrm{M}$ in both cases. A temperature change (incubation for $1 \mathrm{~h}$ at $4{ }^{\circ} \mathrm{C}$ and then $1 \mathrm{~h}$ at $37^{\circ} \mathrm{C}$ ) was proposed since EFGR internalization is an energy-dependent mechanism, and thus, at $4{ }^{\circ} \mathrm{C}$, the endocytosis process is supressed. Nevertheless, the complex was non-toxic ( $\mathrm{IC}_{50}>$ $35 \mu \mathrm{M})$. Moreover, no ROS production was found in A431 cells.

\subsubsection{NHS: lysine linkage}

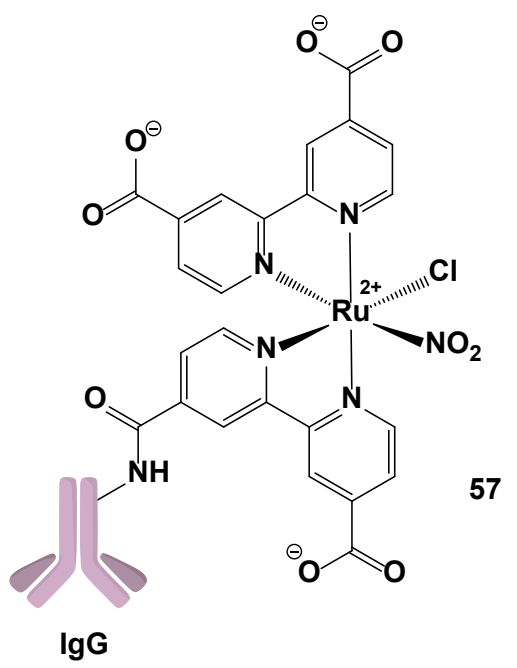

Fig. 28. Structure of the ADC 57. 
A nitrosyl ruthenium complex conjugated with a polyclonal antibody anti-VDAC (anti voltagedependent anion channel), 57 (Fig.28), was described as a NO delivery anticancer agent by Ramos et al.[91] This Ab participates on the mitochondria-mediated apoptosis through ROS. To simplify the measurement, the authors prepared the parent complex cis- $[\mathrm{Ru}(\mathrm{NO}) \mathrm{Cl}(\mathrm{dcbpy}-$ $\mathrm{H})_{2}$, where dcbpy is 2,2'-bipyridine-4,4'-dicarboxylic acid, and evaluated some of its properties. At different $\mathrm{pHs}$, there are different possible structures. For instance, at physiological pH, cis-[Ru(NO)Cl(dcbpy-H $\left.)_{2}\right]$ slowly turns into cis-[RuCl(dcbpy $\left.)_{2}\left(\mathrm{NO}_{2}\right)\right]^{4-}$. Cyclic voltammetry measurements in aqueous solution $(\mathrm{KCl} 0.1 \mathrm{M}$ and acetate buffer solution $0.01 \mathrm{M})$ demonstrated the release of $\mathrm{NO}$ in the presence of $\mathrm{NADH}$, through a one-electron reduction centred on the nitric oxide derivative ligand site. NADH plays an important role in the respiratory chain in the mitochondria. The production of ROS/RNS (reactive oxygen / nitrogen species) was evaluated for cis-[Ru(NO)Cl(dcbpy-H)2] in $\mathrm{HepG} 2$ cells (human hepatocarcinoma cells). High levels of ROS/RNS were found in succinate-energized mitochondria. Furthermore, at $100 \mu \mathrm{M}$ of complex, the mitochondrial permeability transition (MPT) inhibitor cyclosporine A (CsA) partially supressed the release of NO. At $50 \mu \mathrm{M}$ of complex, CsA inhibited almost completely the swelling caused by the complex. These features, along with the inhibition of swelling by a NO scavenger, suggested that NO was an MPT inducer. In addition, this complex was found to decrease the mitochondrial membrane potential. This means that mitochondria efficiently induced NO release from cis-[Ru(NO)Cl(dcbpy-H $\left.)_{2}\right]$. As a mechanism of action, high NO concentrations are known to inhibit mitochondrial respiration, increasing the ROS levels and inducing MPT and finally cell death. Different fractions obtained after purification of conjugate $\mathbf{5 7}$ showed cytotoxicity $(25 \%-90 \%$ cell viability) against HepG2 cells. The cellular uptake determined by ICP-MS showed a Ru content of $10^{-8} \mathrm{M}$, confirming internalisation of the conjugate. Thus, this ADC is able to induce cell death, probably due to release of NO in the mitochondria, targeted thanks to the $\mathrm{Ab}$. 


\subsection{Sugars/carbohydrates}

The coordination of sugars to metal ions aims to enhance the solubility in biological tissues (i.e., water) and thus, increase the biocompatibility of the metal complexes. There are two main strategies to prepare metal glycoconjugates.[92] The first one consists on the direct attachment of the metal to the carbohydrate. This strategy was widely used with $\mathrm{Pd}, \mathrm{Pt}, \mathrm{Cu}, \mathrm{Fe}, \mathrm{Mo}$ or W.[93] The second methodology introduces the sugar in the periphery and mainly impacts on the solubility of the resulting conjugate. Regarding $\mathrm{Ru}(\mathrm{II})$ polypyridyl complexes, the latter is more appropriate.

As for the uptake, sugars are involved in the cellular internalization based on two classes of transporters: GLUT (glucose transporters) proteins mediate sugar transport in an energyindependent process (passive), whereas the SGLT (solute carriers) use the $\mathrm{Na}^{+} / \mathrm{K}^{+} / \mathrm{ATP}$ pumps in an active mechanism. Larger molecules with more than one sugar residue require an endocytotic or energy-dependent internalization mechanism through multiple steps to reach the cytoplasm.[92] These transporters are key in cancer therapy since they are overexpressed in some kind of tumours.[94]. In addition, there are some special receptor proteins, called lectins, which recognize and reversibly bind to carbohydrates. They play important roles in different biological activities such as cell aggregation, cell signalling or pathogen recognition (inhibition of bacterial and fungal growth). [92,95]

Depending on the atom involved in the bond between the carbohydrate and the metal complex, the bioconjugates can be divided into O-, S- (when an $\mathrm{O}$ atom has been replaced by S) or Cglycosidic bonds.

\subsubsection{O-glycosidic bonds}



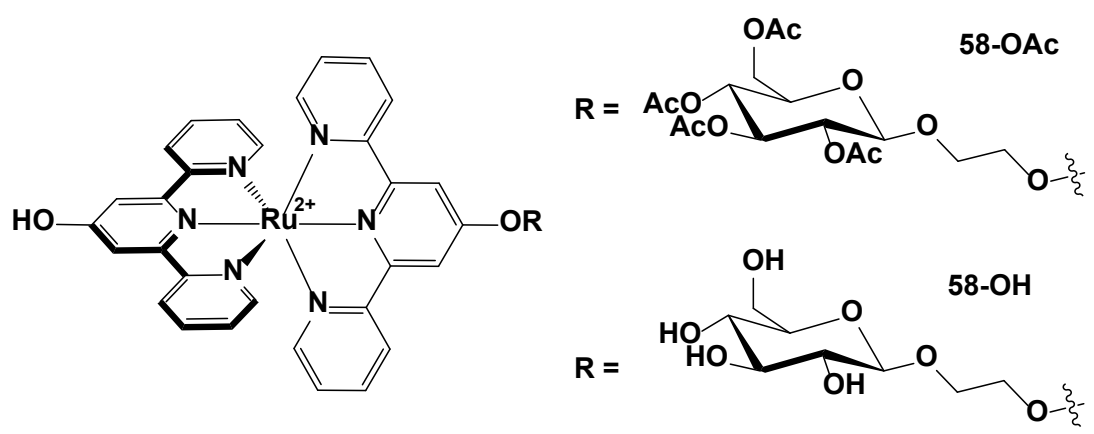

Fig. 29. Structures of glycoconjugates 56-OAc and 56-OH.

Constable and Mundwiler described, in 1999, the first examples of simple carbohydrate functionalization of $\mathrm{Ru}(\mathrm{II})$ terpyridine (tpy) complexes. The study of the stability of the glycoconjugates 58-OAc and 58-OH (Fig. 29) against the enzyme $\beta$-glucosidase at $40{ }^{\circ} \mathrm{C}$ for $24 \mathrm{~h}$ revealed no hydrolysis of the sugar fragments. This important stability opened a new route for drug delivery systems.[96] After this initial study, many systems were developed.

A

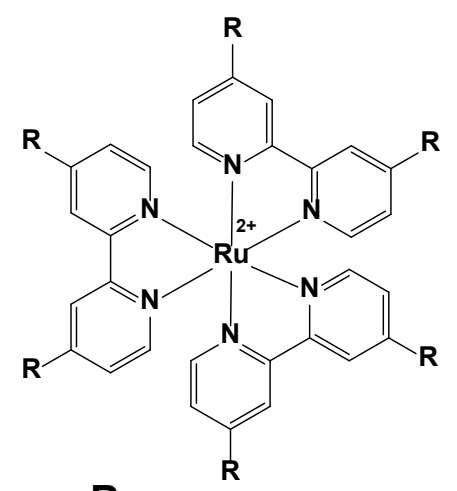

B<smiles>CC(=O)NCCCC(=O)Nc1ccc(O)cc1</smiles>

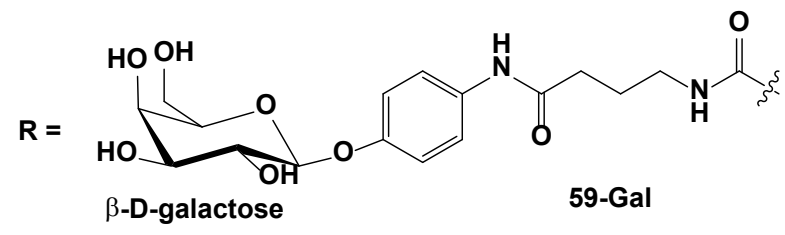<smiles>[R]OC1C(O)C(O)C2COC(Oc3ccc(NC(=O)CCCNC(C)=O)cc3)C1O2</smiles>

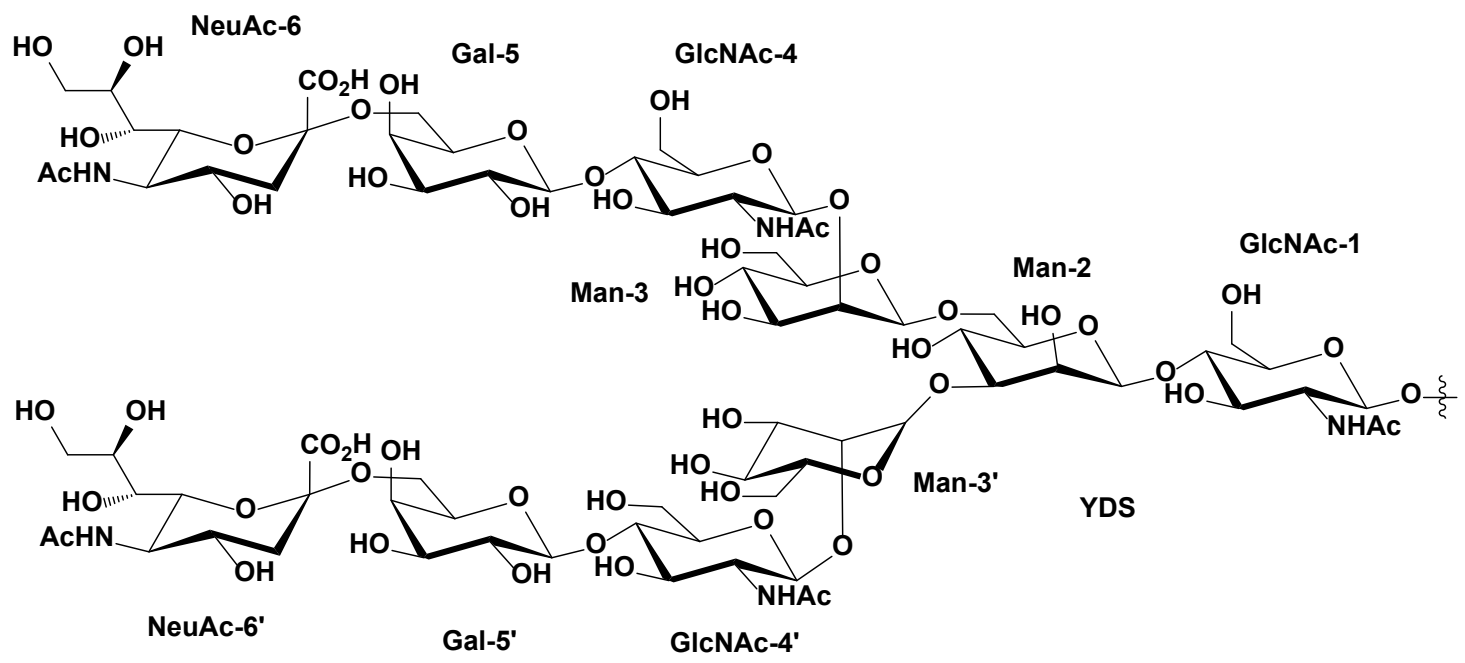


Fig. 30. A) Structures of glycoconjugates 59-Glc, 59-Gal and 59-Man and B) structure of the disialo oligosaccharide YDS.

Some of the first examples of Ru(II) bipyridyl glycoconjugate complexes were reported by Kobayashi and co-workers.[97,98] They coupled different carbohydrates ( $\alpha$-D-glucose, $\beta$-Dgalactose and $\alpha$-D-mannose) to bpy ligands through amid bonds and a $\mathrm{C} 3$ alkyl spacer $(\mathrm{O}$ glyco-bipyridines) to yield complexes 59-Glc, 59-Gal and 59-Man in their corresponding $\Lambda$ and $\Delta$ isomers, except for 59-Gal (Fig. 30A) The stable glycoconjugates exhibited enhanced luminescence, when compared with $\left[\mathrm{Ru}(\mathrm{bpy}-\mathrm{OH})_{3}\right] \mathrm{Cl}_{2}$. This increase could be assigned to the tightly packed saccharide clusters, which could isolate the luminescent core (the Ru centre) from the outer shell, avoiding thermal degradation. In addition, their ability as lectin binders towards concavalin A (ConA) and Ricinus comunnis agglutinin $120\left(\mathrm{RCA}_{120}\right)$ were tested. The three carbohydrate derivatives exhibited high binding affinity to lectins, stronger than the corresponding free $p$-nitrophenyl glycoderivatives. The $\mathrm{IC}_{\min }$ (minimun inhibition concentration) values for each complex showed the highest affinity for the mannocluster $\mathbf{\Lambda - 5 9 -}$ Man towards ConA $\left(\mathrm{IC}_{\min }=9.0 \times 10^{-8} \mathrm{M}\right)$. Furthermore, no inhibition was observed for 59Gal and 59-Glc against $\mathrm{RCA}_{120}$, and neither for 59-Gal against ConA. Conversely, the galactoconjugate (as the racemic mixture) inhibited $\mathrm{RCA}_{120}\left(\mathrm{IC}_{\min }=2.5 \times 10^{-6} \mathrm{M}\right)$ with moderate affinity. In order to work out the origin of the high affinity, the association constants and the thermodynamic parameters were determined. The association constants $\left(\mathrm{K}_{\mathrm{a}}\right)$ towards ConA for $\mathbf{\Lambda - 5 9 - M a n}$ and $\mathbf{\Lambda - 5 9 - G l e ~ w e r e ~} 5.4 \times 10^{6}$ and $9.5 \times 10^{5} \mathrm{M}^{-1}$, respectively. These are higher than the $\mathrm{K}_{\mathrm{a}}$ for monomannoside and other mannosylated compounds. Regarding the thermodynamics ( $\Delta G^{\mathrm{o}}=-9.7$ and $-8.4 \mathrm{kcal} \mathrm{mol}^{-1}$, for $\Lambda$-59-Man and $\boldsymbol{\Lambda}$-59-Glc, respectively), $\Delta H^{\mathrm{o}}$ and $\Delta S^{\mathrm{o}}$ were all negative, showing that the interaction was favourable in enthalpy and unfavourable in entropy. The stopped motion of the glycoclusters in the binding-sites of the lectins could be the reason of the negative entropy values. The strong luminescence of the 
glycoclusteres was quenched when the lectins were added, confirming again, higher sensitivity for the mannoconjugate than for the glucoconjugate towards ConA.

The same authors also performed a disialo oligosaccharide functionalization from yolk egg (YDS) in the glucoconjugate 59-Glc (through 4-OH of the $\alpha$-glucoside) as a probe to detect type-A influenza viruses.[99] The mono- (59-GIc-YDS 1 ) and bis-adducts (59-GIc-YDS 2 ) were obtained (Fig. 30B) and their inhibitory potency in MDCK cells (Madin-Darby Canine Kidney cells) were tested. While 59-Glc did not show any inhibition $\left(\mathrm{IC}_{50}>100 \mathrm{mM}\right)$, 59- Glc-YDS $\mathbf{1}$ and 59- GIc-YDS $\mathbf{2}_{\mathbf{2}}$ showed extremely high virus-affinity ( $\mathrm{IC}_{50}=19$ and $8.4 \mu \mathrm{M}$, respectively), even higher than fetuin (positive control, $\mathrm{IC}_{50}=270 \mu \mathrm{M}$ ). Moreover, the YDS-adducts displayed strong luminescence, which was quenched after the addition of the type-A influenza virus, showing again their great ability as inhibitors.

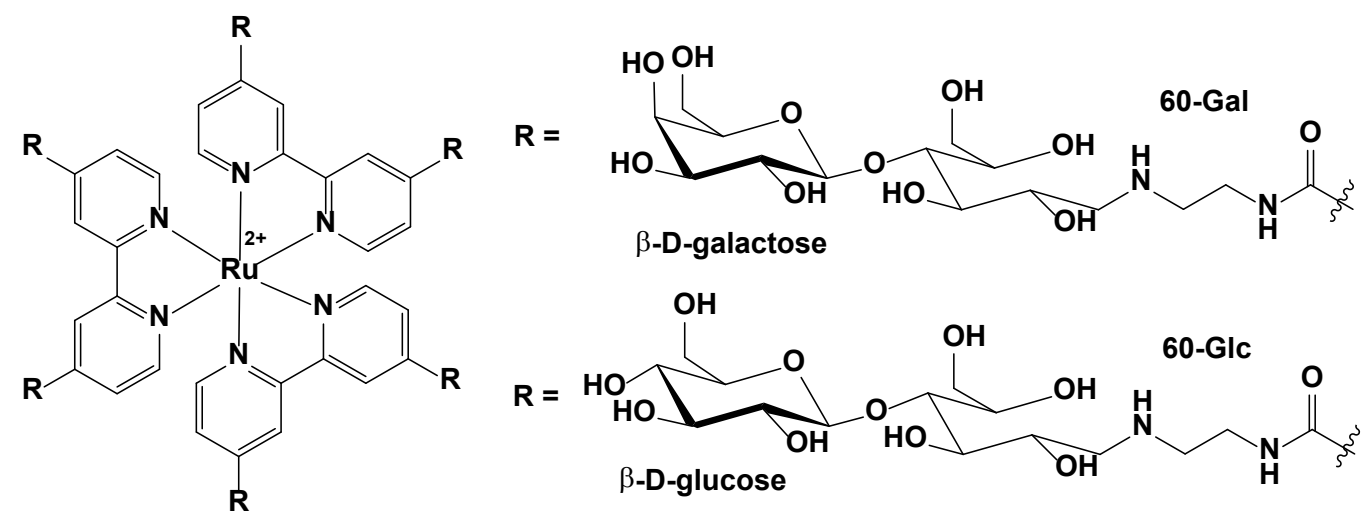

Fig. 31. Structures of glycoconjugates 60-Gal and 60-Glc.

Okada et al. prepared other Ru(II) bipyridyl carbohydrate derivatives, 60-Gal and 60-Glc as lectin binders (Fig. 31).[100] For that purpose, four different lectins were used: peanut agglutinin (PNA), Ricinus comunnis agglutinin 120 (RCA), concavalin A (ConA) and wheat germ agglutinin (WGA). The authors analysed the glycoconjugates 60-Gal and 60-Glc by fluorescence emission and fluorescence polarization (FP). A change in the emission spectrum of 60-Gal and the appearance of a new band after the addition of PNA showed binding specificity of the galactose conjugate towards this lectin. This new peak evidenced that $\mathbf{6 0 - G a l}$ specifically binds to the hydrophobic pocket of PNA. The same occurred to 60-GIc with ConA. 
Changes in the FP experiment of both complexes $(20 \mu \mathrm{M})$ were tracked after the addition of the different lectins $(5 \mu \mathrm{M})$. The results were consistent with the previously reported affinities: 60-Gal to PNA and 60-Glc to ConA. When varying the concentrations of these two lectins, it was possible to determine the dissociation constants $\left(\mathrm{K}_{\mathrm{d}}\right)$. They found lower $\mathrm{K}_{\mathrm{d}}$ of the clustered complexes 60-Gal and 60-Glc towards PNA and ConA $\left(\mathrm{K}_{\mathrm{d}}=6.1 \times 10^{-6}\right.$ and $1.8 \times 10^{-5} \mathrm{M}$, respectively), than the free galactose and glucose $\left(\mathrm{K}_{\mathrm{d}} \approx 10^{-3}\right.$ to $\left.10^{-4} \mathrm{M}\right)$, confirming again the high affinity of the metal complexes. The binding affinity of the conjugates $(2 \mu \mathrm{M})$ was also tested against tetanus toxin c-fragment (TTC, $0.05 \mu \mathrm{M}$ ), a non-toxic peptide, which is transported from peripheral axons into spinal motoneurons. The polarization increment was almost 7 times higher for $\mathbf{6 0 - G a l , ~ t h a n ~ f o r ~} \mathbf{6 0 - G l c}$, which confirmed the already known good affinity of TTC for galactose.[101]
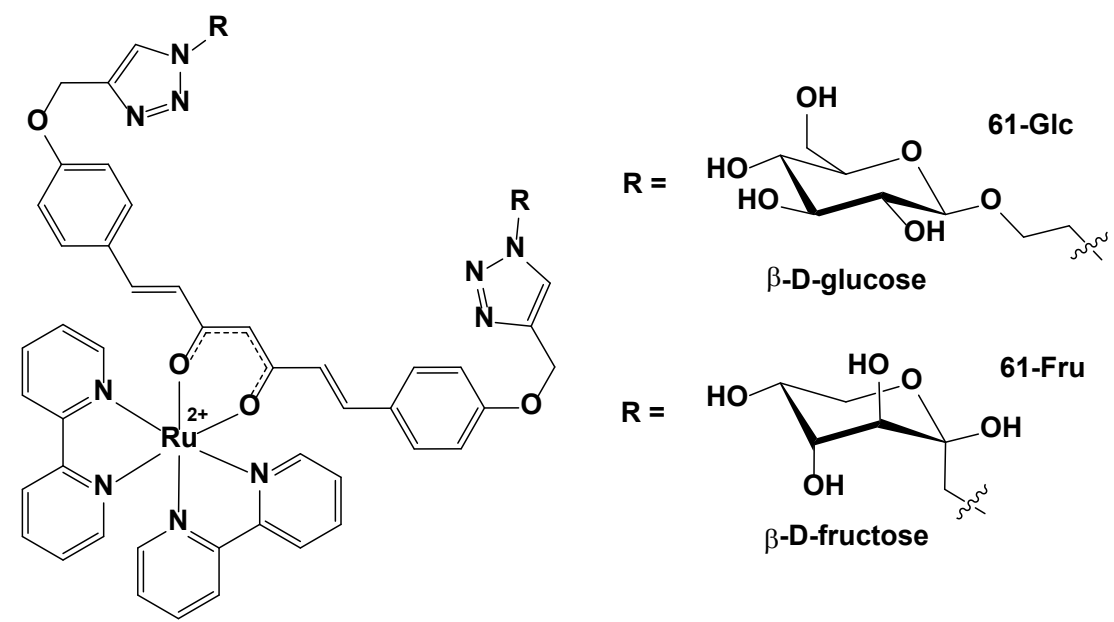

Fig. 32. Structures of conjugates 59-Glc and 59-Fru.

Pröhl et al. designed and prepared other families of Ru(II) polypyridyl diketonate complexes (61-Glc and 61-Fru) as anticancer drugs (Fig. 32).[102] These complexes were synthesized as bis(demethoxy)curcumin (BDC) derivatives coupled with the corresponding glycosides through a click reaction of the azido-sugars with a boroacetylene-BDC derivative, and finally, coordinated to $\mathrm{Ru}(\mathrm{bpy})_{2} \mathrm{Cl}_{2}$. The cytotoxicity of both the ligands and the conjugates was tested in L929 (mouse fibroblast cells), HepG2 (human hepatocarcinoma cells) and MDA-MB-231 (breast cancer cells) after $24 \mathrm{~h}$ incubation. Neither the ligands nor the complexes were toxic 
against the noncancerous cells L929. The Ru-containing glycoconjugates were found to be slightly toxic against MDA-MB-231 cells (75-80\% cell viability for $25-100 \mu \mathrm{M})$. The authors assigned this observation to the lipophilic character of the bpy ligands, which improves diffusion through the cell, when compared to the non-toxicity of the ligands themselves. Both 61-Glc and 61-Fru showed remarkable inhibitory effect against HepG2 cells, which was independent of concentration $(50 \%$ cell viability for the range $25-100 \mu \mathrm{M})$. Although there was some selectivity of the complexes for HepG2 cells over the other cell lines, the study did not show enhancement of toxicity for the fructose conjugate as expected from previous works.[103]

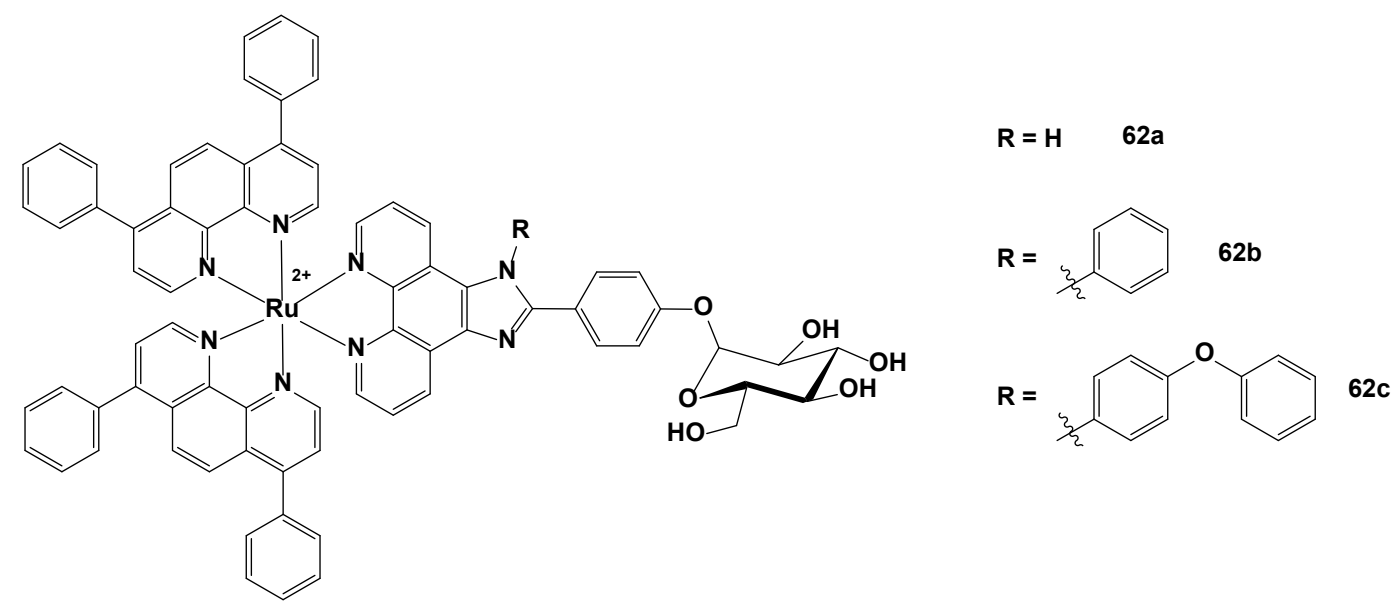

Fig. 33. Structures of glucoconjugates 62a, 62b and 62c.

Very recently, Liu et al. reported some imidazo phenanthroline glucocongujates $(\mathbf{6 2 a}, \mathbf{6 2} \mathbf{b}$ and 62c shown in Fig. 33) as two-photon absorption (TPA) PDT agents.[104] A similar complex to 62a without the glucose moiety was prepared as comparison. The TPA cross sections of the complexes were found to be higher than those for other organometallic complexes. Moreover, singlet oxygen quantum yield values $\left({ }^{1} \mathrm{O}_{2}\right.$ phosphorescence emission) were high (0.74-0.90), meaning the complexes were suitable as PDT agents. Lipophilicity measurements $(\log \mathrm{P})$ as cellular uptake indicators showed a lower lipophilicity for the complexes bearing the glucose moiety and also for $\mathbf{6 2} \mathbf{b}$, with the phenyl ring in the imidazole. Cellular uptake and cytotoxicity 
experiments were tested on HeLa (cervical cancer cells), HepG2 (hepatocellular cancer cells), A549 (human pulmonary carcinoma), A549R (cisplatin resistant) and L02 (human hepatic healthy cells, under glucose starvation). The uptake of the glucoconjugates in HeLa cells was the highest and in L02 cells the lowest, highlighting the selectivity for cancerous over noncancerous cells, whereas for the parent compound, no difference was detected. These evidences suggested an uptake mechanism through energy-dependent glucose transporters (GLUTs) for 62a and a passive transport was assigned for the Ru-derivative without the glucose moiety. Both confocal microscopy and ICP-MS showed that the complexes mainly accumulated in the mitochondria (more than $81 \%$ ) in HeLa cells. None of the complexes were toxic in the dark in HeLa cells. Nonetheless, after irradiation $\left(450 \mathrm{~nm}, 12 \mathrm{~J} / \mathrm{cm}^{2}\right)$, the toxicity increased dramatically, leading to a PI of 44 for 62a. Under TPA ( $25 \mathrm{~mW}, 120 \mathrm{~s})$, 62a was able to generate ROS in HeLa cells. Finally, in vivo experiments in mice with 62a (the most promising PS) showed disappearance of the tumour after 7 days treatment, when two-photon irradiation was used. In addition, no side effects and negligible body weight loss were detected.
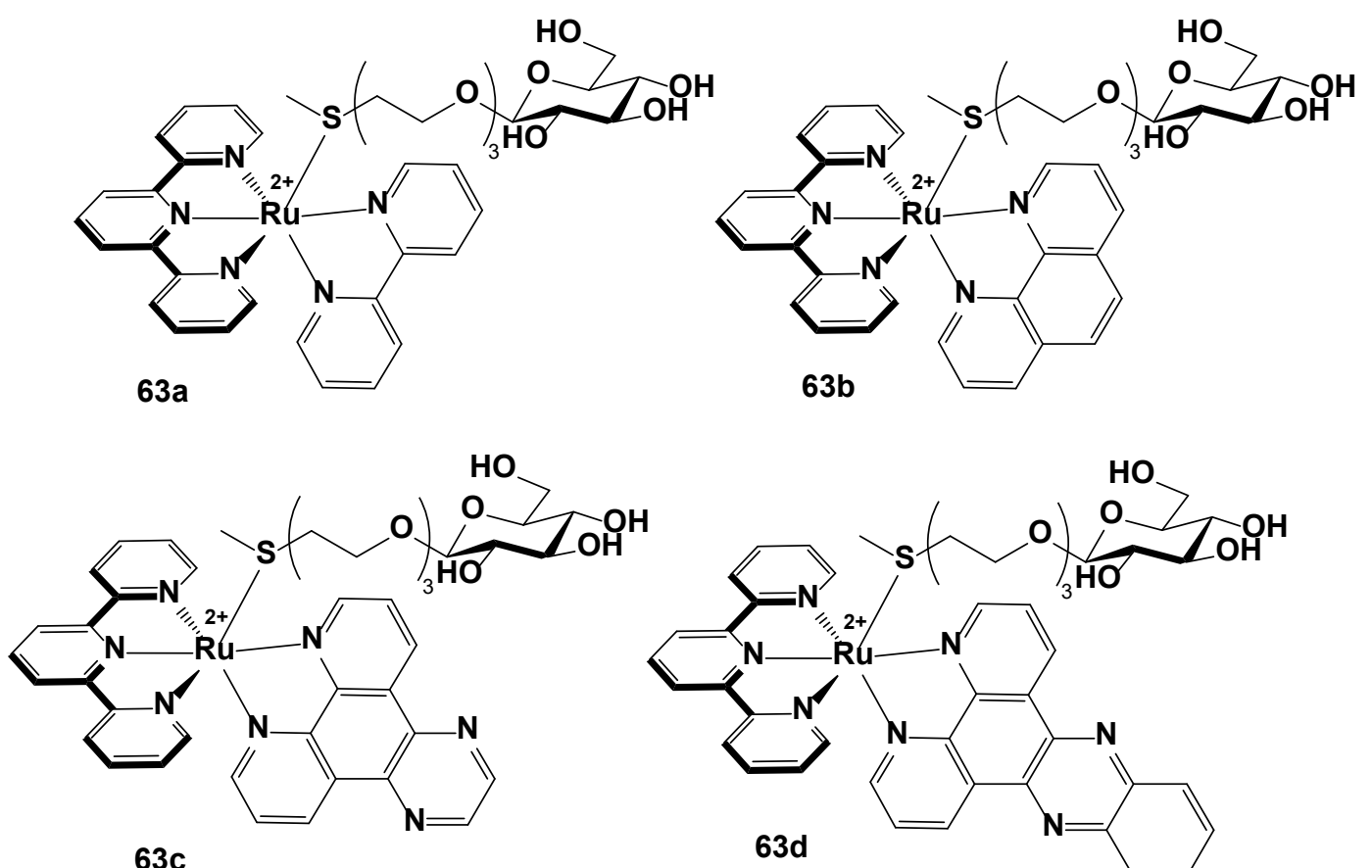

$63 c$

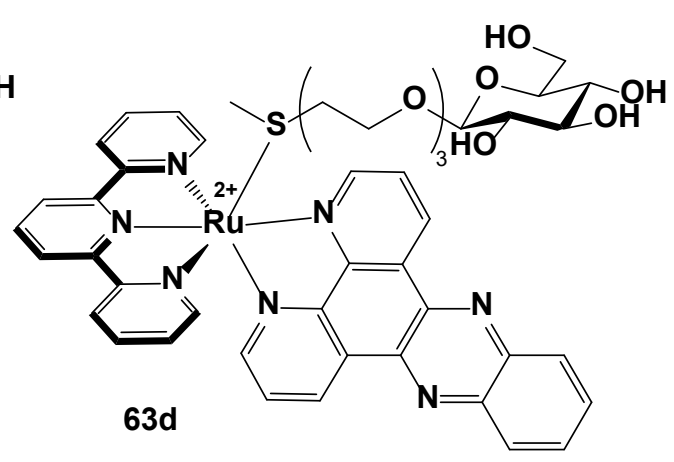




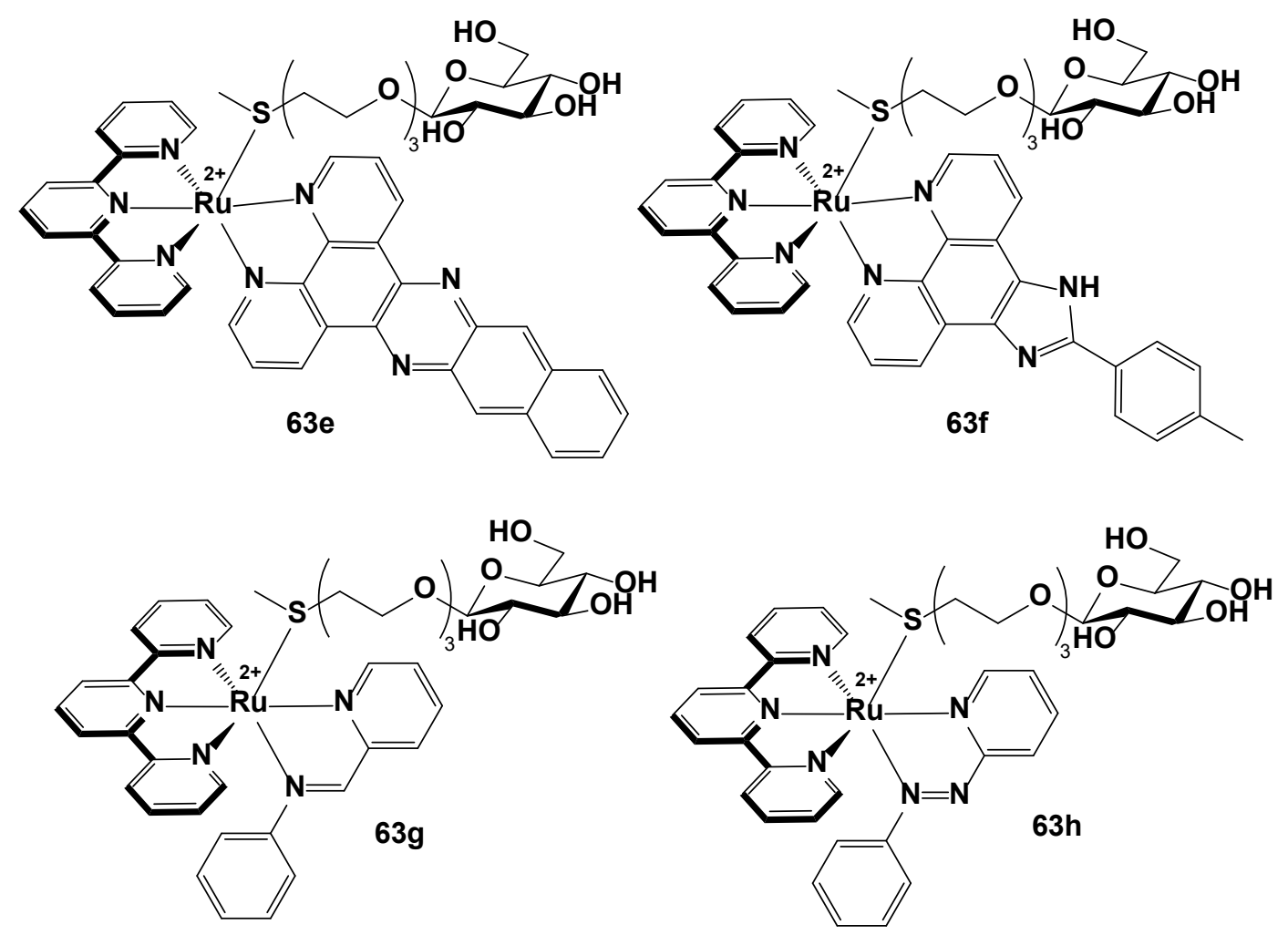

Fig. 34. Structures of S-glucoconjugates 63a-h

Bonnet and co-workers prepared a family of complexes (63a-h) with the formulae $[\mathrm{Ru}(\mathrm{tpy})(\mathrm{NN})(\mathrm{S}-$ glucoconjugate $)]\left(\mathrm{PF}_{6}\right)_{2}\left(\right.$ where tpy $=2,2^{\prime}: 6^{\prime}, 2^{\prime \prime}$-terpyridine, $\mathrm{NN}=\mathrm{N}^{\wedge} \mathrm{N}$ ligand and S-glucoconjugate $=2-(2-(2-($ methylthio $)$ ethoxy $)$ ethoxy $)$ ethyl-b-d-glucopyranoside $)$ as PDT and/or PACT agents (Fig. 34).[105] They also prepared the corresponding chloride complexes $([\mathrm{Ru}(\mathrm{tpy})(\mathrm{NN})(\mathrm{Cl})] \mathrm{Cl})$ as comparison. The water-soluble glucose-containing complexes were photoactivatable (with the exception of complex $\mathbf{6 3 h}$ ), so that the thioether ligand is released and replaced by a water molecule upon light irradiation. The authors measured the photosubstitution quantum yield $\left(\Phi_{450}\right)$ of $63 \mathbf{a}-\mathbf{g}$, using blue light (450 or $470 \mathrm{~nm}$ ) to irradiate the ${ }^{1}$ MLCT band of their complexes. They observed a bathochromic effect on the substitution process, in agreement with the formation of the aqua derivatives. The $\Phi_{450}$ were 0.5-2 \%, leading to photosubstitution reactivities $\left(\xi=\Phi_{450} \times \varepsilon 450\right)$ of 11-256. Complex 63d had the highest $\Phi_{450}$ value (0.02), whereas $63 \mathbf{e}$ had the lowest one, despite being structurally similar. The azo derivative $\mathbf{6 3 h}$ did not show any ligand dissociation, suggesting a strong electronic 
effect of the azo ligand on the photoreactivity of the ruthenium core. The singlet oxygen quantum yield $\left(\Phi_{\Delta}\right)$ of the complexes revealed small production of ${ }^{1} \mathrm{O}_{2}$ in $\mathrm{CD}_{3} \mathrm{OD}\left(\Phi_{\Delta}=0.002\right.$ 0.14), except for 63e $\left(\Phi_{\Delta}=0.71\right)$. Surprisingly, its chloride derivative 63e had a yield of 0.023 , highlighting the influence of the thioether ligand. The addition of a phenyl ring in the bidentate ligand of 63e compared with its analogue $63 \mathrm{~d}$, lowers the energy of the ${ }^{3} \pi \pi^{*}$ of the bidentate ligand. However, for $\mathbf{6 3 d}$, the ${ }^{3} \pi \pi^{*}$ states might be too high in energy or there is a quick conversion to the ${ }^{3} \mathrm{MC}$ state, making impossible the energy transfer process with molecular oxygen. This is also in agreement with the non-emissive nature of the complexes. The cytotoxicity and phototoxicity $\left(3.2 \mathrm{~J} \mathrm{~cm}^{-2}\right.$ at $\left.454 \mathrm{~nm}\right)$ of the complexes was tested in two cell lines, namely A549 (human lung carcinoma) and MCF-7 (human breast adenocarcinoma) after $48 \mathrm{~h}$ complex incubation (see Table 1). None of the glyconconjugates were photocytotoxic, except 63e. Nonetheless, after modifying the protocol for $\mathbf{6 3 d}$, they found an improved phototoxicity index (PI, 2.4 and 2.6 for A549 and MCF-7, respectively). The normal protocol implied the replacement of the cell media, so that compound, which did not enter the cell, was removed and only complex inside the cell could be photoactivated. In the new protocol, they did not change the media. Thus, the complex could be activated outside the cell membrane and, after release of the thioether ligand, enter the cell. However, this modification did not show improvement for 63a-c and 63f-g. The cellular uptake (25 $\mu \mathrm{M}, \mathrm{A} 549$ cells after $24 \mathrm{~h})$ and the lipophilicity $\left(\log \mathrm{P}_{\mathrm{o} / \mathrm{w}}\right)$ of complexes showed some correlations. Although the cellular uptake of the glycoconjugates was low, internalization of 63d-f was 10 times higher than for $\mathbf{6 3 a - c}$, correlating well with the more lipophilic nature of $\mathbf{6 3 d - f}$. In conclusion, all these complexes are good photocaging agents, but only 63d showed potential as a PACT agent, whereas 63e could act as a photosensitizer for PDT.

In a previous work, complex 63e was studied in depth.[106] Apart from the D-glycoconjugate, the L-glycoconjugate was also prepared (D-63e and L-63e, Fig. 34). The properties of both enantiomers were similar, except the optical density, as expected, and both complexes 
underwent photoactivation. (Photo)cytotoxicity experiments measured using the same conditions as above (the "normal" protocol with replacement of the media, see above) showed some differences. Complex L-63e exhibited lower toxicity in the dark than D-63e, but higher toxicity after light irradiation, leading to high PI values (11-86). Thus, the chiral nature of the glucoses has a clear effect on the cytotoxicity. Cellular localization was independent of the incubation times and both conjugates showed almost the same cellular localization. Further experiments revealed localization in mitochondria and an energy-independent mechanism of cellular uptake (using $\mathrm{NaN}_{3}$ as all energy-dependent uptake mechanisms). Since DNA is present in mitochondria and $\mathrm{Ru}(\mathrm{II})$ complexes with the $\mathrm{N}^{\wedge} \mathrm{N}$ ligand (dppn, benzo[i]dipyrido-[3,2a:2',3'-c]phenazine) are known as good DNA intercalators,[107,108] some experiments to check interaction with DNA were performed. In the presence of CT-DNA and blue light, the emission maximum of D-63e were red-shifted by $42 \mathrm{~nm}$ and the intensity enhanced by up to 10 times. Under these conditions, the respective aqua complex is also formed. In addition, a competitive experiment for DNA intercalation between ethidium bromide (a well-known DNA intercalator, EtBr) and D-63e showed competition of both compounds for the same binding sites. Finally, the authors worked out two extra conclusions. First, the aqua complex interacts with plasmid DNA with a high base pair/Ru ratio. Second, both the D-glycoconjugate and the aqua complex generate singlet oxygen, which triggers DNA photocleavage.

Table 1. Cytotoxicity and phototoxicity of complexes 63d and 63e in A549 and MCF-7 cells reported as effective concentrations $\left(\mathrm{EC}_{50}\right)$. PI is the phototoxicity index, calculated as $\mathrm{EC}_{50 \text { dark }} / \mathrm{EC}_{50 \text { light. }}$ Confidence interval values are not shown for clarity.

\begin{tabular}{|c|c|c|c|c|c|c|}
\hline & \multicolumn{3}{|c|}{ A549 } & \multicolumn{3}{|c|}{ MCF-7 } \\
\hline Complex & $\mathrm{EC}_{50}$ dark & $\mathrm{EC}_{50}$ light & PI & $\mathrm{EC}_{50}$ dark & $\mathrm{EC}_{50}$ light & PI \\
\hline $63 d$ & $>100$ & $>100$ & - & $>100$ & $>100$ & - \\
\hline $63 d^{a}$ & 64 & 27 & 2.4 & 52 & 20 & 2.6 \\
\hline $63 e(D-63 e)$ & 19 & 0.72 & 26 & 9.6 & 0.86 & 11 \\
\hline $63 e(L-63 e)$ & 50 & 0.58 & 86 & 18 & 0.61 & 30 \\
\hline
\end{tabular}

${ }^{a}$ Modified protocol. 


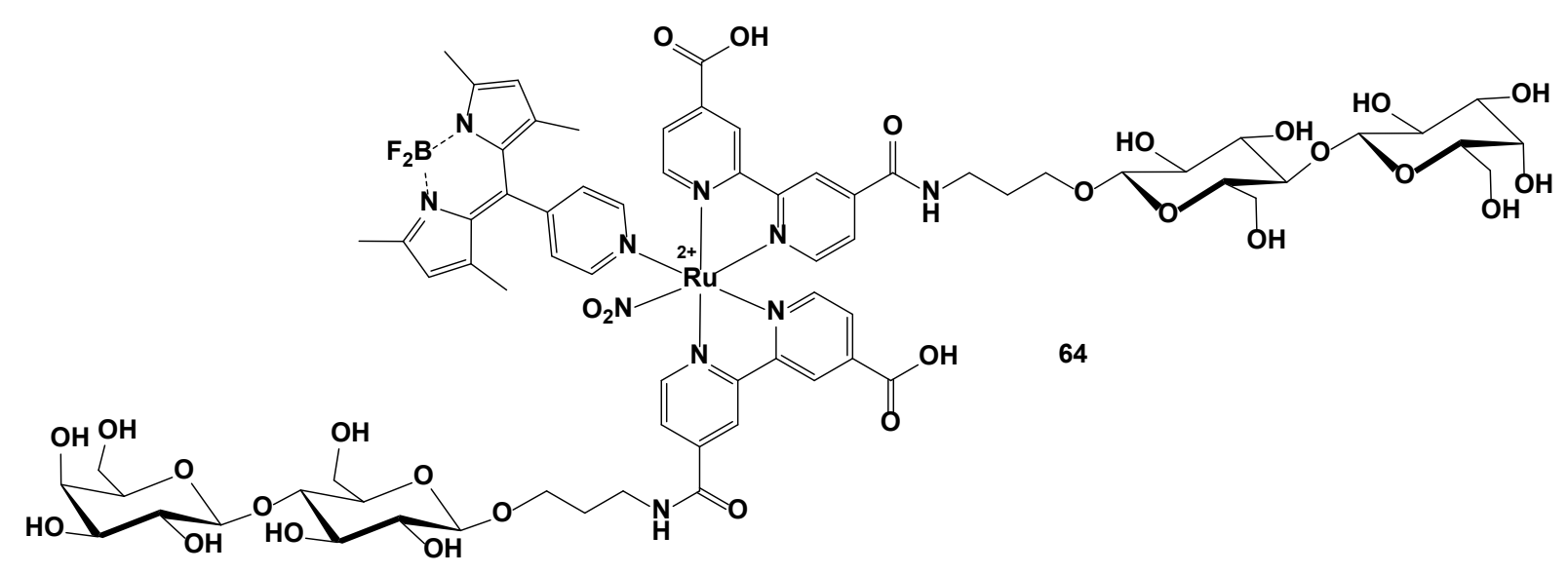

Fig. 35. Structure of Ru-BODIPY glycoconjugate 64.

According to the idea of the photoinduced release of a monodentate ligand, dos Santos et al. prepared a Ru(II) complex (complex 64, Fig. 35) containing a BODIPY moiety, a nitrogen oxide precursor and two lactose units and its parent compound without the lactose moieties.[109] Both complexes showed similar spectroscopic features, indicating that the lactose incorporation does not modify these features. The cellular uptake of the lactose derivative $64(10 \mu \mathrm{M})$ in B16F10 cells (murine melanoma) after $1 \mathrm{~h}$ showed $99 \%$ of internalization, whereas the parent compound (i.e., without lactose units) only showed $13 \%$. Even 30 min were enough for $\mathbf{6 4}$ to be internalized in the cytoplasm. The subcellular location was found to be near the mitochondria, while the nucleus was excluded. The reason of the rapid uptake could be the presence of the aminopropyl- $\beta$-lactose moieties, easily taken up by lectins. The cytotoxicity was evaluated in the same cell line. Although the internalization was extremely different, both complexes caused $75 \%$ of cell death and produced NO (nitric oxide), meaning that the parent compound is much more toxic than its lactose conjugate. $150 \mu \mathrm{M}$ of both 64 and the parent compound produced the maximum concentration of NO after $24 \mathrm{~h}$. Therefore, the cytotoxic activity might be caused by the release of NO. 


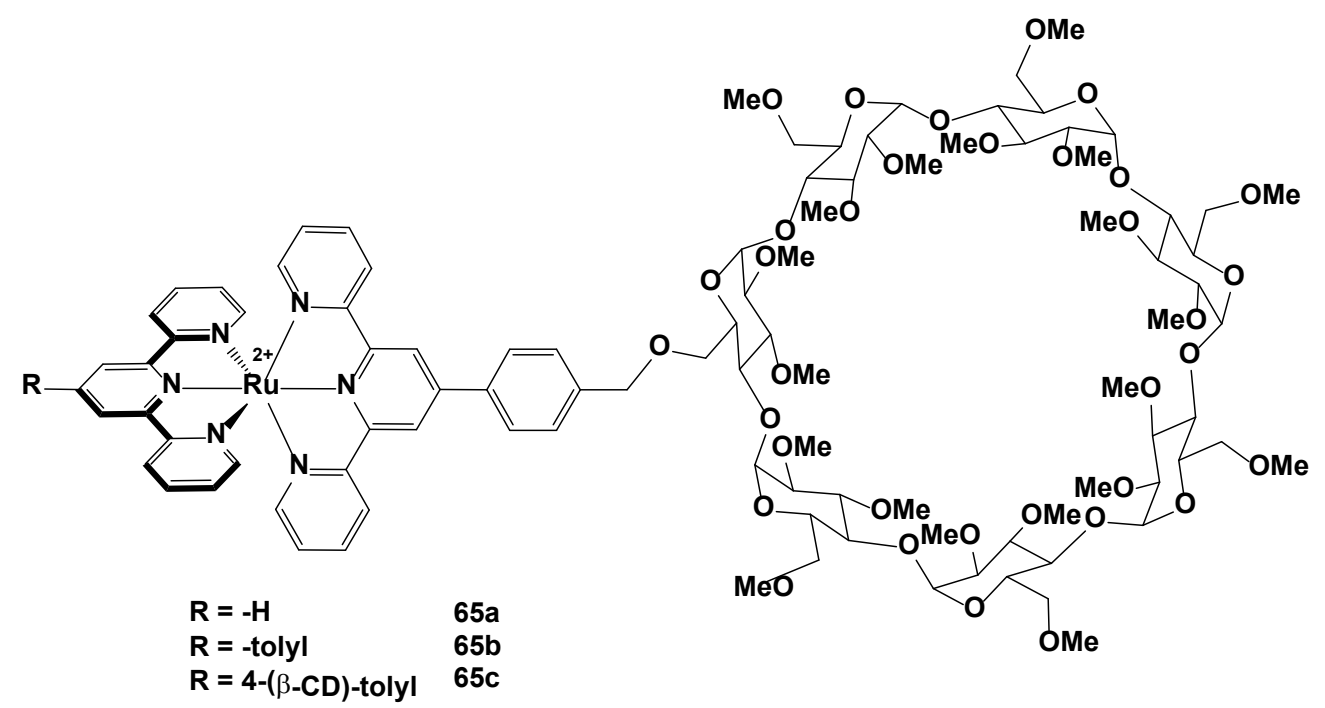

Fig. 36. Structure of cyclodextrine $(C D)$ conjugates $65 a, 65 b$ and $65 c$.

Supramolecular conjugates were also prepared and used as host-guest cages to study photoinduced electron transfer processes. Haider et al. synthesised three $\beta$-cyclodextrin ( $\beta$-CD) derivatives 65a, 65b and 65c (Fig. 36).[110] Since cyclodextrins are both externally and internally hydrophobic, the guest can bind through non-covalent interactions. Firstly, some quinones, shown in Fig. 35, were used as guests: AQC (anthraquinone-2-carboxylic acid), AQS (anthraquinone-2-sulfonic acid) and BQ (1,4-benzoquinone). The emission intensity of $\mathbf{6 5 b}$ decreased (40\%, $20 \%$ and $25 \%$, for AQS, AQC and BQ, respectively) when the quinones were added. The rate constants were $5 \times 10^{8} \mathrm{~s}^{-1}$ for AQS and $3 \times 10^{8} \mathrm{~s}^{-1}$ for AQC. The equilibrium constants were also determined in saturated conditions. The authors found out that $85 \%$ of AQS and $77 \%$ of AQC were bound to the cyclodextrin appended moiety in $\mathbf{6 5 b}$ $\left(\mathrm{K}_{\mathrm{a}(\mathrm{AQC})}=860 \pm 200 \mathrm{M}^{-1}\right.$, and $\left.\mathrm{K}_{\mathrm{a}(\mathrm{AQS})}=1100 \pm 100 \mathrm{M}^{-1}\right)$. This quenching suggests an electron transfer process. For the $\mathrm{BQ}$, it was not possible to obtain a value due to the weak binding of this quinone with CD. Secondly, an osmium metalloguest was prepared $\left[\mathrm{Os}(\text { biptpy)(tpy) }]^{2+}\right.$, where biptpy $=4^{\prime}$-(4-biphenyl)- 2,2':6',2"'-terpyridine (Fig. 37). The photoinduced transfer from the ruthenium host to the osmium guest was measured with steady state and time-resolved spectroscopy. Excess of the Ru derivative was needed to ensure all of the osmium complex is in the cyclodextrin cavities. However, no effect was observed for the energy transfer (ET) 
mechanism. In the electron transfer (eT) option, the Os(II) is previously oxidized to Os(III), in the presence of cerium(IV) salt, which is used as the oxidizing agent. The lifetime of the Rucyclodextrin was quenched by the Os(III) metalloguest. For the free ruthenium complex, the lifetime was $1.9 \mathrm{~ns}$, whereas for the quenched species, two lifetimes were detected: $100 \pm 10 \mathrm{ps}$ (80\%) and $1.9 \mathrm{~ns}(20 \%)$. Independent binding studies of the osmium guest to free CD performed in the same conditions confirms $80 \%$ of the osmium species are bound to the cyclodextrin cavities mediated by an electron transfer pathway $\left(k=9.5 \times 10^{9} \mathrm{~s}^{-1}\right)$. This indicates the high efficiency of the process.
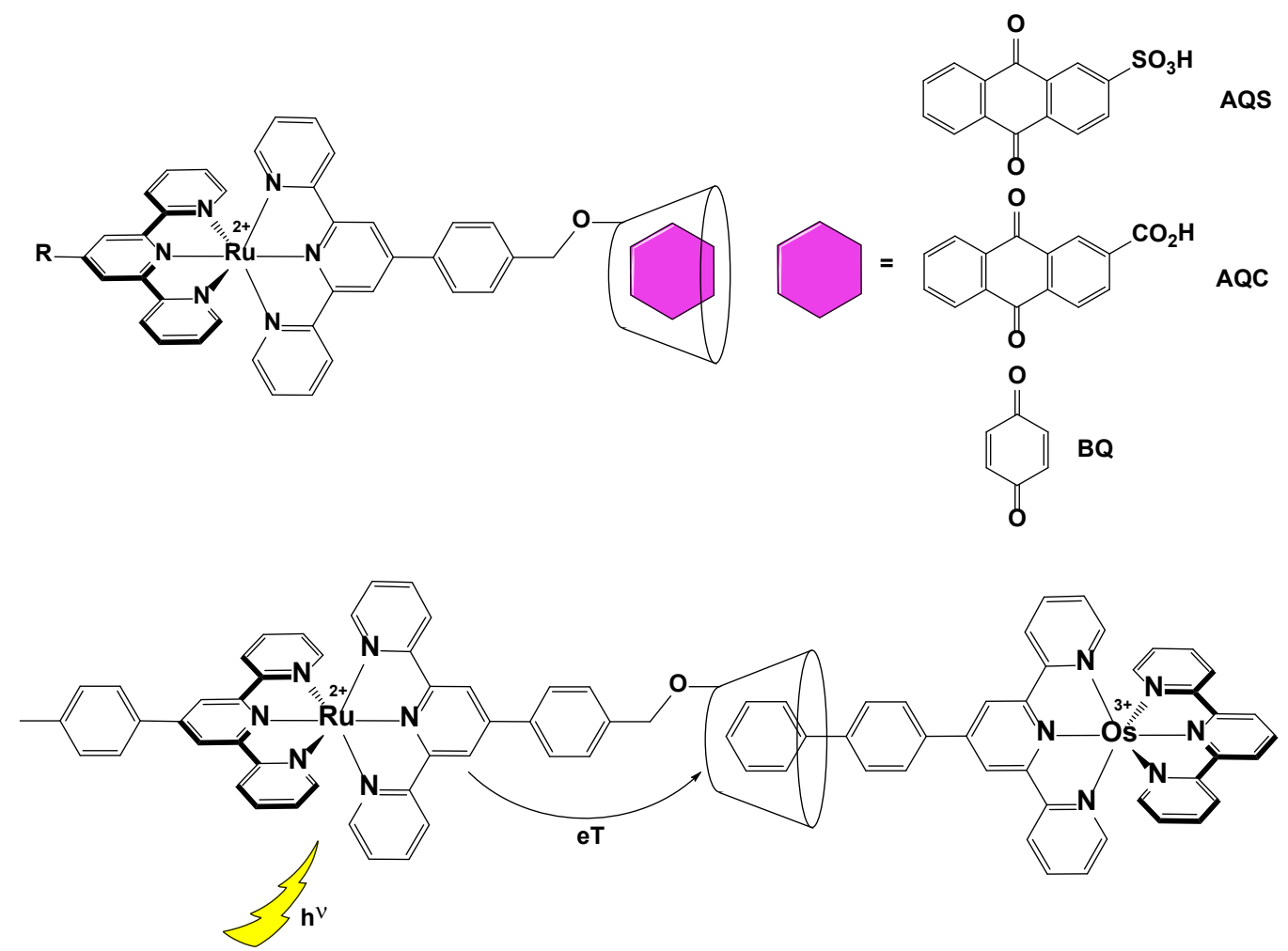

Fig. 37. Host-guest interaction for cyclodextrin conjugates $\mathbf{6 5}$ (host) with guest quinones (top. AQS = anthraquinone-2-sulfonic acid, AQC = anthraquinone-2-carboxylic acid and BQ = 1,4-benzoquinone) or the Os(III) metalloguest (down) and the electron transfer mechanism of $\mathbf{6 5} \mathbf{b}$ with Os(III) metalloguest (down). 


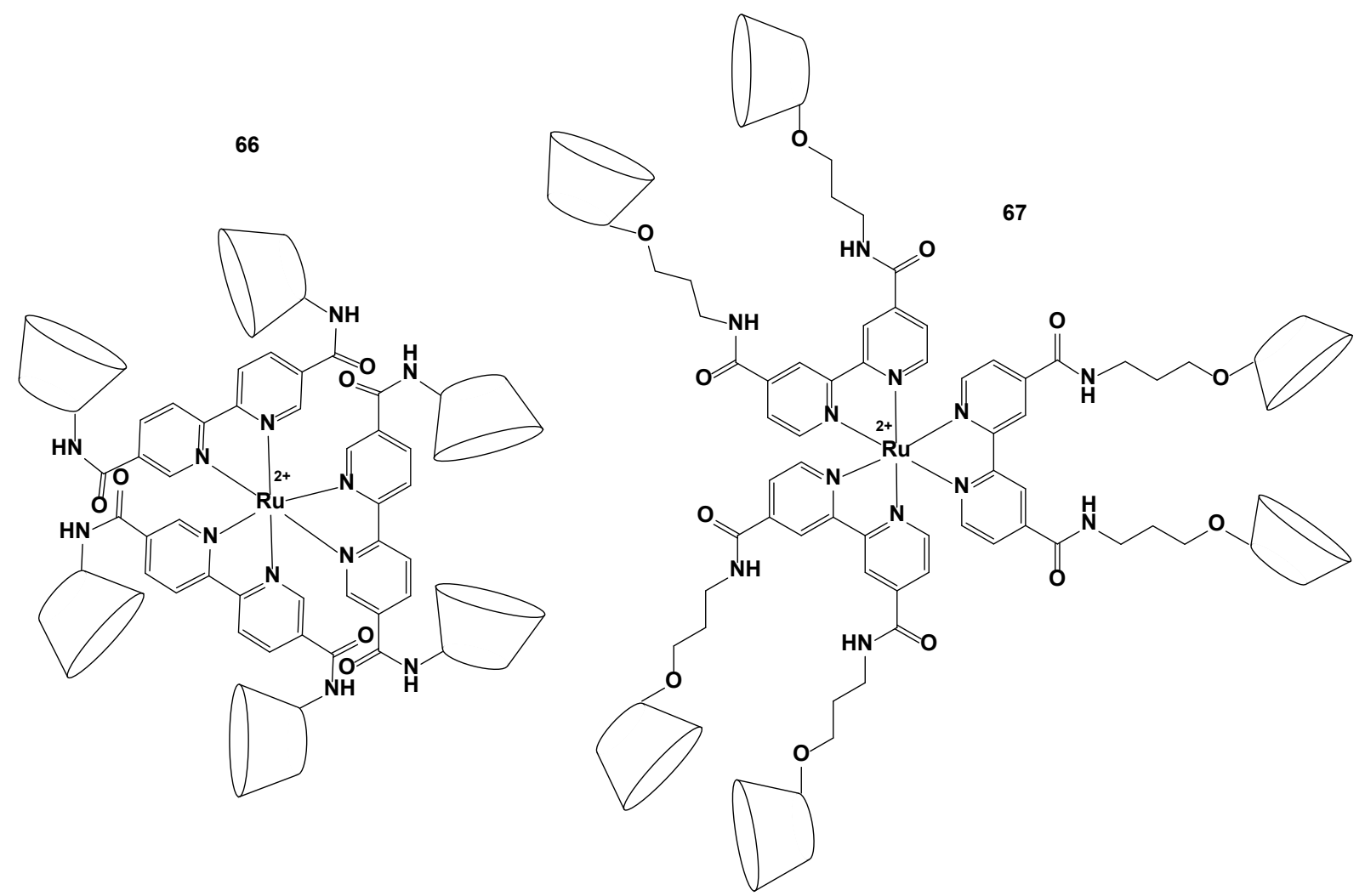

Fig. 38. Structures of the supramolecular conjugates 66 and 67.

Complexes decorated with cyclodextrin cavities were also used as probes to detect steroids. Nolte and co-workers synthesised two complexes, 66 and 67 (Fig. 38), separated in their $\Lambda$ and $\Delta$ enantiomers.[111] However, owing to the low emission intensity of $\mathbf{6 6}$, only $\mathbf{6 7}$ was tested as a probe. When directly adding the steroids to a solution of 67 , no change in the emission was detected. Therefore, a viologen (N,N'-dinonyl-4,4'-bipyridinium bromide) was firstly used as a guest molecule. The viologen quenched the emission of 67 by $92 \%$ and a 1:1 complex was formed $\left(\mathrm{K}_{\mathrm{a}}=2.8 \times 10^{5} \mathrm{M}^{-1}\right)$. The interaction of the first bipyridinium was observed to quench the emission of 67 , whereas the interaction with the second one had no effect over the emission intensity. Then, different steroids (i.e., ursodeoxycholic acid, lithocholic acid and cholesterol) were added, so that the emission was recovered, suggesting the displacement of the viologen. Only ursodeoxycholic acid strongly increased the emission of 67 , while lithocholic acid only recovered a $30 \%$ of the intensity and cholesterol showed too weak emission. Thus, this sensor is useful to detect and distinguish steroids. The authors concluded that, like in complex $\mathbf{6 5} \mathbf{b}$, 
there is a photoinduced electron transfer process from the Ru core (host) to the viologen (guest). As an extra advantage, the multiple binding sites available in the molecule prevents the complex to be quenched by oxygen.[112]

\subsubsection{S-glycosidic bonds}
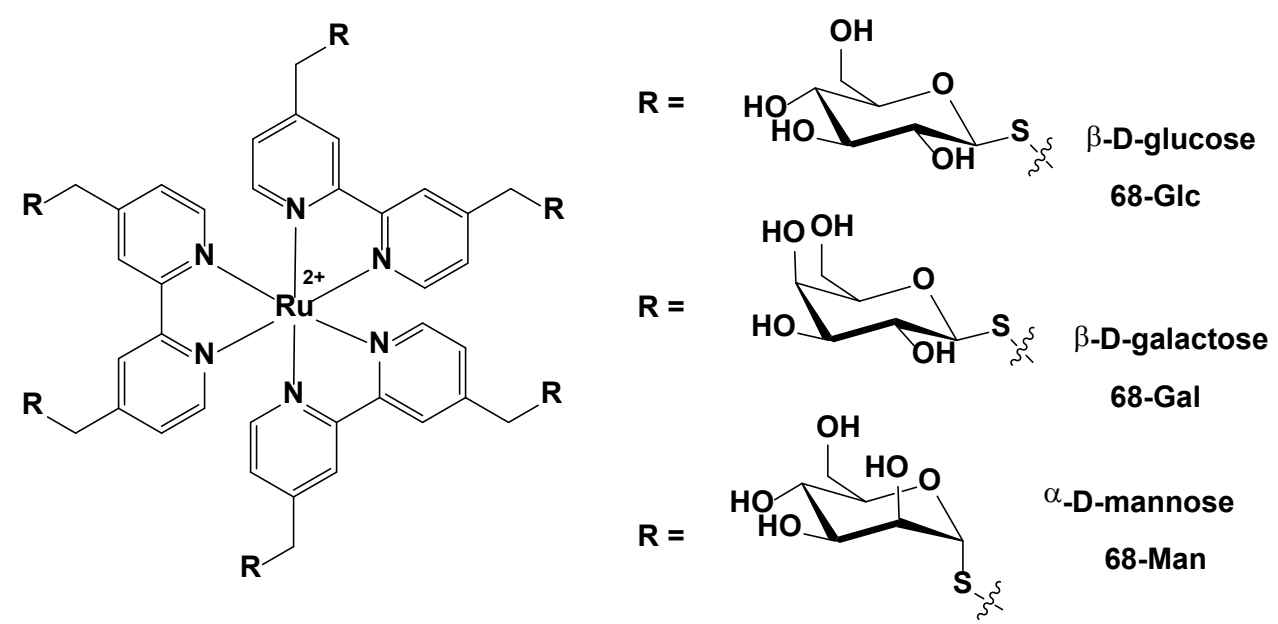

Fig. 39. Structures of S-glycoconjugates 68-Glc, 68-Gal and 68-Man.

Nevertheless, not all the complexes were prepared as $O$-glycosidic conjugates. The watersoluble thioglycoconjugates 68-Glc, 68-Gal and 68-Man (Fig. 39) were reported by Gottschaldt et al. to check the biodistribution of the complexes inside cancer cells.[113] They selected different carbohydrates closely connected to the bipyridine ligands through the $S$ glycosidic bonds to avoid lectin binding in cell surfaces. An extra advantage is that $S$-glycosidic bonds resist hydrolysis from glycosidases.[114] The photophysical properties of the complexes were similar with longer lifetimes for the deaerated solutions, indicating in this case the production of singlet oxygen. The uptake of the complexes in HepG2 cells (human hepatocarcinoma cells) was tested after $24 \mathrm{~h}$ incubation of aqueous solutions of the complexes by CLSM. As a result, the glucoconjugate 68-Glc was the most efficiently taken up by cells, whereas less accumulation was observed for the galactoconjugate 68-Gal. The distribution inside cells (Fig. 40) displayed granulation for the glucose derivative. This indicates an endocytotic uptake pathway. The internalization for the galactose derivative, however, revealed 
homogeneous distribution in the cytoplasm. For the mannose derivative 68-Man and the parent compound $\mathrm{Ru}(\mathrm{dmbpy})_{3} \mathrm{Cl}_{2}$, very low intensity was detected, suggesting a weak uptake.
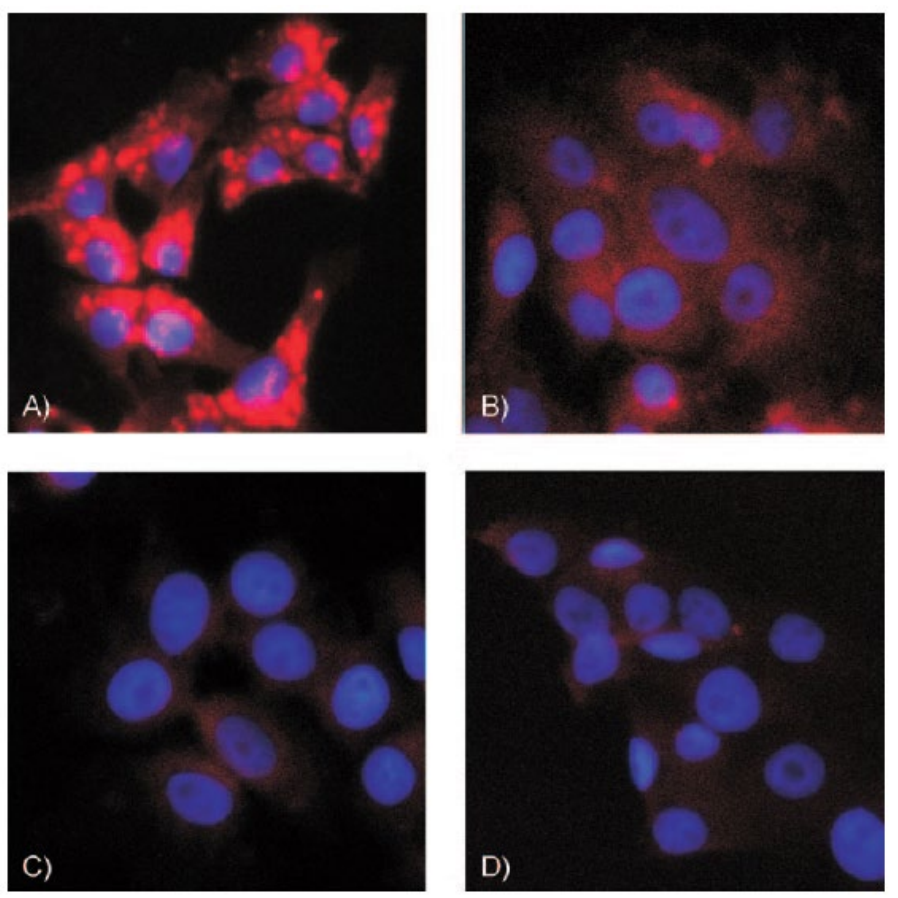

Fig. 40. Cellular distribution of glycoconjugated Ru complexes in HepG2 cells ( 24 h, $500 \mu \mathrm{M}$, red). A) Glucose, B) galactose, C) mannose Ru-complex and D) parent compound $\mathbf{R u}(\mathbf{d m b p y})_{\mathbf{3}} \mathbf{C l}_{\mathbf{2}}$, Blue: cell nuclei after staining with Hoechst33258. Reproduced from [113]. Copyright (C) 2010 WILEY-VCH Verlag GmbH \& Co. KGaA, Weinheim

Flow cytometry analysis confirmed as well a favourable internalization of 68-Glc, whereas a lower effect was observed for 68-Gal. Both 68-Man and $\mathrm{Ru}(\mathrm{dmbpy})_{3} \mathrm{Cl}_{2}$ were undistinguishable by flow cytometry analysis. In order to discard a mechanism of internalization through glucose transporters (GLUT), some glucose $(20 \mathrm{mM}, 24 \mathrm{~h})$ was added to the cells treated with the glucoconjugate $(500 \mu \mathrm{M}, 24 \mathrm{~h})$. No relevant changes were observed when comparing the cells with or without the complex, suggesting again an endocytotic uptake mechanism.

\subsubsection{C-glycosidic bonds}




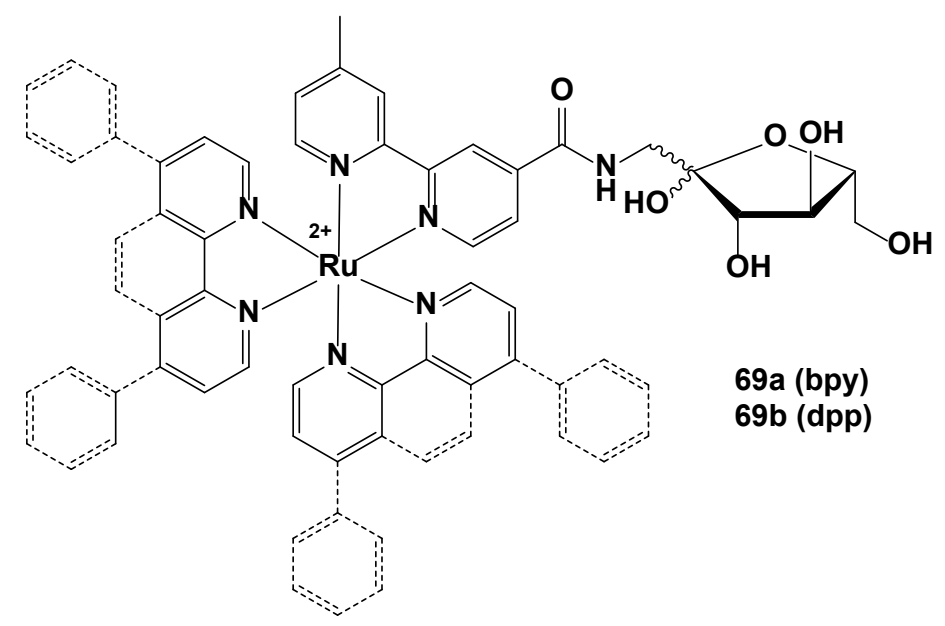

Fig. 41. Structure of the fructose conjugates $69 \mathrm{a}$ and $69 \mathrm{~b}$.

The interest in the fructose functionalization of the $\mathrm{Ru}(\mathrm{II})$ polypyridyl complexes has been pursued since fructose can take part in many favourable mechanisms. GLUT5 (a glucose transporter), for instance, facilitates fructose uptake and is overexpressed in some breast cancers. Thus, Lau et al. prepared the fructo-conjugates 69a and 69b, with the fructose appended through an amid bond on one bpy (Fig. 41).[115] Both complexes showed emission intensities comparable to those of the parent compounds (non-fructose derivatives). The lipophilicity of the complexes showed increased lipophilicity for the dpp (4,7-diphenyl-1,10phenanthroline) complex. However, both fructo-conjugates are more hydrophilic than their non-fructose counterparts. Their cytotoxicity was tested in MCF-7 cells. After $48 \mathrm{~h}$ incubation, no cytotoxic effect was found for any of the complexes (cell viability $>70 \%$ ). The colocalization experiments performed on MCF-7 cells showed intense staining of the cell membrane exclusively for the dpp complex. Oppositely, no staining was observed for 69a, bearing bpy. Other cell lines were selected for further studies with 69b: MDCK (Madin Darby Canine Kidney cells), $3 \mathrm{~T} 3$ (mouse embryonic fibroblasts) and HeLa (human cervical epitheloid carcinoma). Conjugate $69 \mathrm{~b}(10 \mu \mathrm{M}, 1 \mathrm{~h})$ was found to localize in the cytoplasm in MDCK and 3T3, whereas in HeLa, it was strongly concentrated in the cell membrane. Since the GLUT5 transporter favours the fructose uptake, a competitive experiment between $\mathbf{6 9 b}$ and $\mathrm{D}$-fructose was carried out in MCF-7 cells. Cells treated with 69b $(50 \mu \mathrm{M}, 1 \mathrm{~h})$ showed lower intracellular 
emission intensity when D-fructose $(50 \mathrm{mM})$ was added. The same effect was detected in flow cytometry assays, suggesting that the uptake of complex 69b is competitively inhibited by fructose. These assays also showed that cells treated with $69 \mathrm{~b}$ displayed stronger emission intensity than the untreated cells, highlighting its good internalization. Thereby, these complexes display promising properties as imaging agents.

\subsection{Lipids}

Cell membranes are lipophilic. Thus, one of the best strategies to achieve internalization of drugs is by modifying complexes with lipids. Lipid-drug conjugates (LDCs) also present other interesting features. Linking lipids to drugs can improve the performance of orally administrated drugs, enhancing, for example, their gastrointestinal absorption. This approach can be also beneficial in the delivery of anticancer drugs, since tumour cells frequently take up lipids as energy suppliers. In addition, LDCs have been found to overcome drug resistance in anticancer therapy. Small, uncharged and lipid-soluble molecules (i.e. LDCs) are able to cross the blood brain barrier (BBB), a permeable barrier that separates circulating blood from the cranial fluid, by two mechanisms: increasing lipophilicity or targeting membrane receptors capable of transport them through the BBB.[116]

From a photophysical point of view, lipids absorb light in the therapeutic window of the nearinfrared (NIR) spectrum.[117,118] Since the use of red or NIR light as activation light is a key parameter for some application in PDT and PACT, the attachment of lipids to metal complexes could significantly improve their use as photosensitizers for these techniques.

\subsubsection{Fatty acids}

One of the first examples of $\mathrm{Ru}(\mathrm{II})$ polypyridyl lipid conjugates was reported by Killeen et al.[119] They synthesised a $\left[\mathrm{Ru}(\text { bpy })_{3}\right]^{2+}$ derivative 70 (Fig. 42), in which one of the bipyridyl ligands has been substituted in 5-position with a bolaamphiphile (i.e., molecules with two hydrophilic ends separated by a long lipophilic chain). Amphiphiles have been widely used to 
form highly ordered assemblies. However, these membranes are not completely homogeneous since some pores are formed in-between the assemblies. Therefore, the authors proposed the attachment of $\mathrm{Ru}(\mathrm{II})$ complexes as closure points for the pores, and subsequent homogenization of the layer. The modification of the bpy ligand did not significantly change the photophysical and electrochemical properties of $\mathbf{7 0}$, compared to those of $[\mathrm{Ru}(\mathrm{bpy}) 3]^{2+}$.

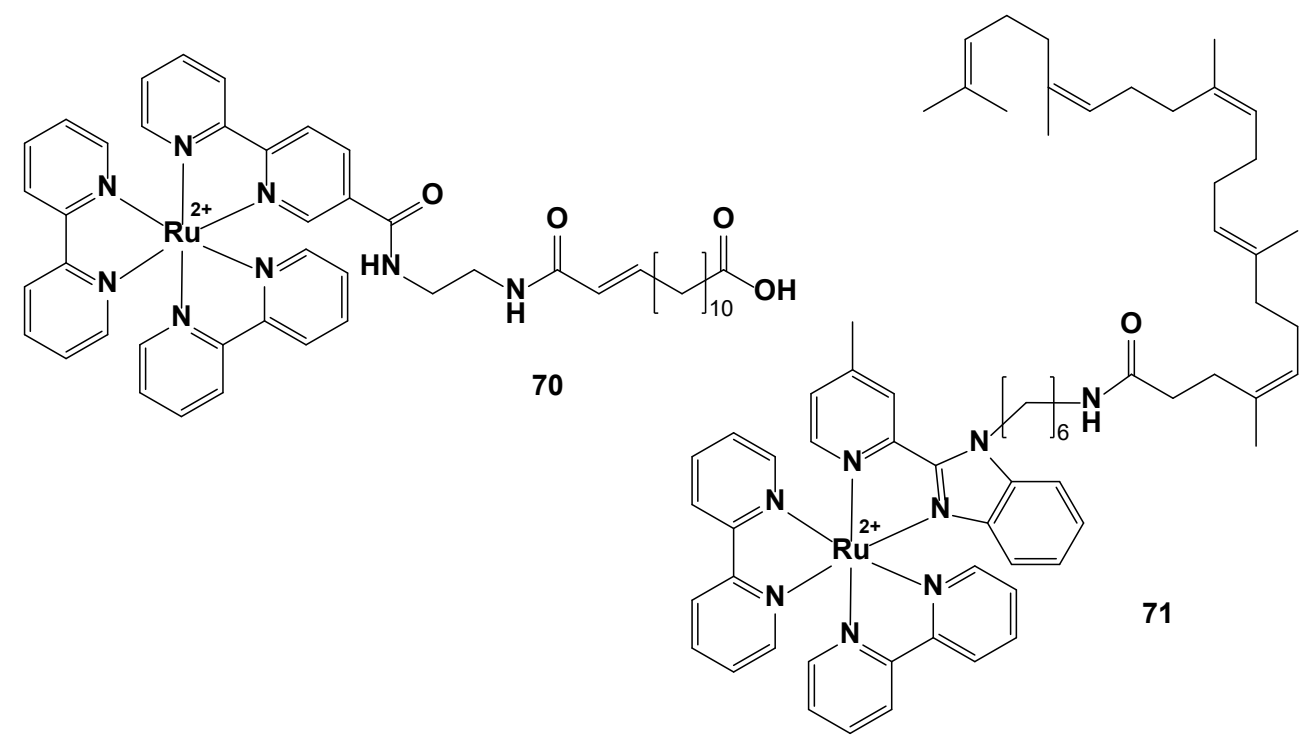

Fig. 42. Structures of the fatty acid conjugates $\mathbf{7 0}$ and $\mathbf{7 1 .}$

The conjugation of Ru complexes with lipids was proposed to achieve self-aggregates in water and improve the cellular uptake and diffusion. Dosio et al. prepared a probe for cellular imaging 71 (Fig. 42), based on a Ru(II) polypyridyl complex attached to squalene (squalenoylation), a natural organic precursor for the synthesis of all plant and animal sterols.[120] The authors found out that $\mathbf{7 1}$ accumulates inside the cell by passive diffusion, even in multicellular spheroids, unlike the parent compound without the squalene moiety. ICP-MS experiments showed an internalisation of $13 \mathrm{amol} / \mathrm{cell}$ for the non-squalenoyl complex and $270 \mathrm{amol}$ of $\mathrm{Ru} /$ cell for 71, when MCF-7 cells were incubated with $50 \mu \mathrm{M}$ of complex, respectively. The cellular concentration for the conjugate was $160 \mu \mathrm{M}$, more than 3 times higher than the initial concentration. This evidences the high lipophilicity of 71. Furthermore, the authors found out that the toxicity of both complexes in HT-29 (human colon cancer cells) and MCF-7 cell lines was relatively low $(>100 \mu \mathrm{M})$. However, the global emission intensity impressively increased 
for the squalene-derivative. The emission of $\mathbf{7 1}$ could be detected in the nucleus and the cytosol, whereas no emission was observed for the non-squalenoyl compound owing to its slight internalization.

\subsubsection{Steroids}

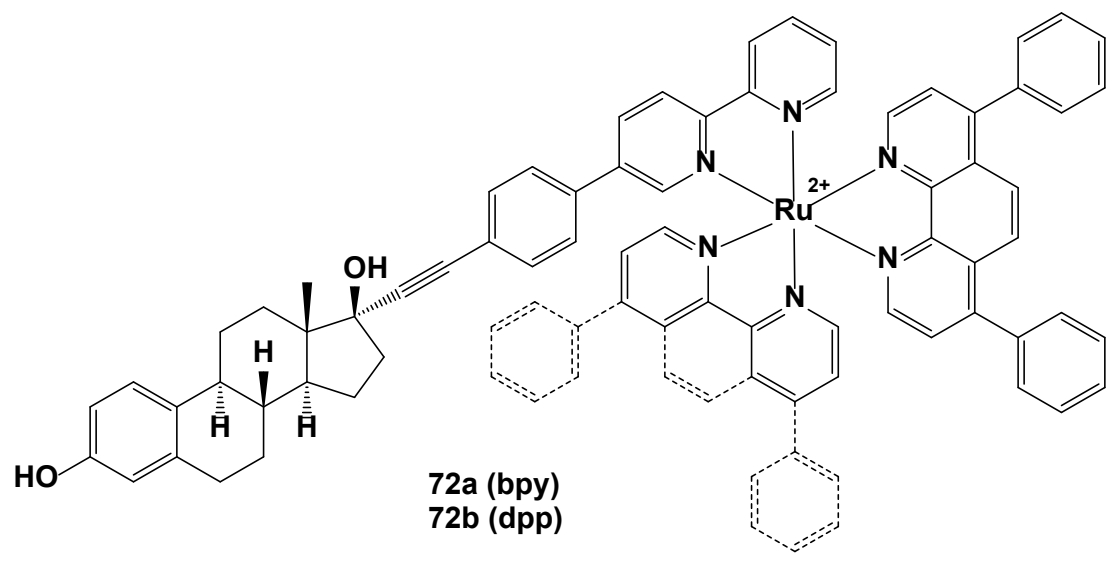

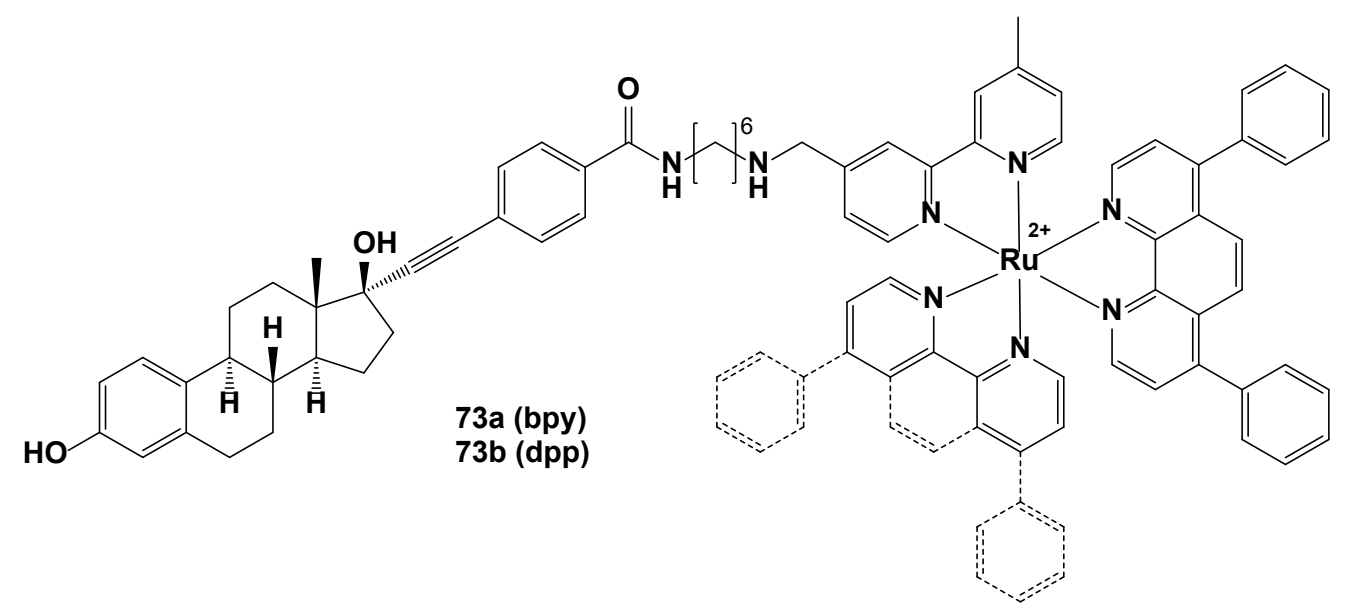

Fig. 43. Structures of lipoconjugates 72a-b and 73a-b.

Lo et al. reported a series of $\mathrm{Ru}(\mathrm{II})$ polypyridyl estradiol conjugates, 72a-b and 73a-b (Fig. 43), successfully designed as biological luminescent probes.[121] Estradiol belongs to the family of estrogens and has the highest binding affinity to estrogen receptors (ERs). The lipophilicity of the complexes measured as the partition coefficients $\left(\log \mathrm{P}_{\mathrm{o} / \mathrm{w}}\right)$ revealed an increase for complexes bearing dpp ligands, especially for the estradiol derivative with the longer spacer. The emission intensities and lifetimes also increased for the conjugates with the dpp ligand in the presence of ER $\alpha$, evidencing the enhanced binding affinity of the new complexes. However, 
the binding constants were lower than that of the estradiol, but similar to other estradiolcontaining metal complexes. The cytotoxicity of the complexes, studied in HeLa cells after 48 $\mathrm{h}$ incubation was low ( $\mathrm{IC}_{50}$ values ranged from 83.1 to $166.6 \mu \mathrm{M}$ ) compared to that of cisplatin (34 $\mu \mathrm{M})$. Thus, the complexes could be considered as non-toxic. The cellular uptake data showed better internalization for derivatives with dpp, which are in good agreement with the emission intensities and binding affinities. In addition, complex $\mathbf{7 3 b}$ showed distribution mainly inside the cytoplasm of HeLa cells, with higher degree in the perinuclear region, suggesting interaction with hydrophobic organelles such as the Golgi apparatus or the endoplasmic reticulum.

Bonnet and co-workers designed steroid derivatives based on another approach: the photochemical activation and subsequent release of the lipid-containing monodentate ligand, through a thioether bond. This is the same strategy that they have followed for other bioconjugates, which have been previously described (see Section 1.3.1. O-glycosidic bonds, complexes 63a-h). The steroid-thioether moiety coordinates to the $\mathrm{Ru}(\mathrm{II})$ polypyridyl core through the $\mathrm{S}$ atom. Thus, complexes $\mathbf{7 4}$ and 75, shown in Fig. 44, were prepared as cholestanol[122] and cholesterol[123] derivatives, respectively. The photochemical activation triggers the substitution of the S-ligands by water molecules, forming the aqua complex. 


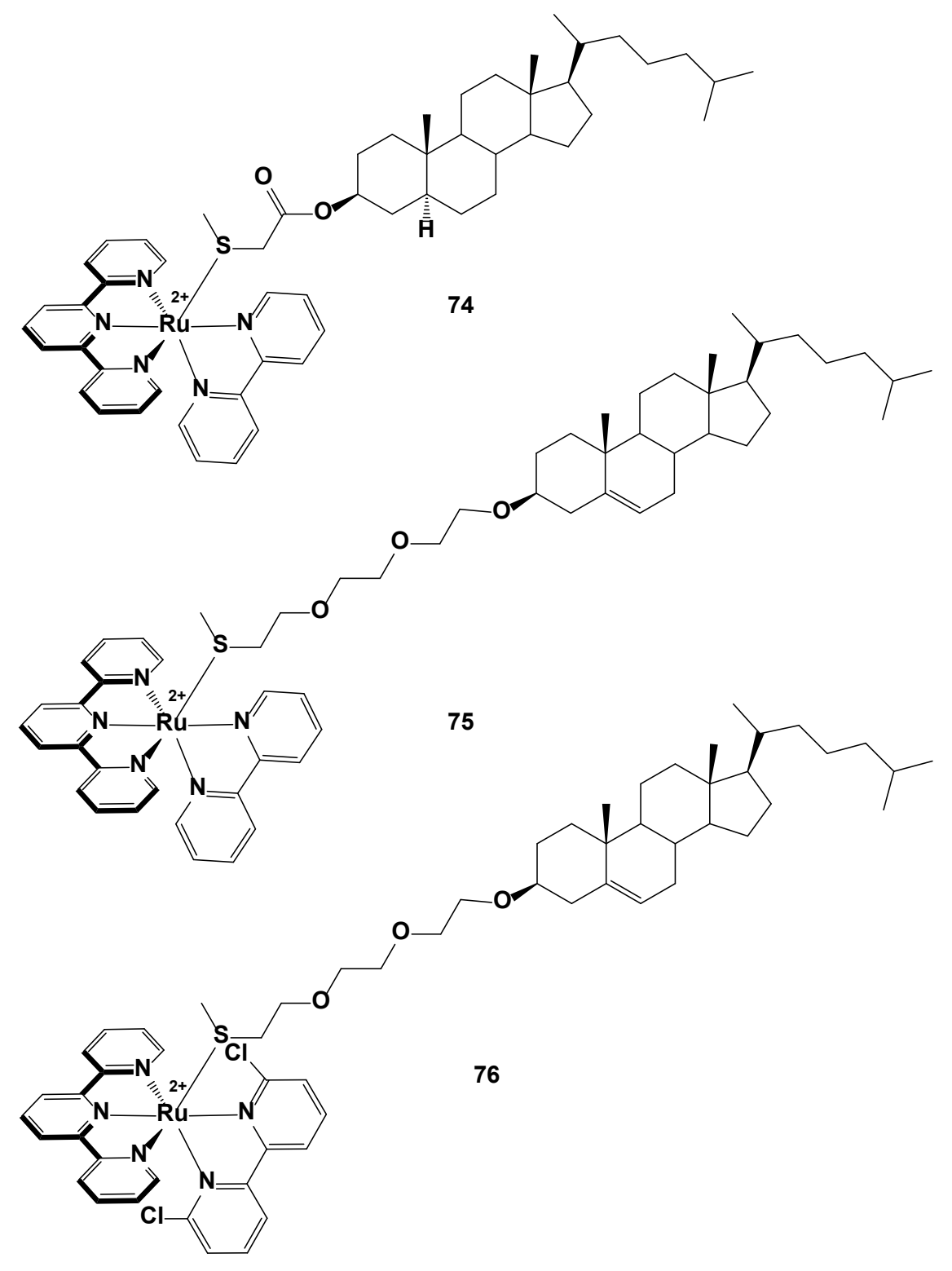

Fig. 44. Structures of the cholestanol 74 and cholesterol bioconjugates $\mathbf{7 5}$ and $\mathbf{7 6 .}$

The cholestanol conjugate 74 (Fig. 44)[122] was prepared as a first attempt to mimic the behaviour of $\mathrm{Ru}(\mathrm{II})$ polypyridyl complexes in the lipid bilayer since $5 \alpha$-3 $\beta$-cholestanol is a membrane intercalator. For that purpose, the researchers incorporated the Ru-containing conjugates to lipid vesicles to facilitate the solubility in water and to gain understanding of the behaviour of this kind of complexes in the water-membrane interface. These vesicles (140 $180 \mathrm{~nm}$ ) were successfully prepared with two lipids (dimyristoylphosphatidylglycerol DMPG, anionic and dimyristoylphosphatidylcholine DMPC, neutral). They found out that the complex interacted both electrostatically and through insertion of the cholestanol in the membrane when 
using negatively charged lipids. After light irradiation and cleavage of the Ru-S bond, the remaining aqua complex was still interacting with the membrane with electrostatic interactions. When neutral lipids were used, only the lipophilic tail were inserted in the membrane and, after light irradiation, the aqua derivative formed diffused away.

The Ru-cholesterol conjugate 75 (Fig. 44)[123] was found to be a potent cytotoxic agent in the dark in various cell lines $\left(\mathrm{EC}_{50}=5.0-6.5 \mu \mathrm{M}\right)$, whereas neither the free cholesterol nor the aqua complex showed any toxicity. Also, the cellular uptake was higher for $\mathbf{7 5}$ than for the aqua complex. The authors found out that there were two different modes of action for the drug. Concentrations above $3.5 \mu \mathrm{M}$ led to the formation of aggregates, which were able to form holes in the cell membrane and extract lipids and proteins from it. This caused the permeabilization of the cell membrane, like a detergent, taking the cell into necrosis. At lower concentrations, the conjugate behaved as a monomer and the lipophilic/fatty tail inserted in the cell membrane. Since the internalization is a slow process, after short incubation times ( 1 to $6 \mathrm{~h})$, light $(\lambda=455$ $\mathrm{nm}, 10 \mathrm{~min}, 6.3 \mathrm{~J} \cdot \mathrm{cm}^{-2}$ ) triggers the release of the aqua derivative outside the cell, without affecting it. However, for longer incubation times $(24 \mathrm{~h})$, light induces the release of the aqua complex inside the cell, leading to high toxicity. In both cases, the similar mechanisms of action involve PACT principles.

The same authors prepared complex 76 (Fig. 44) and a derivative with 2-(methylthio)ethanol (Hmte) as the S-coordinating ligand, to try to better understand the behaviour of this kind of complexes in a lipid bilayer. When the bpy ligand was replaced by a sterically hindered dcbpy (6,6'-dichloro-2,2'-bipyridine), the corresponding aqua complex and the S-containing complexes were found to be in equilibrium at room temperature in the dark. However, the use of light shifted the equilibrium towards the aqua species. When light was switched off, the initial equilibrium was spontaneously recovered. This process is not thermally dependent and allows a direct control of the complexes over the lipid bilayer.[124] Kinetic studies of the same complex allowed determining a two-step mechanism for the thermal binding of the aqua 
complex to the thioether-cholesterol ligand in a negatively charged lipid bilayer, forming $\mathbf{7 6}$. The first step is the adsorption of the metal complex, which is driven by entropy and completed in a few minutes. The second is coordination of the metal complex to the S-ligand, probably electrostatically. This could take hours.[125]

\subsection{Vitamins}

Vitamins are small molecules essential for any organism. They can be classified as hydrophilic (B and C) and lipophilic (A, D, E and K). The water-soluble vitamins are easily taken up and excreted. Therefore, the conjugation with these vitamins can improve the water solubility of metal complexes and their subsequent cellular internalization. This is the reason why some ruthenium polypyridyl complexes have been functionalized with B vitamins.

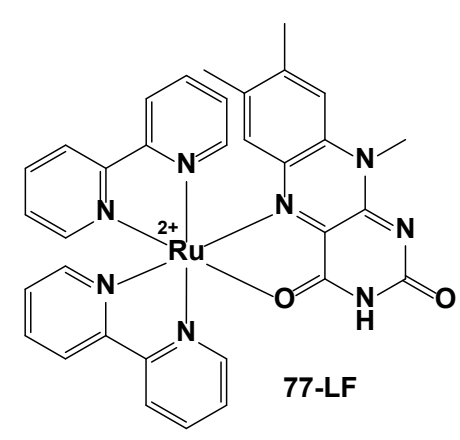

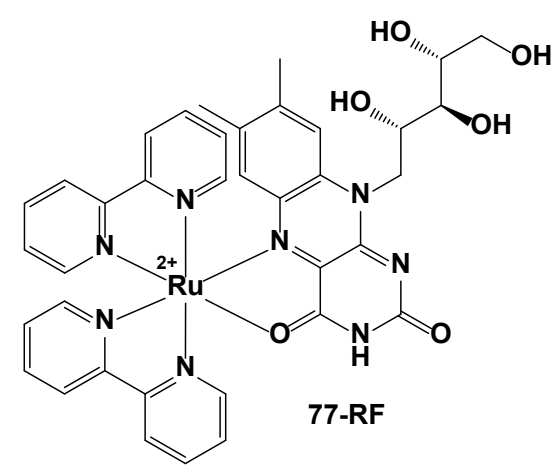

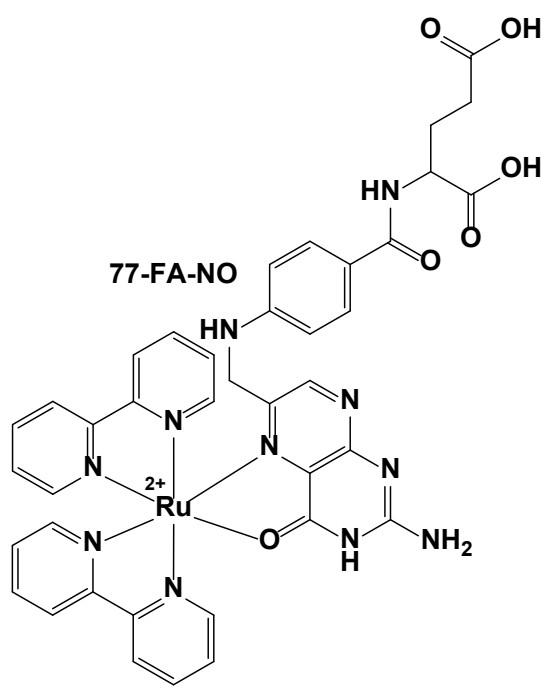

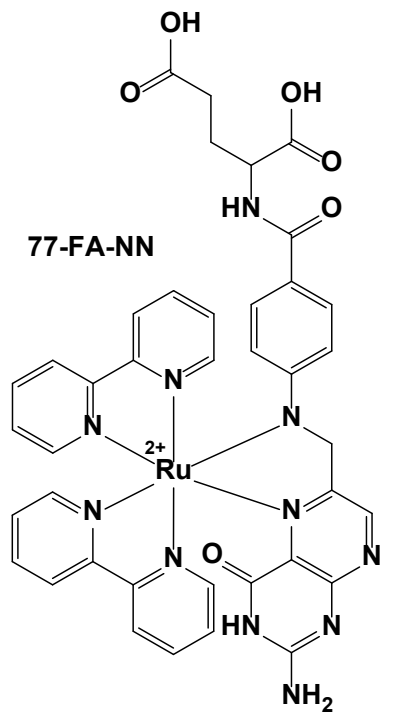

Fig. 45. Structures of the flavin conjugates 77-LF and 77-RF, and the pterin derivatives 77-FA-NO and 77-FA$\mathbf{N N}$, where $\mathrm{LF}=$ lumiflavin, $\mathrm{RF}=$ riboflavin and $\mathrm{FA}=$ Folic acid. $\mathrm{NO}$ and $\mathrm{NN}$ stand for the atom coordination. 
Schwederski and Kaim reported one of the first syntheses of Ru(II) polypyridyl complexes attached to two flavins, namely lumiflavin (LF, 77-LF) and riboflavin (RF, vitamin $\left.\mathrm{B}_{2}, 77-\mathrm{RF}\right)$, and a pterin derivative, folic acid (FA, vitamin $\mathrm{B}_{9}, \mathbf{7 7 - F A - N O}$ and 77-FA-NN), shown in Fig. 45.[126] Both scaffolds have the same characteristics: i) a reducible $\pi$ system, ii) a $\pi$ electron deficient $\alpha$-iminocarbonyl chelation site $(\mathrm{O}=\mathrm{C}-\mathrm{C}=\mathrm{N})$ and iii) an acidic $\mathrm{NH}$ proton from the pyrimidine ring. For the flavins, the coordination to the ruthenium centre is through the fivemembered chelate ring involving $\mathrm{N}^{\wedge} \mathrm{O}$. For the pterin, there are two possibilities: the fivemembered $\mathrm{N}^{\wedge} \mathrm{O}$ chelate ring (77-FA-NO) or the five-membered chelate ring involving the $\mathrm{NH}$ of the side chain $\left(\mathrm{N}^{\wedge} \mathrm{N}, 77-\mathrm{FA}-\mathrm{NN}\right)$. Cyclic voltammetry experiments $(0.1 \mathrm{M}$ perchloric acid or $0.1 \mathrm{M} \mathrm{NaOH}$ ) showed one reversible reduction wave for the flavin derivatives $\mathbf{7 7 - \mathbf { L F }}$ and 77-RF. However, the folic acid derivative did not exhibit any reduction peak, but two oxidation waves related to the irreversible oxidation of the aromatic amine and to the $\mathrm{Ru}(\mathrm{II} / \mathrm{III})$ redox centre. This is because the pterin ring is slightly more electron rich than the flavin rings. All complexes showed interesting MLCT bands in the absorption spectra, which were $\mathrm{pH}$ dependent. Thus, the free ligands had $\mathrm{pKa} \approx 9$ for the $\mathrm{NH}$ of the pyrimidine ring, but after coordination to the metal centre, the acidity of that $\mathrm{NH}$ was higher $(\mathrm{pKa}=4.3-5.4)$. In addition, the absorption spectrum of 77-FA was the same as the one of a similar complex, namely $\left[\mathrm{Ru}(\mathrm{bpy})_{2}(1,3 \text {-dimethyllumazine })\right]^{2+}$, bearing the same chromophore and $\mathrm{N}^{\wedge} \mathrm{O}$ coordination. Some years later, Scrase et al. demonstrated the coordination of the folate to the ruthenium core through the $\mathrm{N}^{\wedge} \mathrm{N}$ (77-FA right).[127] The authors explored the synthesis of 77-FA at physiological conditions $\left(37^{\circ} \mathrm{C}\right)$ and also at higher temperatures $\left(65^{\circ} \mathrm{C}\right)$. In both cases, the NMR characterization revealed two set of signals, corresponding to the diastereomers $(\Lambda S / \Delta R: \Lambda R / \Delta S)$. The peaks corresponding to the methylene group directly attached to the pterin moiety were crucial to determine the coordination mode of FA, since the protons displayed loss of degeneracy (compared to the free FA), suggesting direct coordination of the non-aromatic amine. Some more evidences of the coordination mode were reported with $\mathrm{pH}$ changes. At $\mathrm{pH}$ 
6 and 9.9, the same products were obtained, while at $\mathrm{pH} 2.5$, the protonation of the $\mathrm{NH}$ avoided the coordination of the FA.

Since the content of FA in cells is low, the sequestration of this molecule by an excess of ruthenium complexes could lead to an alteration of the balance of this cofactor.

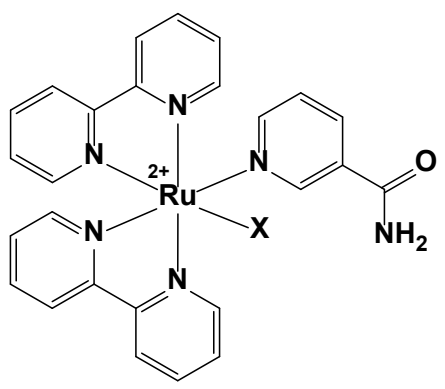<smiles>NC(=O)c1ccc(I)nc1</smiles>

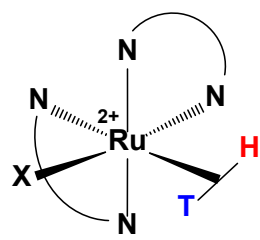

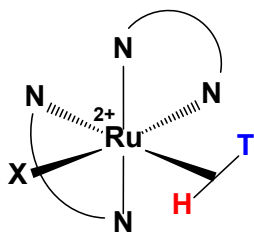

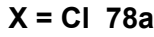

Conf.1 Conf.2

$X=I \quad 78 b$<smiles>[X]#[W]</smiles>

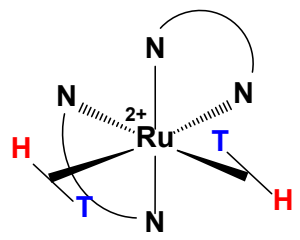

A

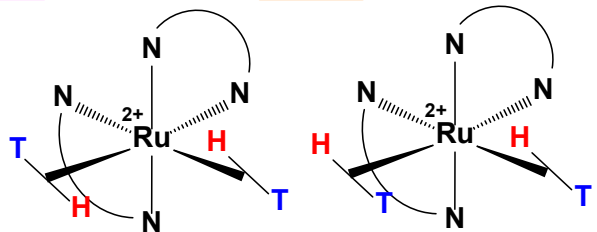

C

Fig. 46. Structures of the nicotinamide conjugates complexes $\mathbf{7 8 a}, \mathbf{7 8 b}$ and $\mathbf{7 8 c}(\mathrm{left})$. Structure and nomenclature of the atropisomers of $\mathbf{7 8 a}$ and $\mathbf{7 8 b}$ (Conf. 1 and Conf. 2) detected at $185 \mathrm{~K}$. The nomenclature to describe the atropisomers of 78c (A, B and C) detected at $185 \mathrm{~K}$ (right). $\mathrm{H}$ is defined as the head group and $\mathrm{T}$ as the tail. Adapted from reference [128] C) 2016 The Authors. Published by Elsevier B.V.

Sadler and co-workers reported the synthesis and dynamic behaviour of nicotinamide (NA, vitamin $\mathrm{B}_{3}$ ) conjugates 78a, 78b and 78c (Fig. 46 left).[128] NMR experiments performed, first at room temperature $(298 \mathrm{~K})$, then at $323 \mathrm{~K}$ and finally at $185 \mathrm{~K}$, showed hindered rotation of the NA for $\mathbf{7 8 a}$ and $\mathbf{7 8 b}$, leading to the formation of two atropisomers, Conf. 1 and Conf. 2, with Conf. 1 as the most stable in solution (see Fig. 46 right). These findings indicated that the halide ligand (-Cl or -I) was interacting with the protons of the pyridyl group (H9 and H10) through hydrogen bonding and thus, hindering rotation. 78c, however, showed a normal behaviour at room temperature, whereas, at $185 \mathrm{~K}$, three atropisomers were detected, A, B and 
$\mathrm{C}$, with $\mathrm{C}$ as the most stable one and $\mathrm{B}$ the least. In this case, the cooling slowed down the rotation of the NA, making the atropisomers visible. DFT studies supported the experimental results, confirming atropisomer Conf. 1 as the most stable, since $-\mathrm{Cl}$ has a higher $\mathrm{H}$-bonding acceptor ability than -I. Due to these properties, these complexes could be interesting as photoactivated drugs to deliver nicotinamide as an antibacterial agent.

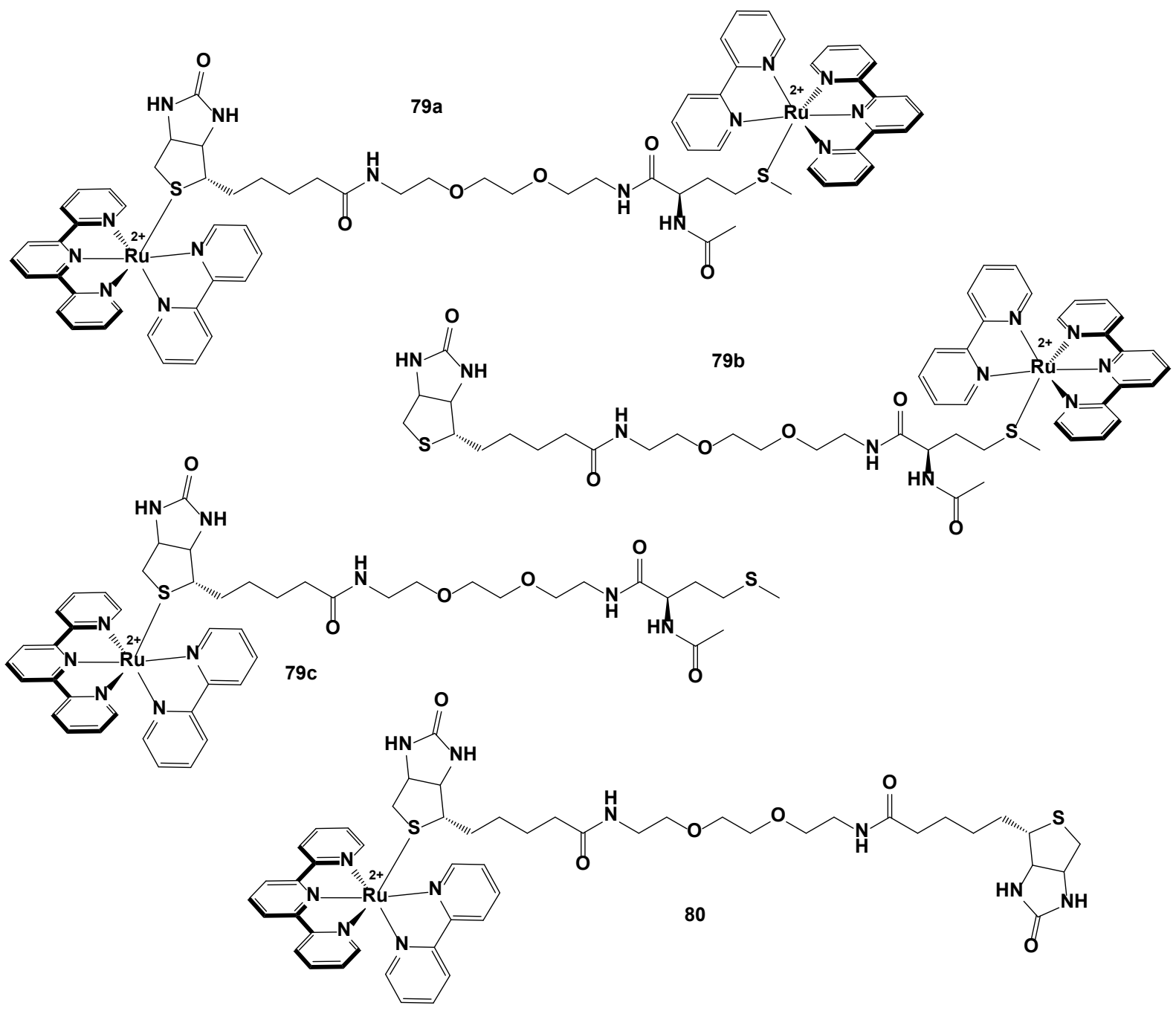

Fig. 47. Structures of Ru-biotin derivatives 79a-c and $\mathbf{8 0 .}$

Biotin (vitamin $\mathrm{B}_{7}$ or vitamin $\mathrm{H}$ ) in $\mathrm{Ru}(\mathrm{II})$ polypyridyl bioconjugates was extensively used. Bonnet and co-workers prepared some biotin conjugates (79a-c and 80, Fig. 47), following the same strategy used for previous bioconjugates of the type $[\mathrm{Ru}(\mathrm{tpy})(\mathrm{bpy})(\mathrm{S}-\mathrm{biomolecule})]^{2+}$ (see sections 1.3.1. O-glycosidic bonds and 1.4.2. Steroids).[129] As previously shown, this kind of complexes is well-known as photocleavable molecules. The synthesis of the chloride derivative 
$[\mathrm{Ru}(\mathrm{tpy})(\mathrm{bpy}) \mathrm{Cl}]^{+}$with the biotin precursor yielded complex 79a $(9 \%)$ and a mixture of complexes 79b and 79c $(83: 17)$. When the synthetic conditions were modified and the ligand$\mathrm{Ru}$ ratio increased, the formation of 79a was supressed. Moreover, changes in temperature and reaction times yielded an enrichment of $79 b$ vs $79 c$, suggesting $79 b$ as the thermodynamically stable isomer. Since regioselectivity was not achieved, the separation of both isomers by avidinaffinity column chromatography was performed. Avidin is known to strongly interact with biotin $\left(\mathrm{K}_{\mathrm{a}}=10^{13}\right.$ to $\left.10^{15} \mathrm{M}^{-1}\right)$ [130], forming the avidin-biotin complex (ABC). After $24 \mathrm{~h}$ incubation of the $79 \mathbf{b} / 79 \mathrm{c}$ mixture with an avidin column, the unbound complex mixture was washed off the column with PBS. Finally, a biotin-loaded PBS solution was used to displace the avidin-bound biotin moiety in $\mathbf{7 9 b}$ with native biotin. Thus, $79 \mathrm{~b}$ was obtained as a pure complex. Surprisingly, bioconjugate $\mathbf{8 0}$ was shown to uniquely coordinate to one biotin moiety. The photochemical behaviour of this complex was studied, tracking absorption changes under light irradiation $(\lambda=465 \mathrm{~nm})$ in PBS for $4 \mathrm{~h}$ at $298 \mathrm{~K}$. After $80 \mathrm{~min}$, a plateau was reached, leading to a photosubstitution constant of $k_{\Phi}=7.1 \times 10^{-4} \mathrm{~s}^{-1}$. A photosubstitution quantum yield of 0.011 was also determined. Furthermore, the bioconjugate $\mathbf{8 0}$ was found to bind streptavidin as strongly as biotin, suggesting that it could be a good candidate for the ABC-based strategy.
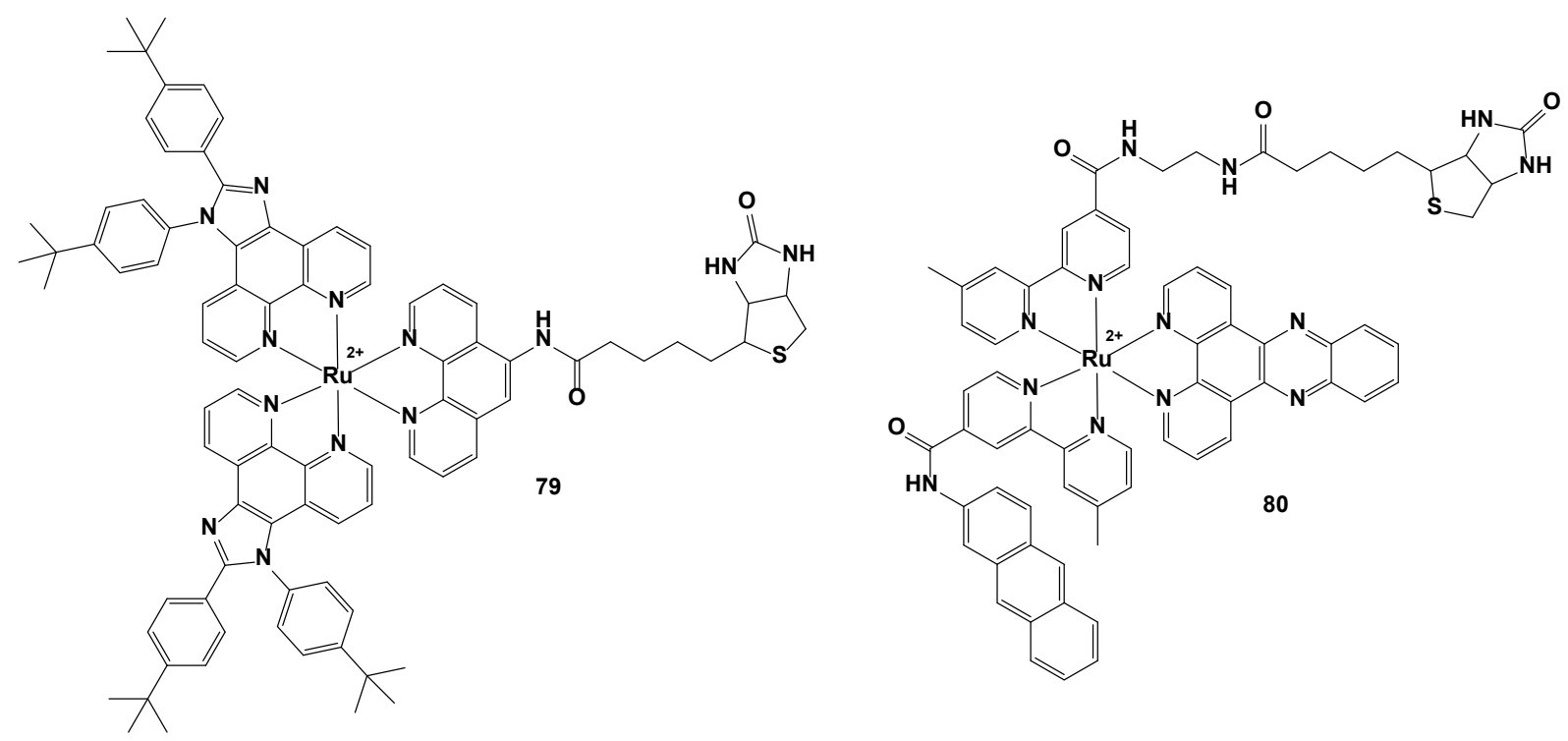

Fig. 48. Structures of biotin conjugates $\mathbf{8 1}$ and $\mathbf{8 2}$. 
Another Ru-biotin conjugate $\mathbf{8 1}$ was prepared by Li et al. as a two-photon (TP)-PDT photosensitizer (Fig. 48).[8] The maximum TPA cross-section at $820 \mathrm{~nm}$ was $140.26 \mathrm{GM}$, much higher than that for the clinical PS tetraphenylporphyrin ( $\left.\mathrm{H}_{2} \mathrm{TPP}, 2.2 \mathrm{GM}\right)$ and the singlet oxygen quantum yield was 0.87 after irradiation at $450 \mathrm{~nm}$. These features make 81 a good PS for TP-PDT. This biotin conjugate showed lipophilicity $\left(\log P_{0 / \mathrm{w}}=1.77\right)$ favouring, a priori, the uptake in cells. The uptake was evaluated in biotin receptor (BR) positive A549R cells and BR negative HLF-a cells (primary human lung fibroblasts). Complex $\mathbf{8 1}$ was found to accumulate more in cancerous cells than healthy cells (13.9-fold accumulation in A549R than in HLF-a cells). A competitive uptake assay with biotin pre-treated cells showed that the uptake of BR positive A549R cells is mediated by BRs. Photocytotoxicity was assessed in BR positive HeLa, A549 and A549R cells lines and BR negative HLF-a cells under $820 \mathrm{~nm}$ (two-photon) and $450 \mathrm{~nm}$ (one-photon). While the complex was found to be non-toxic in the dark, after TP irradiation $(820 \mathrm{~nm})$, the toxicity increased in all the cell lines studied in this work, with the best results for $\mathrm{A} 549 \mathrm{R}$ cells $\left(\mathrm{IC}_{50}=3.3 \mu \mathrm{M}\right)$. The phototoxicity upon one-photon irradiation (450 nm) was similar to the TP irradiation. 3D multicellular spheroids (MCTSs) were used to assess the behaviour of $\mathbf{8 1}$ under TP-PDT. Stronger phosphorescence was observed for $\mathbf{8 1}$ in MTCSs of A459R cells than in MTCSs based on HLF-a cells, highlighting again the selectivity towards cancerous cells. To check whether apoptosis was the mechanism of cell death, the activity of caspase-3/7 was evaluated in the dark and upon irradiation. In the dark, caspase activity remained intact, whereas, after light irradiation, caspase activity increased more than 3 times. All these results suggest that singlet oxygen or ROS generation upon light irradiation leads to apoptosis.

Very recently, Oliveira et al. synthesised a Ru(II) complex with an anthracene pendant $\mathbf{8 2}$ as PS for PDT (Fig. 48). This complex has three different ligands, a bpy-biotin modified ligand, a dppz ligand and an anthracene-pendant bpy ligand. The singlet oxygen quantum yield $\left(\Phi_{\Delta}\right)$ was 
determined with three different irradiation wavelengths. The highest efficiency for singlet oxygen production was achieved upon blue light irradiation ( $\left.463 \mathrm{~nm}, \Phi_{\Delta}=0.75\right)$, although to a lesser extent, green light $\left(520 \mathrm{~nm}, \Phi_{\Delta}=0.51\right)$ and red light also produce ${ }^{1} \mathrm{O}_{2}\left(631 \mathrm{~nm}, \Phi_{\Delta}=\right.$ 0.19). DNA binding constants, determined by absorption and emission, showed similar values as those obtained for typical DNA intercalators $\left(\mathrm{K}_{\mathrm{a}}=6.28 \times 10^{6} \mathrm{M}^{-1}\right.$ and $5.8 \times 10^{6} \mathrm{M}^{-1}$, respectively). Thus, the insertion of the biotin moiety did not significantly change the ability of the complex towards DNA binding. Complex 82 was able to photocleave DNA using both blue and green light. However, red light did not cause any cleavage. The biotin conjugate showed lipophilicity $\left(\log P_{0 / \mathrm{w}}=1.32\right)$, possibly favouring cellular uptake. Biological tests were assayed in bacteria and cells. Regarding bacteria, 82 was only active against $S$. aureus upon blue light irradiation $(\mathrm{MIC}=14 \mu \mathrm{M})$. Nevertheless, better results were obtained when these compounds were tested as anticancer agents. The cytotoxic activity was evaluated in HaCaT (normal keratinocyte), LS174T (colorectal cancer cells), A549 (lung carcinoma cells) and MCF-7 (breast cancer cells). Whereas the parent complex without biotin did not show any effect, the biotinylated compound 82 caused substantial reduction of cell viability: around $40 \%$ cell viability for A549 at $12.5 \mu \mathrm{g} \mathrm{mL}^{-1}$ and ca. $50 \%$ for MCF-7 cells at the same concentration. These results are in line with the fact that both cell lines have highly overexpressed BRs. For the other cell lines, neither toxicity or phototoxicity was observed. Like $\mathbf{8 1}$ and as expected for a biotin conjugate, compound $\mathbf{8 2}$ also showed avidin affinity. 

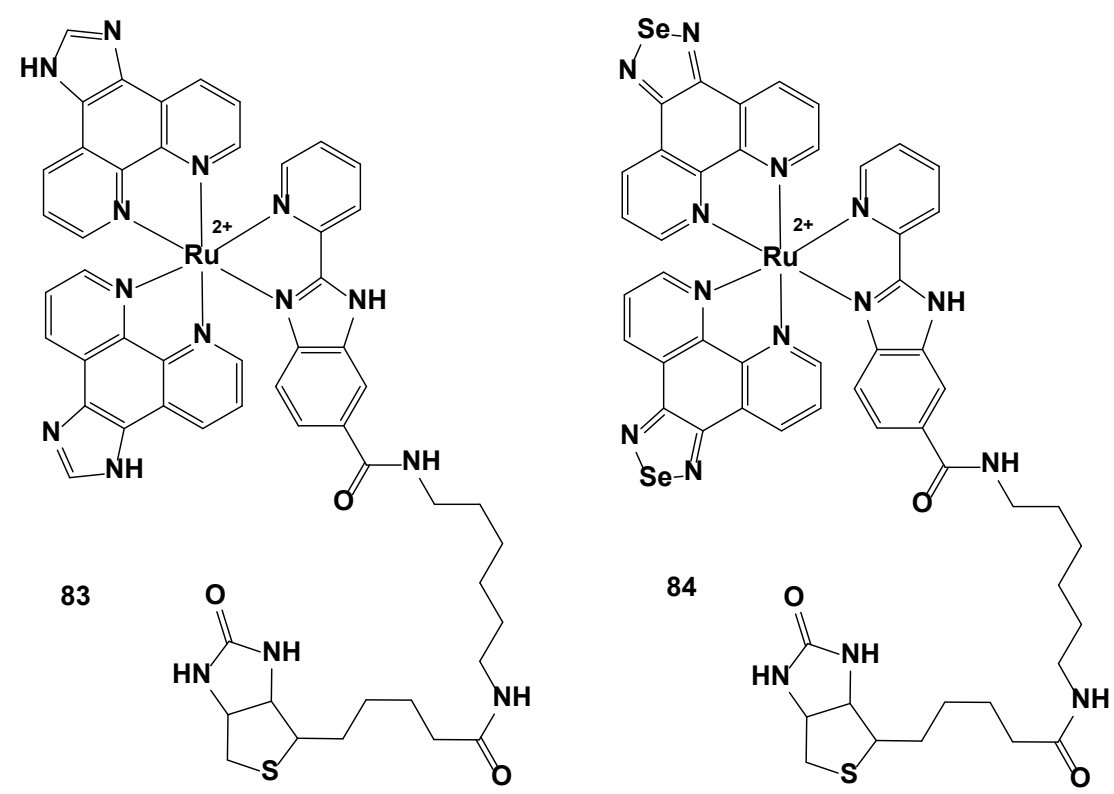

Fig. 49. Structures of bioconjugates 83 and 84 .

Chen and co-workers reported ruthenium biotin conjugates 83 and 84 (Fig. 49) based on the derivatization from the benzimidazole ligand.[131] In addition, the authors introduced selenium in the structure of the complex with the aim of increasing their anticancer activity, as they previously showed[132] that selenium activates ROS production in ER and improves the selectivity between cancer cells and non-cancerous cells. Under hypoxic conditions (acidic, $\mathrm{pH}$ 6.86), complex 84 was able to release the pyridylbenzimidazole-biotin ligand, generating the complex $\left[\mathrm{Ru}(\mathrm{phenSe})_{2}\left(\mathrm{H}_{2} \mathrm{O}\right)_{2}\right]$, which can be considered as the therapeutic drug. Biological assays were performed in biotin receptor-positive HeLa cells and receptor-negative L02 cells. The bioconjugate 84 was preferentially taken up by HeLa than L02 in a co-cultured model. The number of apoptotic cells in HeLa increased to $20.8 \%$ after drug incubation with 84, whereas in L02, the increment was only $2.1 \%$. In vivo experiments in mice inoculated with HeLa revealed accumulation of the Se-bioconjugate selectively in the tumour than in other organs. In cancer cells, 84 enters the cell after $6 \mathrm{~h}$, mostly accumulating in mitochondria (Pearson's coefficient 0.9). Thus, the disruption of the mitochondrial membrane potential (MtMP) was tested. 84 induced dose-dependent disruption, whereas 83 only showed a slight variation. High intracellular levels of ROS were detected for $\mathbf{8 4}$ after 4 h, whereas $\mathbf{8 3}$ generated much lower amounts of ROS. The accumulation of ROS triggers ER stress, and the release of calcium in 
ER is an indicator of this stress. The calcium levels in cytoplasm after 30 min of incubation with the complexes, showed higher levels for $\mathbf{8 4}$ than for $\mathbf{8 3}$. All these fact supports the ROSmediated ER stress signal pathway. Finally, in vivo antitumour activity was evaluated in mice. The tumour inhibition rate after 30 days treatment with 84 was $64.2 \%$ and no body weight change or death was observed. In addition, the complex was found to reduce side effects on liver, lung and kidney and to return blood parameters to normal levels after treatment.
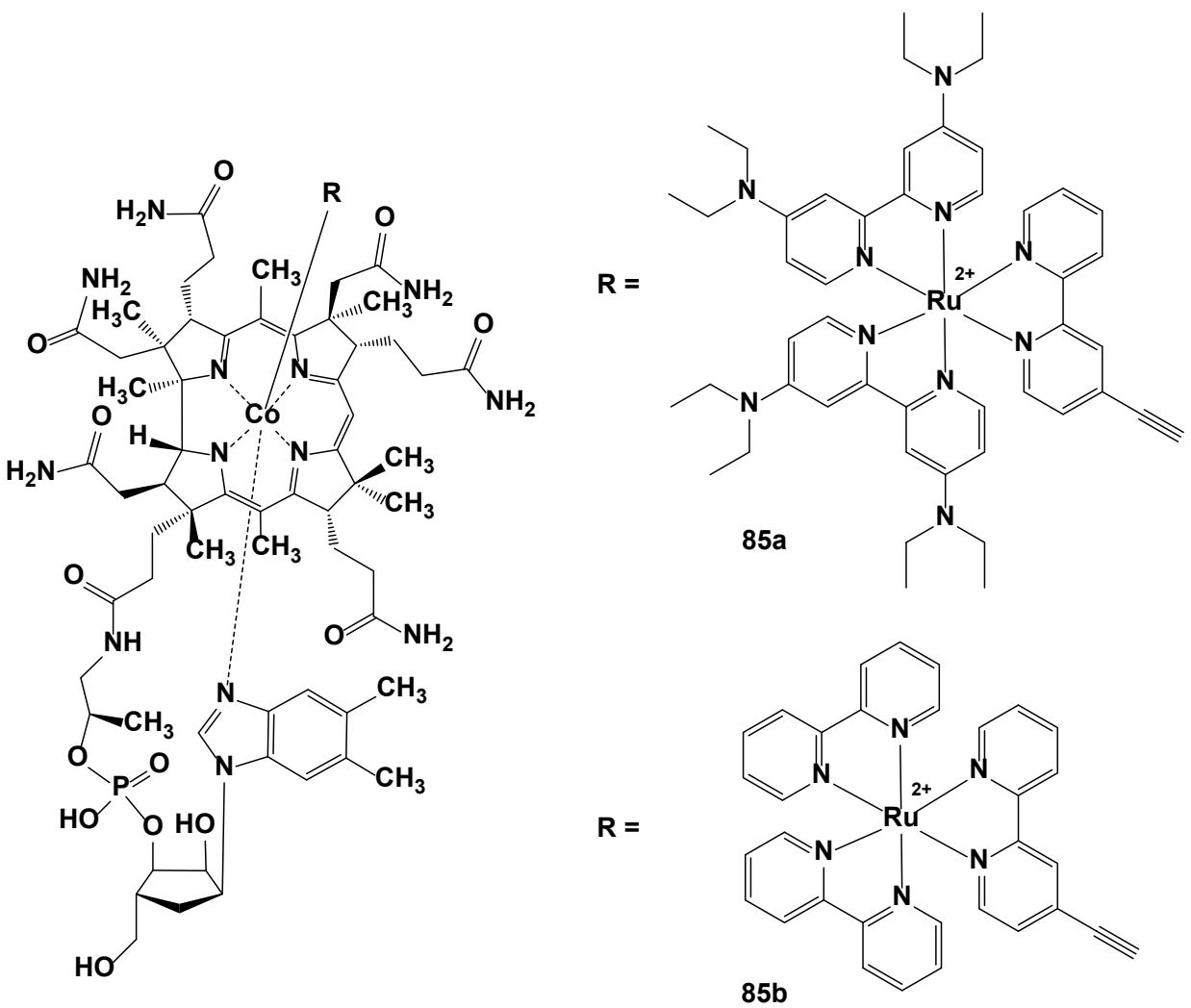

Fig. 50. Structures of cobalamin conjugates $\mathbf{8 5 a}$ and $\mathbf{8 5 b}$.

Very recently, our group, in collaboration with the one of Zobi, reported the first Ru-cobalamine (vitamin $\mathrm{B}_{12}$ ) conjugates, 85a and $\mathbf{8 5 b}$ (Fig. 50), modified in the $\beta$-position, through an alkyne group.[133] The non-conjugated ruthenium complexes were poorly singlet oxygen producers. The biological activity of both the conjugated and non-conjugated complexes in HeLa (cervical cancer cells) and RPE-1 (non-cancerous retina pigmented epithelium cells) revealed surprising results. None of the bioconjugates $\mathbf{8 5 a}$ and $\mathbf{8 5 b}$ were cytotoxic in the dark or after light 
irradiation. Only the non-conjugated $\mathrm{Ru}(\mathrm{II})$ complex modified with the amino groups showed cytotoxicity in the dark ( $\mathrm{IC}_{50}=9.33$ and $6.08 \mu \mathrm{M}$ in HeLa and RPE-1, respectively). This toxicity was similar after light irradiation. The cellular uptake experiments by CLSM showed weak emission in HeLa cells, avoiding localization to be determined. As a result, the coupling of cobalamin did not improve the toxicity, probably due to the bulkiness of the conjugate, preventing it to get delivered to cells. 


\section{Conclusions}

This review highlights the advantages of the conjugation of ruthenium polypyridyl complexes to biomolecules in view of drug delivery and directed targeting. It is remarkable to note that the use of biomolecules is not limited to biology-related applications but also extended to photoinduced electron/energy transfer processes and asymmetric synthesis. This review also focused on the different manners of linking the biomolecules and the ruthenium complexes, which has a direct impact in their behaviours, especially in terms of stability of the resulting bioconjugates. The attachment through a covalent bond between the ruthenium polypyridyl complexes and (small) biomolecules mostly improves (with some exceptions) water solubility, cellular uptake, phototoxicity or binding affinity, without altering the excellent photophysical properties of the metal complexes. The biomolecules are generally linked to ruthenium through the second coordination sphere of ligands (e.g. with a spacer) and rarely directly attached to the ruthenium core in the first coordination sphere. Only some amino acids and vitamins have the correct structure design and available atoms to directly coordinate to ruthenium.

This strategy of bioconjugation has helped to the exponential growth of the ruthenium polypyridyl complexes and allowed to gain understanding in the behaviour of the complexes in biology-related topics. We strongly believe that much more research dedicated to the use of ruthenium polypyridyl complex-containing bioconjugates will be published over the next years, hopefully demonstrating better or even completely new applications, especially in the field of medicinal/biological chemistry. We are convinced that much more in vivo experiments will need to be undertaken to fully unveil the potential of such bioconjugates since the number of articles reporting mice experiments is disappointingly scarce. Regarding the risks associated with the use of such bioconjugates for therapeutic purposes, we believe that it will actually increase the chance of success since the biomolecule should enable lowering the potential toxicity of the metal-based drug. 


\section{Declaration of Competing Interest}

The authors declare no competing financial interests.

\section{Acknowledgements}

This work was financially supported by an ERC Consolidator Grant PhotoMedMet to G.G. (GA 681679) and has received support under the program Investissements d'Avenir launched by the French Government and implemented by the ANR with the reference ANR-10-IDEX-0001-02

PSL (G.G.). M.M. acknowledges the European Commission for the H2020-MSCA-IF-2018 (839499 - OrganometRuPDT) grant. 


\section{References}

[1] D.M. Arias-rotondo, J.K. Mccusker, The photophysics of photoredox catalysis: a roadmap for catalyst design, Chem. Soc. Rev. 45 (2016) 5803-5820. https://doi.org/10.1039/C6CS00526H.

[2] F. Zeng, Z. Yu, Exceptionally Efficient Unsymmetrical Ruthenium(II) NNN Complex Catalysts Bearing a Pyridyl-Based Pyrazolyl-Imidazolyl Ligand for Transfer Hydrogenation of Ketones, Organometallics. 27 (2008) 2898-2901. https://doi.org/10.1021/om8002043.

[3] M.D. Kärkäs, R.-Z. Liao, T.M. Laine, T. Åkermark, S. Ghanem, P.E.M. Siegbahn, B. Åkermark, Molecular ruthenium water oxidation catalysts carrying non-innocent ligands: mechanistic insight through structure-activity relationships and quantum chemical calculations, Catal. Sci. Technol. 6 (2016) 1306-1319. https://doi.org/10.1039/C5CY01704A.

[4] B.A. Johnson, S. Maji, H. Agarwala, T.A. White, E. Mijangos, S. Ott, Activating a Low Overpotential CO2 Reduction Mechanism by a Strategic Ligand Modification on a Ruthenium Polypyridyl Catalyst, Angew. Chemie - Int. Ed. 55 (2016) 1825-1829. https://doi.org/10.1002/anie.201508490.

[5] S. Aghazada, M. Nazeeruddin, Ruthenium Complexes as Sensitizers in Dye-Sensitized Solar Cells, Inorganics. 6 (2018) 52. https://doi.org/10.3390/inorganics6020052.

[6] A. Adeloye, P. Ajibade, Towards the Development of Functionalized PolypyridineLigands for Ru(II) Complexes as Photosensitizers inDye-Sensitized Solar Cells (DSSCs), Molecules. 19 (2014) 12421-12460. https://doi.org/10.3390/molecules 190812421.

[7] P.G. Bomben, K.C.D. Robson, B.D. Koivisto, C.P. Berlinguette, Cyclometalated ruthenium chromophores for the dye-sensitized solar cell, Coord. Chem. Rev. 256 (2012) 1438-1450. https://doi.org/10.1016/j.ccr.2012.02.005. 
[8] J. Li, L. Zeng, K. Xiong, T.W. Rees, C. Jin, W. Wu, Y. Chen, L. Ji, H. Chao, A biotinylated ruthenium(II) photosensitizer for tumor-targeted two-photon photodynamic therapy, Chem. Commun. 55 (2019) 10972-10975. https://doi.org/10.1039/C9CC05826E.

[9] K. Wiederholt, L.W. McLaughlin, A 2,2"-bipyridine ligand for incorporation into oligodeoxynucleotides: synthesis, stability and fluorescence properties of rutheniumDNA complexes, Nucleic Acids Res. 27 (1999) 2487-2493. https://doi.org/10.1093/nar/27.12.2487.

[10] B. Nemati Bideh, H. Shahroosvand, Efficient near infrared light emitting electrochemical cell (NIR-LEEC) based on new binuclear ruthenium phenanthroimidazole exhibiting desired charge carrier dynamics, Sci. Rep. 7 (2017) 17. https://doi.org/10.1038/s41598-017-16133-7.

[11] X. Gong, P.K. Ng, W.K. Chan, Trifunctional Light-Emitting Molecules Based on Rhenium and Ruthenium Bipyridine Complexes, Adv. Mater. 10 (1998) 1337-1340. https://doi.org/10.1002/(SICI)1521-4095(199811)10:16<1337::AIDADMA1337>3.0.CO;2-D.

[12] J. Liu, C. Zhang, T.W. Rees, L. Ke, L. Ji, H. Chao, Harnessing ruthenium(II) as photodynamic agents: Encouraging advances in cancer therapy, Coord. Chem. Rev. 363 (2018) 17-28. https://doi.org/10.1016/j.ccr.2018.03.002.

[13] A. Levina, A. Mitra, P. a Lay, Recent developments in ruthenium anticancer drugs, Metallomics. 1 (2009) 458-470. https://doi.org/10.1039/b904071d.

[14] L. Zeng, P. Gupta, Y. Chen, E. Wang, L. Ji, H. Chao, Z.-S. Chen, The development of anticancer ruthenium(II) complexes: from single molecule compounds to nanomaterials, Chem. Soc. Rev. 46 (2017) 5771-5804. https://doi.org/10.1039/C7CS00195A.

[15] U. Schatzschneider, J. Niesel, I. Ott, R. Gust, H. Alborzinia, S. Wölfl, Cellular Uptake, 
Cytotoxicity, and Metabolic Profiling of Human Cancer Cells Treated with Ruthenium(II) Polypyridyl Complexes [Ru(bpy)2(N-N)]Cl 2 with N-N=bpy, phen, dpq, dppz, and dppn, ChemMedChem. 3 (2008) 1104-1109. https://doi.org/10.1002/cmdc.200800039.

[16] A. Notaro, G. Gasser, Monomeric and dimeric coordinatively saturated and substitutionally inert $\mathrm{Ru}(\mathrm{II})$ polypyridyl complexes as anticancer drug candidates, Chem. Soc. Rev. 46 (2017) 7317-7337. https://doi.org/10.1039/C7CS00356K.

[17] C. Mari, V. Pierroz, S. Ferrari, G. Gasser, Combination of Ru(II) complexes and light: new frontiers in cancer therapy, Chem. Sci. 6 (2015) 2660-2686. https://doi.org/10.1039/C4SC03759F.

[18] H. Huang, B. Yu, P. Zhang, J. Huang, Y. Chen, G. Gasser, L. Ji, H. Chao, Highly Charged Ruthenium(II) Polypyridyl Complexes as Lysosome-Localized Photosensitizers for Two-Photon Photodynamic Therapy, Angew. Chemie Int. Ed. 54 (2015) 14049-14052. https://doi.org/10.1002/anie.201507800.

[19] J. Hess, H. Huang, A. Kaiser, V. Pierroz, O. Blacque, H. Chao, G. Gasser, Evaluation of the Medicinal Potential of Two Ruthenium(II) Polypyridine Complexes as One- and Two-Photon Photodynamic Therapy Photosensitizers, Chem. - A Eur. J. 23 (2017) 9888-9896. https://doi.org/10.1002/chem.201701392.

[20] F. Heinemann, J. Karges, G. Gasser, Critical Overview of the Use of Ru(II) Polypyridyl Complexes as Photosensitizers in One-Photon and Two-Photon Photodynamic Therapy, Acc. Chem. Res. 50 (2017) 2727-2736. https://doi.org/10.1021/acs.accounts.7b00180.

[21] S. Monro, K.L. Colón, H. Yin, J. Roque, P. Konda, S. Gujar, R.P. Thummel, L. Lilge, C.G. Cameron, S.A. McFarland, Transition Metal Complexes and Photodynamic Therapy from a Tumor-Centered Approach: Challenges, Opportunities, and Highlights from the Development of TLD1433, Chem. Rev. 119 (2019) 797-828. 
https://doi.org/10.1021/acs.chemrev.8b00211.

[22] F.H. Burstall, 34. Optical activity dependent on co-ordinated bivalent ruthenium, J. Chem. Soc. (1936) 173. https://doi.org/10.1039/jr9360000173.

[23] H. Dau, C. Limberg, T. Reier, M. Risch, S. Roggan, P. Strasser, The Mechanism of Water Oxidation: From Electrolysis via Homogeneous to Biological Catalysis, ChemCatChem. 2 (2010) 724-761. https://doi.org/10.1002/cctc.201000126.

[24] J.G. Vos, J.M. Kelly, Ruthenium polypyridyl chemistry; from basic research to applications and back again, Dalt. Trans. (2006) 4869. https://doi.org/10.1039/b606490f.

[25] G. Shi, S. Monro, R. Hennigar, J. Colpitts, J. Fong, K. Kasimova, H. Yin, R. DeCoste, C. Spencer, L. Chamberlain, A. Mandel, L. Lilge, S.A. McFarland, Ru(II) dyads derived from $\alpha$-oligothiophenes: A new class of potent and versatile photosensitizers for PDT, Coord. Chem. Rev. 282-283 (2015) 127-138.

https://doi.org/10.1016/j.ccr.2014.04.012.

[26] T. Inc., TLD-1433 Clinical Trial, (n.d.). https://clinicaltrials.gov/ct2/show/NCT03945162.

[27] G.T. Hermanson, Introduction to Bioconjugation, in: Bioconjugate Tech., Elsevier, 2013: pp. 1-125. https://doi.org/10.1016/B978-0-12-382239-0.00001-7.

[28] K. Hussain Reddy, Coordination compounds in biology, Resonance. 16 (2011) 12731283. https://doi.org/10.1007/s12045-011-0143-8.

[29] A. Monney, M. Albrecht, Transition metal bioconjugates with an organometallic link between the metal and the biomolecular scaffold, Coord. Chem. Rev. 257 (2013) 24202433. https://doi.org/10.1016/j.ccr.2012.12.015.

[30] F.E. Poynton, S.A. Bright, S. Blasco, D.C. Williams, J.M. Kelly, T. Gunnlaugsson, The development of ruthenium(II) polypyridyl complexes and conjugates for: In vitro cellular and in vivo applications, Chem. Soc. Rev. 46 (2017) 7706-7756. 
https://doi.org/10.1039/c7cs00680b.

[31] J. Shum, P.K. Leung, K.K. Lo, Luminescent Ruthenium(II) Polypyridine Complexes for a Wide Variety of Biomolecular and Cellular Applications, Inorg. Chem. 58 (2019) 2231-2247. https://doi.org/10.1021/acs.inorgchem.8b02979.

[32] J. Li, T. Chen, Transition metal complexes as photosensitizers for integrated cancer theranostic applications, Coord. Chem. Rev. 418 (2020) 213355. https://doi.org/10.1016/j.ccr.2020.213355.

[33] L. Jacquet, J.M. Kelly, A.K.-D. Mesmaeker, Photoadduct between tris(1,4,5,8tetraazaphenanthrene)ruthenium(II) and guanosine monophosphate-a model for a new mode of covalent binding of metal complexes to DNA, J. Chem. Soc., Chem. Commun. (1995) 913-914. https://doi.org/10.1039/C39950000913.

[34] S.I. Khan, A.E. Beilstein, M.T. Tierney, M. Sykora, M.W. Grinstaff, Solid-Phase Synthesis and Photophysical Properties of DNA Labeled at the Nucleobase with Ru(bpy) 2 (4-m-4'-pa-bpy)2+, Inorg. Chem. 38 (1999) 5999-6002. https://doi.org/10.1021/ic990810f.

[35] D.J. Hurley, Y. Tor, Ru(II) and Os(II) Nucleosides and Oligonucleotides: Synthesis and Properties, J. Am. Chem. Soc. 124 (2002) 3749-3762. https://doi.org/10.1021/ja0123103.

[36] J. Irvoas, A. Noirot, N. Chouini-Lalanne, O. Reynes, J.-C. Garrigues, V. Sartor, Programmable multimetallic linear nanoassemblies of ruthenium-DNA conjugates, RSC Adv. 2 (2012) 9538. https://doi.org/10.1039/c2ra21645k.

[37] E. Kahrović, A. Zahirović, Š. Kadrić, E. Turkušić, I. Osmanković, H. Džudžević Čančar, Structural feature of calf thymus deoxyribonucleic acid-ruthenium(III) interaction in aqueous solution by difference Fourier transformed infrared spectroscopy, Spectrosc. Lett. 50 (2017) 426-431. https://doi.org/10.1080/00387010.2017.1350720. 
[38] M. Flamme, E. Clarke, G. Gasser, M. Hollenstein, Applications of Ruthenium Complexes Covalently Linked to Nucleic Acid Derivatives, Molecules. 23 (2018) 1515. https://doi.org/10.3390/molecules23071515.

[39] K. Qiu, Y. Chen, T.W. Rees, L. Ji, H. Chao, Organelle-targeting metal complexes: From molecular design to bio-applications, Coord. Chem. Rev. 378 (2019) 66-86. https://doi.org/10.1016/j.ccr.2017.10.022.

[40] Q. Lam, M. Kato, L. Cheruzel, Ru(II)-diimine functionalized metalloproteins: From electron transfer studies to light-driven biocatalysis, Biochim. Biophys. Acta Bioenerg. 1857 (2016) 589-597. https://doi.org/10.1016/j.bbabio.2015.09.004.

[41] S.M. Meier-Menches, A. Casini, Design Strategies and Medicinal Applications of Metal-Peptidic Bioconjugates, Bioconjug. Chem. 31 (2020) 1279-1288. https://doi.org/10.1021/acs.bioconjchem.0c00152.

[42] A. Magnuson, H. Berglund, P. Korall, L. Hammarström, B. Åkermark, S. Styring, L. Sun, Mimicking Electron Transfer Reactions in Photosystem II: Synthesis and Photochemical Characterization of a Ruthenium(II) Tris(bipyridyl) Complex with a Covalently Linked Tyrosine, J. Am. Chem. Soc. 119 (1997) 10720-10725. https://doi.org/10.1021/ja972161h.

[43] R. Eswaran, S. Kalayar, M.M. Paulpandian, R. Seenivasan, Photoinduced Electron Transfer Reactions of Ruthenium(II)-Complexes Containing Amino Acid with Quinones, J. Fluoresc. 24 (2014) 875-884. https://doi.org/10.1007/s10895-014-1365-4.

[44] V. Ramu, S. Aute, N. Taye, R. Guha, M.G. Walker, D. Mogare, A. Parulekar, J.A. Thomas, S. Chattopadhyay, A. Das, Photo-induced cytotoxicity and anti-metastatic activity of ruthenium(II)-polypyridyl complexes functionalized with tyrosine or tryptophan, Dalt. Trans. 46 (2017) 6634-6644. https://doi.org/10.1039/C7DT00670E.

[45] B. Geisser, A. Ponce, R. Alsfasser, pH-Dependent Excited-State Dynamics of [Ru(bpy)3] 2+-Modified Amino Acids: Effects of an Amide Linkage and Remote 
Functional Groups, Inorg. Chem. 38 (1999) 2030-2037.

https://doi.org/10.1021/ic980896x.

[46] C. Fu, M. Wenzel, E. Treutlein, K. Harms, E. Meggers, Proline as Chiral Auxiliary for the Economical Asymmetric Synthesis of Ruthenium(II) Polypyridyl Complexes, Inorg. Chem. 51 (2012) 10004-10011. https://doi.org/10.1021/ic3015157.

[47] M. Helms, C. Wang, B. Orth, K. Harms, E. Meggers, Proline and $\alpha$-Methylproline as Chiral Auxiliaries for the Synthesis of Enantiopure Bis-Cyclometalated Iridium(III) Complexes, Eur. J. Inorg. Chem. 2016 (2016) 2896-2901. https://doi.org/10.1002/ejic.201600260.

[48] R.S. Vagg, P.A. Williams, Chiral metal complexes. 1. Photochemical inversion in ternary $\mathrm{Ru}(\mathrm{II})$ complexes of diimines and L-tryptophane, Inorganica Chim. Acta. 51 (1981) 61-65. https://doi.org/10.1016/S0020-1693(00)88318-8.

[49] R.S. Vagg, P.A. Williams, Chiral metal complexes 2. Light-catalysed diastereoisomeric equilibration in aqueous solutions of cis-[Ru(phen)2(L-serine) $]+$ and its 2,2'-bipyridyl analogue, Inorganica Chim. Acta. 52 (1981) 69-72. https://doi.org/10.1016/S00201693(00)88574-6.

[50] J.-A. Cuello-Garibo, E. Pérez-Gallent, L. van der Boon, M.A. Siegler, S. Bonnet, Influence of the Steric Bulk and Solvent on the Photoreactivity of Ruthenium Polypyridyl Complexes Coordinated to L-Proline, Inorg. Chem. 56 (2017) 4818-4828. https://doi.org/10.1021/acs.inorgchem.6b02794.

[51] V.H.S. Van Rixel, B. Siewert, S.L. Hopkins, S.H.C. Askes, A. Busemann, M.A. Siegler, S. Bonnet, Green light-induced apoptosis in cancer cells by a tetrapyridyl ruthenium prodrug offering two: Trans coordination sites, Chem. Sci. 7 (2016) 49224929. https://doi.org/10.1039/c6sc00167j.

[52] C.A. Puckett, R.J. Ernst, J.K. Barton, Exploring the cellular accumulation of metal complexes, Dalt. Trans. 39 (2010) 1159-1170. https://doi.org/10.1039/B922209J. 
[53] S.B. Gunnoo, A. Madder, Bioconjugation - using selective chemistry to enhance the properties of proteins and peptides as therapeutics and carriers, Org. Biomol. Chem. 14 (2016) 8002-8013. https://doi.org/10.1039/C6OB00808A.

[54] U. Neugebauer, Y. Pellegrin, M. Devocelle, R.J. Forster, W. Signac, N. Moran, T.E. Keyes, Ruthenium polypyridyl peptide conjugates: membrane permeable probes for cellular imaging, Chem. Commun. 2 (2008) 5307. https://doi.org/10.1039/b810403d.

[55] U. Neugebauer, L. Cosgrave, Y. Pellegrin, M. Devocelle, R.J. Forster, T.E. Keyes, Membrane permeable luminescent metal complexes for cellular imaging, in: J. Popp, W. Drexler, V. V. Tuchin, D.L. Matthews (Eds.), Biophotonics Photonic Solut. Better Heal. Care III, 2012: p. 84270C. https://doi.org/10.1117/12.919992.

[56] L. Cosgrave, M. Devocelle, R.J. Forster, T.E. Keyes, Multimodal cell imaging by ruthenium polypyridyl labelled cell penetrating peptides, Chem. Commun. 46 (2010) 103-105. https://doi.org/10.1039/B918611E.

[57] K. Adamson, C. Dolan, N. Moran, R.J. Forster, T.E. Keyes, RGD Labeled Ru(II) Polypyridyl Conjugates for Platelet Integrin $\alpha \operatorname{Ilb} \beta 3$ Recognition and as Reporters of Integrin Conformation, Bioconjug. Chem. 25 (2014) 928-944. https://doi.org/10.1021/bc5000737.

[58] L. Blackmore, R. Moriarty, C. Dolan, K. Adamson, R.J. Forster, M. Devocelle, T.E. Keyes, Peptide directed transmembrane transport and nuclear localization of $\mathrm{Ru}(\mathrm{II})$ polypyridyl complexes in mammalian cells, Chem. Commun. 49 (2013) 2658. https://doi.org/10.1039/c3cc40453f.

[59] A. Byrne, C.S. Burke, T.E. Keyes, Precision targeted ruthenium(II) luminophores; highly effective probes for cell imaging by stimulated emission depletion (STED) microscopy, Chem. Sci. 7 (2016) 6551-6562. https://doi.org/10.1039/C6SC02588A.

[60] C.S. Burke, A. Byrne, T.E. Keyes, Highly Selective Mitochondrial Targeting by a Ruthenium(II) Peptide Conjugate: Imaging and Photoinduced Damage of 
Mitochondrial DNA, Angew. Chemie - Int. Ed. 57 (2018) 12420-12424.

https://doi.org/10.1002/anie.201806002.

[61] A. Martin, A. Byrne, C.S. Burke, R.J. Forster, T.E. Keyes, Peptide-Bridged Dinuclear $\mathrm{Ru}(\mathrm{II})$ Complex for Mitochondrial Targeted Monitoring of Dynamic Changes to Oxygen Concentration and ROS Generation in Live Mammalian Cells, J. Am. Chem. Soc. 136 (2014) 15300-15309. https://doi.org/10.1021/ja508043q.

[62] Z. Zhao, X. Zhang, C. Li, T. Chen, Designing luminescent ruthenium prodrug for precise cancer therapy and rapid clinical diagnosis, Biomaterials. 192 (2019) 579-589. https://doi.org/10.1016/j.biomaterials.2018.12.002.

[63] C. Mari, V. Pierroz, A. Leonidova, S. Ferrari, G. Gasser, Towards Selective LightActivated Ru II -Based Prodrug Candidates, Eur. J. Inorg. Chem. 2015 (2015) 3879_ 3891. https://doi.org/10.1002/ejic.201500602.

[64] T. Joshi, V. Pierroz, S. Ferrari, G. Gasser, Bis(dipyridophenazine)(2-(2'pyridyl)pyrimidine-4-carboxylic acid)ruthenium(II) Hexafluorophosphate: A Lesson in Stubbornness, ChemMedChem. 9 (2014) 1419-1427. https://doi.org/10.1002/cmdc.201400029.

[65] T. Wang, N. Zabarska, Y. Wu, M. Lamla, S. Fischer, K. Monczak, D.Y.W. Ng, S. Rau, T. Weil, Receptor selective ruthenium-somatostatin photosensitizer for cancer targeted photodynamic applications, Chem. Commun. 51 (2015) 12552-12555. https://doi.org/10.1039/c5cc03473f.

[66] N.M. Vegi, S. Chakrabortty, M.M. Zegota, S.L. Kuan, A. Stumper, V.P.S. Rawat, S. Sieste, C. Buske, S. Rau, T. Weil, M. Feuring-Buske, Somatostatin receptor mediated targeting of acute myeloid leukemia by photodynamic metal complexes for light induced apoptosis, Sci. Rep. 10 (2020) 1-10. https://doi.org/10.1038/s41598-01957172-6.

[67] C.A. Puckett, J.K. Barton, Fluorescein Redirects a Ruthenium-Octaarginine Conjugate 
to the Nucleus, J. Am. Chem. Soc. 131 (2009) 8738-8739.

https://doi.org/10.1021/ja9025165.

[68] C.A. Puckett, J.K. Barton, Targeting a ruthenium complex to the nucleus with short peptides, Bioorg. Med. Chem. 18 (2010) 3564-3569.

https://doi.org/10.1016/j.bmc.2010.03.081.

[69] K. Ypsilantis, J.C. Plakatouras, M.J. Manos, A. Kourtellaris, G. Markopoulos, E. Kolettas, A. Garoufis, Stepwise synthesis, characterization, DNA binding properties and cytotoxicity of diruthenium oligopyridine compounds conjugated with peptides, Dalt. Trans. 47 (2018) 3549-3567. https://doi.org/10.1039/C7DT04639A.

[70] A. Lobo-Ruiz, J. Tulla-Puche, Synthetic approaches of naturally and rationally designed peptides and peptidomimetics, in: Pept. Appl. Biomed. Biotechnol. Bioeng., Elsevier, 2018: pp. 23-49. https://doi.org/10.1016/B978-0-08-100736-5.00002-8.

[71] J. Lee, D.G. Udugamasooriya, H. Lim, T. Kodadek, Potent and selective photoinactivation of proteins with peptoid-ruthenium conjugates, Nat. Chem. Biol. 6 (2010) 258-260. https://doi.org/10.1038/nchembio.333.

[72] H. Szmacinski, E. Terpetschnig, J.R. Lakowicz, Synthesis and evaluation of Rucomplexes as anisotropy probes for protein hydrodynamics and immunoassays of highmolecular-weight antigens, Biophys. Chem. 62 (1996) 109-120. https://doi.org/10.1016/S0301-4622(96)02199-0.

[73] H. Szmacinski, F.N. Castellano, E. Terpetschnig, J.D. Dattelbaum, J.R. Lakowicz, G.J. Meyer, Long-lifetime Ru(II) complexes for the measurement of high molecular weight protein hydrodynamics, Biochim. Biophys. Acta - Protein Struct. Mol. Enzymol. 1383 (1998) 151-159. https://doi.org/10.1016/S0167-4838(97)00196-9.

[74] J.R. Winkler, H.B. Gray, Electron transfer in ruthenium-modified proteins, Chem. Rev. 92 (1992) 369-379. https://doi.org/10.1021/cr00011a001.

[75] J.T. Lin, P.C. Chen, T.V. Goud, B.R. Huang, T.C. Lin, J.F. Biellmann, C.S. Chen, A 
sulfhydryl-reactive ruthenium (II) complex and its conjugation to protein $\mathrm{G}$ as a universal reagent for fluorescent immunoassays, PLoS One. 7 (2012) e36086. https://doi.org/10.1371/journal.pone.0036086.

[76] J.R. Peterson, T.A. Smith, P. Thordarson, Photoinduced reduction of catalytically and biologically active $\mathrm{Ru}(\mathrm{II})$ bisterpyridine-cytochrome c bioconjugates, Chem. Commun. (2007) 1899-1901. https://doi.org/10.1039/B702996A.

[77] D. Hvasanov, A.F. Mason, D.C. Goldstein, M. Bhadbhade, P. Thordarson, Optimising the synthesis, polymer membrane encapsulation and photoreduction performance of $\mathrm{Ru}(\mathrm{II})-$ and Ir(III)-bis(terpyridine) cytochrome c bioconjugates, Org. Biomol. Chem. 11 (2013) 4602. https://doi.org/10.1039/c3ob40620b.

[78] K. Okeyoshi, R. Kawamura, R. Yoshida, Y. Osada, Thermo- and photo-enhanced microtubule formation from $\mathrm{Ru}(\mathrm{bpy}) 32+$-conjugated tubulin, J. Mater. Chem. B. 2 (2014) 41-45. https://doi.org/10.1039/C3TB21242D.

[79] S. Chakrabortty, B.K. Agrawalla, A. Stumper, N.M. Vegi, S. Fischer, C. Reichardt, M. Kögler, B. Dietzek, M. Feuring-Buske, C. Buske, S. Rau, T. Weil, Mitochondria Targeted Protein-Ruthenium Photosensitizer for Efficient Photodynamic Applications, J. Am. Chem. Soc. 139 (2017) 2512-2519. https://doi.org/10.1021/jacs.6b13399.

[80] J. Finkelstein, Metalloproteins, Nature. 460 (2009) 813-813. https://doi.org/10.1038/460813a.

[81] D.R. Paulson, A.W. Addison, D. Dolphin, B.R. James, Preparation of ruthenium(II) and ruthenium(III) myoglobin and the reaction of dioxygen, and carbon monoxide, with ruthenium(II) myoglobin., J. Biol. Chem. 254 (1979) 7002-7006.

[82] H. Ishida, Y. Maruyama, M. Kyakuno, Y. Kodera, T. Maeda, S. Oishi, Artificial Metalloproteins with a Ruthenium Tris(bipyridyl) Complex as the Core, ChemBioChem. 7 (2006) 1567-1570. https://doi.org/10.1002/cbic.200600162.

[83] I. Gamba, I. Salvadó, G. Rama, M. Bertazzon, M.I. Sánchez, V.M. Sánchez-Pedregal, 
J. Martínez-Costas, R.F. Brissos, P. Gamez, J.L. Mascareñas, M. Vázquez López, M.E. Vázquez, Custom-Fit Ruthenium(II) Metallopeptides: A New Twist to DNA Binding With Coordination Compounds, Chem. - A Eur. J. 19 (2013) 13369-13375. https://doi.org/10.1002/chem.201301629.

[84] N. Jain, S.W. Smith, S. Ghone, B. Tomczuk, Current ADC Linker Chemistry, Pharm. Res. 32 (2015) 3526-3540. https://doi.org/10.1007/s11095-015-1657-7.

[85] E. Terpetschnig, J.D. Dattelbaum, H. Szmacinski, J.R. Lakowicz, Synthesis and Spectral Characterization of a Thiol-Reactive Long-Lifetime Ru(II) Complex, Anal. Biochem. 251 (1997) 241-245. https://doi.org/10.1006/abio.1997.2253.

[86] X. Zhou, D. Zhu, Y. Liao, W. Liu, H. Liu, Z. Ma, D. Xing, Synthesis, labeling and bioanalytical applications of a tris(2,2'-bipyridyl)ruthenium(II)-based electrochemiluminescence probe, Nat. Protoc. 9 (2014) 1146-1159. https://doi.org/10.1038/nprot.2014.060.

[87] V. del Solar, M. Contel, Metal-based antibody drug conjugates. Potential and challenges in their application as targeted therapies in cancer, J. Inorg. Biochem. 199 (2019) 110780. https://doi.org/10.1016/j.jinorgbio.2019.110780.

[88] S. Aghevlian, Y. Lu, M.A. Winnik, D.W. Hedley, R.M. Reilly, Panitumumab Modified with Metal-Chelating Polymers (MCP) Complexed to 111 In and $177 \mathrm{Lu}$-An EGFRTargeted Theranostic for Pancreatic Cancer, Mol. Pharm. 15 (2018) 1150-1159. https://doi.org/10.1021/acs.molpharmaceut.7b01000.

[89] M.R. Mortensen, N.L. Nielsen, J. Palmfeldt, K.V. Gothelf, Imidazole carbamate probes for affinity guided azide-transfer to metal-binding proteins, Org. Biomol. Chem. 17 (2019) 1379-1383. https://doi.org/10.1039/C8OB03017K.

[90] J. Karges, M. Jakubaszek, C. Mari, K. Zarschler, B. Goud, H. Stephan, G. Gasser, Synthesis and Characterization of an Epidermal Growth Factor Receptor-Selective RuII Polypyridyl-Nanobody Conjugate as a Photosensitizer for Photodynamic Therapy, 
ChemBioChem. 21 (2020) 531-542. https://doi.org/10.1002/cbic.201900419.

[91] P.E. Bunney, A.N. Zink, A.A. Holm, C.J. Billington, C.M. Kotz, Orexin activation counteracts decreases in nonexercise activity thermogenesis (NEAT) caused by highfat diet, Physiol. Behav. 176 (2017) 139-148.

https://doi.org/10.1016/j.physbeh.2017.03.040.

[92] M. Gottschaldt, U.S. Schubert, Prospects of Metal Complexes Peripherally Substituted with Sugars in Biomedicinal Applications, Chem. - A Eur. J. 15 (2009) 1548-1557. https://doi.org/10.1002/chem.200802013.

[93] T. Allscher, P. Klüfers, P. Mayer, Carbohydrate-Metal ComplexesCarbohydrate-metal complexes : Structural Chemistry of Stable Solution Species, in: Glycoscience, Springer Berlin Heidelberg, Berlin, Heidelberg, 2008: pp. 1077-1139. https://doi.org/10.1007/978-3-540-30429-6_24.

[94] M.B. Calvo, A. Figueroa, E.G. Pulido, R.G. Campelo, L.A. Aparicio, Potential Role of Sugar Transporters in Cancer and Their Relationship with Anticancer Therapy, Int. J. Endocrinol. 2010 (2010) 1-14. https://doi.org/10.1155/2010/205357.

[95] A.F.S. Santos, M.D.C. da Silva, T.H. Napoleão, P.M.G. Paiva, M.T.S. Correia, L.C.B.B. Coelho, Lectins: Function, structure, biological properties and potential applications, in: Curr. Top. Pept. Protein Res., Research Trends, 2014: pp. 41-62. https://repositorium.sdum.uminho.pt/handle/1822/43440.

[96] E.C. Constable, S. Mundwiler, Metal-ion control of molecular recognition-sugarfunctionalised 2,2':6',2"-terpyridines, Polyhedron. 18 (1999) 2433-2444. https://doi.org/10.1016/S0277-5387(99)00134-5.

[97] T. Hasegawa, T. Yonemura, K. Matsuura, K. Kobayashi, Tris-bipyridine ruthenium complex-based glyco-clusters: amplified luminescence and enhanced lectin affinities, Tetrahedron Lett. 42 (2001) 3989-3992. https://doi.org/10.1016/S00404039(01)00424-5. 
[98] T. Hasegawa, T. Yonemura, K. Matsuura, K. Kobayashi, Artificial Metalloglycoclusters: Compact Saccharide Shell to Induce High Lectin Affinity as Well as Strong Luminescence, Bioconjug. Chem. 14 (2003) 728-737. https://doi.org/10.1021/bc020026a.

[99] S. Kojima, T. Hasegawa, T. Yonemura, K. Sasaki, K. Yamamoto, Y. Makimura, T. Takahashi, T. Suzuki, Y. Suzuki, K. Kobayashi, Ruthenium complexes carrying a disialo complex-type oligosaccharide: enzymatic synthesis and its application to a luminescent probe to detect influenza viruses, Chem. Commun. (2003) 1250-1251. https://doi.org/10.1039/B210739B.

[100] T. Okada, T. Makino, N. Minoura, Fluorescence Emission and Polarization for Analyzing Binding of Ruthenium Metalloglycocluster to Lectin and Tetanus Toxin CFragment, Bioconjug. Chem. 20 (2009) 1296-1298. https://doi.org/10.1021/bc900101u.

[101] P. Emsley, C. Fotinou, I. Black, N.F. Fairweather, I.G. Charles, C. Watts, E. Hewitt, N.W. Isaacs, The Structures of the Hc Fragment of Tetanus Toxin with Carbohydrate Subunit Complexes Provide Insight into Ganglioside Binding, J. Biol. Chem. 275 (2000) 8889-8894. https://doi.org/10.1074/jbc.275.12.8889.

[102] M. Pröhl, T. Bus, J.A. Czaplewska, A. Traeger, M. Deicke, H. Weiss, W. Weigand, U.S. Schubert, M. Gottschaldt, Synthesis and in vitro Toxicity of d -Glucose and d Fructose Conjugated Curcumin-Ruthenium Complexes, Eur. J. Inorg. Chem. 2016 (2016) 5197-5204. https://doi.org/10.1002/ejic.201600801.

[103] K. Yin Zhang, K. Ka-Shun Tso, M.-W. Louie, H.-W. Liu, K.K.-W. Lo, A Phosphorescent Rhenium(I) Tricarbonyl Polypyridine Complex Appended with a Fructose Pendant That Exhibits Photocytotoxicity and Enhanced Uptake by Breast Cancer Cells, Organometallics. 32 (2013) 5098-5102. https://doi.org/10.1021/om400612f. 
[104] J. Liu, X. Liao, K. Xiong, S. Kuang, C. Jin, L. Ji, H. Chao, Boosting two-photon photodynamic therapy with mitochondria-targeting ruthenium-glucose conjugates, Chem. Commun. (2020). https://doi.org/10.1039/d0cc01148g.

[105] L.N. Lameijer, T.G. Brevé, V.H.S. van Rixel, S.H.C. Askes, M.A. Siegler, S. Bonnet, Effects of the Bidentate Ligand on the Photophysical Properties, Cellular Uptake, and (Photo)cytotoxicity of Glycoconjugates Based on the $[\mathrm{Ru}(\mathrm{tpy})(\mathrm{NN})(\mathrm{L})] 2+$ Scaffold, Chem. - A Eur. J. 24 (2018) 2709-2717. https://doi.org/10.1002/chem.201705388.

[106] L.N. Lameijer, S.L. Hopkins, T.G. Brevé, S.H.C. Askes, S. Bonnet, d- Versus 1Glucose Conjugation: Mitochondrial Targeting of a Light-Activated Dual-Mode-ofAction Ruthenium-Based Anticancer Prodrug, Chem. - A Eur. J. 22 (2016) 1848418491. https://doi.org/10.1002/chem.201603066.

[107] M. Frasconi, Z. Liu, J. Lei, Y. Wu, E. Strekalova, D. Malin, M.W. Ambrogio, X. Chen, Y.Y. Botros, V.L. Cryns, J. Sauvage, J.F. Stoddart, Photoexpulsion of Surface-Grafted Ruthenium Complexes and Subsequent Release of Cytotoxic Cargos to Cancer Cells from Mesoporous Silica Nanoparticles, J. Am. Chem. Soc. 135 (2013) 11603-11613. https://doi.org/10.1021/ja405058y.

[108] S.P. Foxon, C. Metcalfe, H. Adams, M. Webb, J.A. Thomas, Electrochemical and Photophysical Properties of DNA Metallo-intercalators Containing the Ruthenium(II) Tris(1-pyrazolyl)methane Unit, Inorg. Chem. 46 (2007) 409-416. https://doi.org/10.1021/ic0607134.

[109] J.S. dos Santos, L.C. Ramos, L.P. Ferreira, V.L. Campo, L.C.D. de Rezende, F. da Silva Emery, R. Santana da Silva, Cytotoxicity, cellular uptake, and subcellular localization of a nitrogen oxide and aminopropyl- $\beta$-lactose derivative ruthenium complex used as nitric oxide delivery agent, Nitric Oxide - Biol. Chem. 86 (2019) 3847. https://doi.org/10.1016/j.niox.2019.02.005.

[110] J.M. Haider, M. Chavarot, S. Weidner, I. Sadler, R.M. Williams, L. De Cola, Z. 
Pikramenou, Metallocyclodextrins as building blocks in noncovalent assemblies of photoactive units for the study of photoinduced intercomponent processes, Inorg. Chem. 40 (2001) 3912-3921. https://doi.org/10.1021/ic0100166.

[111] H.F.M. Nelissen, A.F.J. Schut, F. Venema, M.C. Feiters, R.J.M. Nolte, Switch-on luminescence detection of steroids by tris(bipyridyl)ruthenium(II) complexes containing multiple cyclodextrin binding sites, Chem. Commun. (2000) 577-578. https://doi.org/10.1039/b000271m.

[112] H.F.M. Nelissen, M. Kercher, L. De Cola, M.C. Feiters, Photoinduced Electron Transfer between Metal-Coordinated Cyclodextrin Assemblies and Viologens, Chem. A Eur. J. 8 (2002) 5407-5414. https://doi.org/10.1002/1521$3765(20021202) 8: 23<5407$.

[113] M. Gottschaldt, U.S. Schubert, S. Rau, S. Yano, J.G. Vos, T. Kroll, J. Clement, I. Hilger, Sugar-selective enrichment of a D-glucose-substituted ruthenium bipyridyl complex inside HepG2 cancer cells, ChemBioChem. 11 (2010) 649-652. https://doi.org/10.1002/cbic.200900769.

[114] S.S. Wang, X. Gao, V. del Solar, X. Yu, A. Antonopoulos, A.E. Friedman, E.K. Matich, G.E. Atilla-Gokcumen, M. Nasirikenari, J.T. Lau, A. Dell, S.M. Haslam, R.A. Laine, K.L. Matta, S. Neelamegham, Thioglycosides Are Efficient Metabolic Decoys of Glycosylation that Reduce Selectin Dependent Leukocyte Adhesion, Cell Chem. Biol. 25 (2018) 1519-1532.e5. https://doi.org/10.1016/j.chembiol.2018.09.012.

[115] C.T.S. Lau, C. Chan, K.Y. Zhang, V.A.L. Roy, K.K.W. Lo, Photophysical, CellularUptake, and Bioimaging Studies of Luminescent Ruthenium(II)-Polypyridine Complexes Containing a d-Fructose Pendant, Eur. J. Inorg. Chem. 2017 (2017) 52885294. https://doi.org/10.1002/ejic.201701038.

[116] D. Irby, C. Du, F. Li, Lipid-Drug Conjugate for Enhancing Drug Delivery, Mol. Pharm. 14 (2017) 1325-1338. https://doi.org/10.1021/acs.molpharmaceut.6b01027. 
[117] C. Tsai, J.C.W. Wang, Near-infrared Absorption Property of Biological Soft Tissue Constituents, J. Med. Biol. Eng. 21 (2001) 7-13.

[118] G.T. Hermanson, 1. Introduction to Bioconjugation, in: Bioconjugate Tech., Third Edit, Academic Press, 2013: pp. 1-128.

[119] J.S. Killeen, W.R. Browne, M. Skupin, J.H. Fuhrhop, J.G. Vos, Functionalisation of bolaamphiphiles with mononuclear bis(2,2'-bipyridyl)ruthenium(II) complexes for application in self assembled monolayers, New J. Chem. 27 (2003) 1078-1083. https://doi.org/10.1039/b302405a.

[120] F. Dosio, B. Stella, A. Ferrero, C. Garino, D. Zonari, S. Arpicco, L. Cattel, S. Giordano, R. Gobetto, Ruthenium polypyridyl squalene derivative: A novel selfassembling lipophilic probe for cellular imaging, Int. J. Pharm. 440 (2013) 221-228. https://doi.org/10.1016/j.ijpharm.2012.07.022.

[121] K.K. Lo, T.K. Lee, J.S. Lau, W. Poon, S.-H. Cheng, Luminescent Biological Probes Derived from Ruthenium(II) Estradiol Polypyridine Complexes, Inorg. Chem. 47 (2008) 200-208. https://doi.org/10.1021/ic701735q.

[122] S. Bonnet, B. Limburg, J.D. Meeldijk, R.J.M.K. Gebbink, J.A. Killian, Rutheniumdecorated lipid vesicles: Light-induced release of $[\mathrm{Ru}($ terpy $)(\mathrm{bpy})(\mathrm{OH} 2)] 2+$ and thermal back coordination, J. Am. Chem. Soc. 133 (2011) 252-261. https://doi.org/10.1021/ja105025m.

[123] B. Siewert, V.H.S. van Rixel, E.J. van Rooden, S.L. Hopkins, M.J.B. Moester, F. Ariese, M.A. Siegler, S. Bonnet, Chemical Swarming: Depending on Concentration, an Amphiphilic Ruthenium Polypyridyl Complex Induces Cell Death via Two Different Mechanisms, Chem. - A Eur. J. 22 (2016) 10960-10968. https://doi.org/10.1002/chem.201600927.

[124] A. Bahreman, B. Limburg, M.A. Siegler, R. Koning, A.J. Koster, S. Bonnet, Ruthenium polypyridyl complexes hopping at anionic lipid bilayers through a 
supramolecular bond sensitive to visible light, Chem. - A Eur. J. 18 (2012) 1027110280. https://doi.org/10.1002/chem.201200624.

[125] A. Bahreman, M. Rabe, A. Kros, G. Bruylants, S. Bonnet, Binding of a ruthenium complex to a thioether ligand embedded in a negatively charged lipid bilayer: A twostep mechanism, Chem. - A Eur. J. 20 (2014) 7429-7438. https://doi.org/10.1002/chem.201400377.

[126] B. Schwederski, W. Kaim, Complexes of folic acid, lumiflavin and riboflavin with bis(2, 2'-bipyridine)ruthenium(II). Facilitated formation of flavosemiquinone complexes and substantial decrease of $\mathrm{pKa}(\mathrm{NH})$, Inorganica Chim. Acta. 195 (1992) 123-126. https://doi.org/10.1016/S0020-1693(00)83859-1.

[127] T.G. Scrase, S.M. Page, P.D. Barker, S.R. Boss, Folates are potential ligands for ruthenium compounds in vivo, Dalt. Trans. 43 (2014) 8158-8161. https://doi.org/10.1039/c4dt00081a.

[128] N.A. Smith, P. Zhang, L. Salassa, A. Habtemariam, P.J. Sadler, Synthesis, characterisation and dynamic behavior of photoactive bipyridyl ruthenium(II)nicotinamide complexes, Inorganica Chim. Acta. 454 (2017) 240-246. https://doi.org/10.1016/j.ica.2016.06.014.

[129] B. Siewert, M. Langerman, A. Pannwitz, S. Bonnet, Synthesis and Avidin Binding of Ruthenium Complexes Functionalized with a Light-Cleavable Free Biotin Moiety, Eur. J. Inorg. Chem. 2018 (2018) 4117-4124. https://doi.org/10.1002/ejic.201800644.

[130] E.P. Diamandis, T.K. Christopoulos, The biotin-(strept)avidin system: principles and applications in biotechnology, Clin. Chem. 37 (1991) 625-636. https://doi.org/10.1093/clinchem/37.5.625.

[131] Z. Zhao, P. Gao, Y. You, T. Chen, Cancer-Targeting Functionalization of SeleniumContaining Ruthenium Conjugate with Tumor Microenvironment-Responsive Property to Enhance Theranostic Effects, Chem. - A Eur. J. 24 (2018) 3289-3298. 
https://doi.org/10.1002/chem.201705561.

[132] H. Lai, D. Zeng, C. Liu, Q. Zhang, X. Wang, T. Chen, Selenium-containing ruthenium complex synergizes with natural killer cells to enhance immunotherapy against prostate cancer via activating TRAIL/FasL signaling, Biomaterials. 219 (2019) 119377. https://doi.org/10.1016/j.biomaterials.2019.119377.

[133] M. Jakubaszek, J. Rossier, J. Karges, J. Delasoie, B. Goud, G. Gasser, F. Zobi, Evaluation of the Potential of Cobalamin Derivatives Bearing Ru(II) Polypyridyl Complexes as Photosensitizers for Photodynamic Therapy, Helv. Chim. Acta. (2019). https://doi.org/10.1002/hlca.201900104. 